\title{
Wandrey de Bortoli Watanabe
}

\section{Verificação da linearidade da resposta oceânica à forçante do vento em larga escala}

Dissertação apresentada ao Instituto Oceanográfico da Universidade de São Paulo, como parte dos requisitos para obtenção do título de Mestre em Ciências, área de Oceanografia Física.

Orientador:

Prof. Dr. Paulo Simionatto Polito

São Paulo 
Universidade de São Paulo

Instituto Oceanográfico

\section{Verificação da linearidade da resposta oceânica à forçante do vento em larga escala}

\section{Wandrey de Bortoli Watanabe}

Dissertação apresentada ao Instituto Oceanográfico da Universidade de São Paulo, como parte dos requisitos para obtenção do título de Mestre em Ciências, área de Oceanografia Física.

Julgada em por

$\operatorname{Prof}(\mathrm{a}) \cdot \operatorname{Dr}(\mathrm{a})$.

Conceito

$\operatorname{Prof}(\mathrm{a}) \cdot \operatorname{Dr}(\mathrm{a})$.

Conceito

Prof(a). Dr(a).

Conceito 
Dedico este trabalho aos meus pais, que sempre me apoiaram em tudo, inclusive em cursar oceanografia. 


\section{Sumário}

Resumo $\quad x$

Abstract xi

\begin{tabular}{lll}
\hline 1 & Introdução & 1
\end{tabular}

\begin{tabular}{lll}
\hline 2 & Objetivos & 9
\end{tabular}

\begin{tabular}{lll}
\hline 3 & Materiais e métodos & 11
\end{tabular}

3.1 Área de estudo . . . . . . . . . . . . . . . . . . 11

$3.2 \mathrm{Dados} \ldots \ldots \ldots \ldots \ldots \ldots \ldots \ldots \ldots \ldots$

3.2 .1 Altimétricos . . . . . . . . . . . . . . 11

3.2 .2 Vento . . . . . . . . . . . . . . . . . 13

3.2 .3 Temperatura da superfície do mar . . . . . . . . . . . . 14

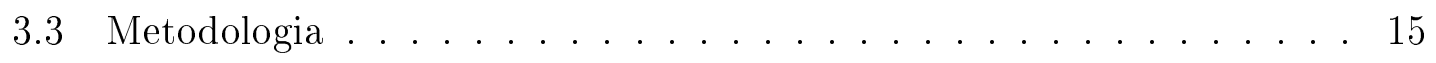

3.3 .1 Tratamento dos dados de vento . . . . . . . . . . 15

3.3 .2 Tratamento dos dados altimétricos . . . . . . . . . . 19 
3.3 .3 Tratamento dos dados de TSM . . . . . . . . . . . 20

3.3 .4 Análise estatística . . . . . . . . . . . . . . . 20

3.3 .5 Modelo linear . . . . . . . . . . . . . . . 23

3.3.5.1 Derivação . . . . . . . . . . . . . . 24

3.3 .5 .2 Discretização . . . . . . . . . . . 26

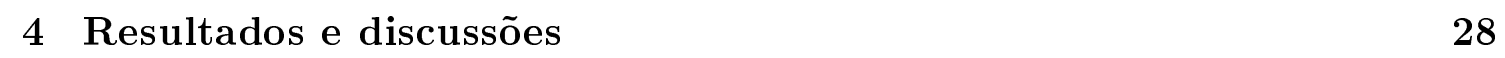

4.1 Coeficientes de correlação . . . . . . . . . . . . . 28

4.1 .1 Velocidades verticais . . . . . . . . . . . . . 28

4.1 .2 Vento e TSM . . . . . . . . . . . . . . . 33

4.1 .3 AASM e TSM . . . . . . . . . . . . . . 46

4.2 Espectros cruzados . . . . . . . . . . . . . . . . . . 48

4.2 .1 Velocidades verticais . . . . . . . . . . . . . 48

4.2 .2 Vento e TSM . . . . . . . . . . . . . . . . 53

$4.3 \quad$ Anomalia da altura da superfície livre modelada . . . . . . . . . . 58

$4.3 .1 \quad$ Componente anual propagante para oeste . . . . . . . . . 58

4.3 .2 Componente semianual propagante para oeste . . . . . . 76

$\begin{array}{lll}5 \text { Conclusões } & 85\end{array}$

\begin{tabular}{ll}
\hline Referências Bibliográficas & 93
\end{tabular} 


\section{Lista de Figuras}

$3.1 \quad$ Exemplo de um mapa diário para a componente zonal de dados de nível 3 bruto à esquerda e o mesmo mapa filtrado à direita. . . . . . . 16

4.1 Coeficiente de correlação cruzada entre $w_{s} \mathrm{e}-w_{E}$. . . . . . . . . . 29

4.2 Coeficiente de correlação cruzada entre as componentes referentes às ondas propagantes para oeste de $w_{s} \mathrm{e}-w_{E} . \ldots . . . . . . .30$

4.3 Coeficiente de correlação cruzada entre a componente anual de onda

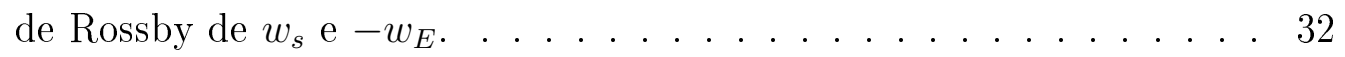

4.4 Coeficiente de correlação cruzada entre a componente semianual de onda de Rossby de $w_{s}$ e $-w_{E}$. . . . . . . . . . . . . . 32

4.5 Coeficiente de correlação cruzada entre $T_{s}$ e $\nabla \times \vec{\tau}$. . . . . . . . 34

4.6 Coeficiente de correlação cruzada entre $T_{s}$ e $\left|\vec{v}_{w}\right| . \ldots$. . . . . . . . 36

4.7 Coeficiente de correlação cruzada entre $T_{s}$ e $\nabla \cdot \vec{v}_{w} . \ldots . \ldots 36$

4.8 Coeficiente de correlação cruzada entre $T_{s}$ e $\nabla \times \vec{\tau}$ sem a componente sazonal. . . . . . . . . . . . . . . . . 38 
4.9 Coeficiente de correlação cruzada entre $T_{s}$ e $\left|\vec{v}_{w}\right|$ sem a componente

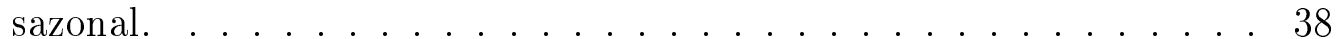

4.10 Coeficiente de correlação cruzada entre $T_{s}$ e $\nabla \cdot \vec{v}_{w}$ sem a componente sazonal. . . . . . . . . . . . . . . . . 40

4.11 Coeficiente de correlação cruzada entre as componentes referentes às ondas propagantes para oeste de $T_{s}$ e de $\nabla \times \vec{\tau}$. . . . . . . . . 40 40

4.12 (a) Coeficiente de correlação cruzada entre as componentes referentes às ondas propagantes para oeste de $T_{s}$ e de $\left|\vec{v}_{w}\right|$; (b) Séries temporais de $T_{s}$ (vermelho) e de $\left|\vec{v}_{w}\right|$ (verde) não filtradas descontadas o valor médio (linhas finas) e filtradas nas componentes de ondas de Rossby (linhas espessas) para o ponto representado no mapa por $*$ $\left(12^{\circ} 37,5^{\prime} \mathrm{E}-7^{\circ} 52,5^{\prime} \mathrm{S}\right) ;(\mathrm{c})$ idem ao item anterior com as curvas para $T_{s}$ em azul e para o ponto representado por $+\left(143^{\circ} 22,5^{\prime} \mathrm{W}-7^{\circ} 22,5^{\prime} \mathrm{N}\right)$.

4.13 Similar à figura 4.12 para $T_{s}$ e $\nabla \cdot \vec{v}_{w}, \operatorname{com} *$ localizado em $00^{\circ} 52,5^{\prime} \mathrm{W}-$ $11^{\circ} 52,5^{\prime} \mathrm{S}$ e + em $136^{\circ} 52,5^{\prime} \mathrm{W}-13^{\circ} 07,5^{\prime} \mathrm{N} . \ldots . . . . . . . .445$

4.14 Coeficiente de correlação cruzada entre $\eta^{\prime}$ e $T_{s}$. . . . . . . . . . . 47

4.15 Coeficiente de correlação cruzada entre as componentes propagantes para oeste com período anual de $\eta^{\prime}$ e de $T_{s} . \ldots \ldots$. . . . . . . . 47

4.16 Potência espectral máxima do espectro cruzado entre $w_{s}$ e $w_{E}$. . . . . 48

4.17 Período de potência espectral máxima entre $w_{s}$ e $w_{E} . \ldots . . . .50$

4.18 Período de potência espectral máxima entre $w_{s}$ e $w_{E}$, retiradas as respectivas componentes sazonais. . . . . . . . . . . . . . 51 
4.19 Potência espectral máxima do espectro cruzado entre as componentes anuais propagantes para oeste de $w_{s}$ e de $w_{E} . \quad \ldots \ldots . \ldots 52$

4.20 Potência espectral máxima do espectro cruzado entre as componentes semi-anuais de $w_{s}$ e de $w_{E} . \ldots \ldots \ldots \ldots$. . . . . . . . . 52

4.21 Potência espectral máxima do espectro cruzado entre $T_{s}$ e $\left|\vec{v}_{w}\right|$. . . . . 54

4.22 Potência espectral máxima do espectro cruzado entre $T_{s}$ e $\nabla \cdot \vec{v}_{w}$. . 54

4.23 Período no qual foi observada a potência espectral máxima entre $T_{s}$

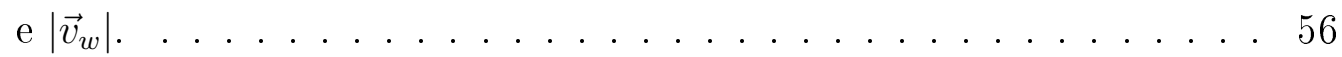

4.24 Período no qual foi observada a potência espectral máxima entre $T_{s}$

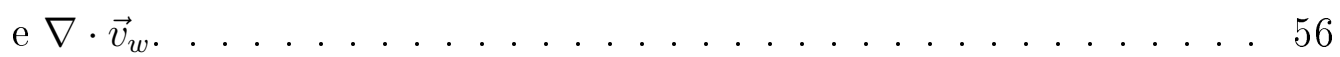

4.25 Potência espectral máxima do espectro cruzado entre as componentes propagantes para oeste de período anual de $T_{s}$ e de $\left|\vec{v}_{w}\right| .$. . . . . . 57

4.26 Potência espectral máxima do espectro cruzado entre as componentes propagantes para oeste de período anual de $T_{s}$ e $\nabla \cdot \vec{v}_{w}$. . . . . . . 57

4.27 Coeficiente de correlação médio entre a componente anual de $w_{s}$ e $w_{E}$ por latitude para cada bacia oceânica. . . . . . . . . . . . . . 58

4.28 Componente anual da anomalia da altura da superfície livre (mm) observada por altímetros (superior) e a mesma modelada (inferior) no oceano Atlântico entre $12^{\circ} \mathrm{N}$ e $16^{\circ} \mathrm{N}$ (colunas). . . . . . . . . . 62

4.29 Similar à figura (4.28) para o oceano Atlântico entre $16^{\circ} \mathrm{N}$ e $20^{\circ} \mathrm{N}$. . . 64 4.30 Similar à figura (4.28) para o oceano Pacífico entre $11^{\circ} \mathrm{S}$ e $15^{\circ} \mathrm{S}$. . . . 67 4.31 Similar à figura (4.28) para o oceano Pacífico entre $15^{\circ} \mathrm{S}$ e $19^{\circ} \mathrm{S}$. . . 69 
4.32 Similar à figura (4.28) para o oceano Atlântico em diversas latitudes.

Os limites absolutos das escalas de cores são, da esquerda para a direita, $107 \mathrm{~mm}, 17 \mathrm{~mm}, 27 \mathrm{~mm}$ e $172 \mathrm{~mm} . \ldots \ldots 70$

4.33 Similar à figura (4.28) para o oceano Pacífico em diversas latitudes.

Os limites absolutos das escalas de cores são, da esquerda para a

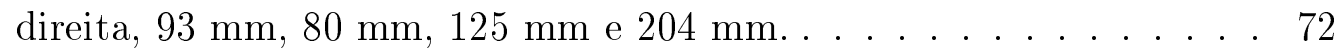

4.34 Similar à figura (4.28) para o oceano Índico em diversas latitudes. Os limites absolutos das escalas de cores são, da esquerda para a direita, $110 \mathrm{~mm}, 89 \mathrm{~mm}, 131 \mathrm{~mm}$ e $63 \mathrm{~mm} . \ldots \ldots . . \ldots 75$

4.35 Coeficiente de correlação médio entre a componente semianual de $w_{s}$ e $w_{E}$ por latitude para cada bacia oceânica. . . . . . . . . . . . 77

4.36 Componente semianual da anomalia da altura da superfície livre observada por altímetros (fileira superior) e a mesma modelada (fileira inferior) no oceano Atlântico em diversas latitudes (colunas). Os limites absolutos das escalas de cores são, da esquerda para a direita, $112 \mathrm{~mm}, 29 \mathrm{~mm}, 67 \mathrm{~mm} \mathrm{e} 177 \mathrm{~mm} . \ldots \ldots . \ldots . \ldots 79$

4.37 Similar à figura (4.36) para o oceano Pacífico em diversas latitudes. Os limites absolutos das escalas de cores são, da esquerda para a direita, $332 \mathrm{~mm}, 75 \mathrm{~mm}, 122 \mathrm{~mm} \mathrm{e} 437 \mathrm{~mm} . \ldots . \ldots . . . .880$

4.38 Similar à figura (4.36) para o oceano Índico em diversas latitudes. Os limites absolutos das escalas de cores são, da esquerda para a direita,

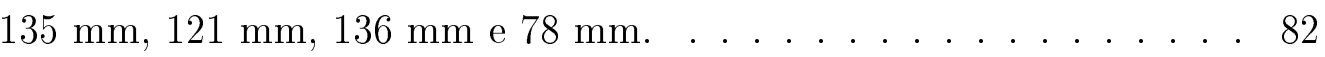




\section{Agradecimentos}

Agradeço ao meu orientador, Prof. Dr. Paulo S. Polito, por todas as ideias, sugestões, críticas, brainstorming e etc. que moldaram meu perfil acadêmico nos últimos 5 anos, e à Profa. Dra. Olga T. Sato, por também estar presente, ensinar e colaborar ao longo deste tempo.

Ao Prof. Dr. Ilson C. A. da Silveira, sempre disponível para discutir ciência, ajudar-me no modelo e também por me mostrar o que é uma fita DAT.

Ao Instituto Oceanográfico da Universidade de São Paulo e a seus funcionários, pela infraestrutura fornecida.

À Coordenação de Aperfeiçoamento de Pessoal de Nível Superior - CAPES, pela concessão de cinco meses de bolsa.

À Fundação de Amparo à Pesquisa do Estado de São Paulo (FAPESP), pelo suporte financeiro através de bolsa concedida sob o processo 2007/56781-0 e de projeto de pesquisa de auxílio regular sob o processo 2008/54206-0.

Aos Dr. Leandro Calado, Comte. Marin e Comte. Ana Cláudia pela compreensão, permitindo que eu me dedicasse à conclusão da dissertação nos momentos críticos. 
Aos colegas de laboratório Lucas, Márcio (comte.), Fabrício, Sebastian, Márcio (japonês) e Carine por compartilharem informações, dados, códigos, frustrações e bom humor!

À minha mãe pela correção ortográfica e gramatical MUITO superior a de qualquer software e ao meu pai por fazer as perguntas certas nas horas certas.

À Luciana por me ajudar a fazer levantamento bibliográfico e, principalmente, por ter ficado ao meu lado sempre que eu precisei.

Enfim, aos meus pais novamente, por me apoiarem, mostrarem interesse nas minhas atividades e sempre me incentivarem nos momentos mais difíceis. 
"The truth is not for all man, but only for those who seek it." 


\section{Resumo}

A resposta oceânica a perturbações com períodos e comprimentos significativamente maiores que o período inercial e que o raio de deformação de Rossby se dá na forma de ondas de Rossby planetárias. Geralmente, as perturbações são atribuídas a variações no rotacional do vento via bombeamento de Ekman. A passagem dessas ondas causa deformação das isopicnais, podendo resultar em anomalias da temperatura da superfície do mar (TSM) por advecção vertical. Dependendo de como ocorre a interação ar-mar, anomalias de TSM podem alterar o campo de ventos ou serem alteradas por ele através de fluxo de calor. Este trabalho utiliza dez anos de dados de temperatura da superfície do mar, velocidade e direção dos ventos e anomalia da altura do mar obtidos por satélites para identificar regiões do oceano onde há forçamento direto do vento na geração de ondas planetárias que se propagam linearmente. Mapas de correlação cruzada entre essas variáveis permitiram identificar onde a interação entre o oceano e a atmosfera é linear. Um modelo simples de uma camada e meia forçado apenas pelo bombeamento de Ekman foi utilizado para testar se, nestas regiões, a variabilidade atmosférica seria suficiente para explicar a variabilidade das ondas de Rossby estimadas pelos dados altimétricos. A interação entre a TSM e a intensidade do vento no Atlântico sul tropical é distinta das demais bacias oceânicas. Das correlações entre a TSM e o rotacional da tensão de cisalhamento do vento, observou-se que a dinâmica de Ekman não é marcante no Índico. Nas regiões tropicais do Atlântico e do Pacífico, as previsões do modelo foram similares às observações. Por fim, foram obtidas evidências de geração e retroalimentação de ondas planetárias nas bordas leste do Atlântico e do Pacífico.

Descritores: altímetro, escaterômetro, TSM, QuikSCAT, TRMM, onda de Rossby, onda planetária, espectro cruzado. 


\section{Abstract}

Rossby waves are the ocean response to perturbations whose temporal and spatial scales are significantly longer than both the inertial period and the Rossby radius of deformation. These perturbations are, more often than not, attributed to variations in the wind stress curl via Ekman pumping. The waves cause isopycnal displacement which due to vertical advection may result in sea surface temperature (SST) anomalies. Depending on the ocean-atmosphere interaction, SST anomalies can either change the wind field or be changed by it due to the heat flux. This study makes use of ten years of satellite derived SST, wind vector, and sea surface height anomaly data to identify regions where there is direct wind forcing of linear Rossby waves. Cross-correlation maps between these variables show where linear interactions occur. A simple $1 \frac{1}{2}$ layer model forced by Ekman pumping was used to check if, in those regions, atmospheric variability alone can explain the observed Rossby wave variability as estimated from radar altimeter data. The interaction between SST and wind magnitude in the South Atlantic is distinct from all other ocean basins. SST and wind stress curl correlations show that the Ekman dynamics is not dominant in the Indian Ocean. In the tropical Atlantic and Pacific the model predictions are similar to the observations. Finally, evidence of genesis and feedback of planetary waves is presented for the eastern boundaries of the Atlantic and Pacific oceans.

Keywords: altimeter, scatterometer, SST, QuikSCAT, TRMM, Rossby wave, planetary wave, cross-spectre. 


\section{Capítulo 1}

\section{Introdução}

A variação de parâmetros físicos observada na superfície do oceano em escalas espaciais de dezenas a milhares de quilômetros e períodos de meses a anos pode ser dividida entre determinística e estocástica. A parte determinística é associada a fenômenos cuja dinâmica é predominantemente linear; nesta componente o ciclo sazonal em geral se sobressai. A parte estocástica, em contraponto, é associada majoritariamente às componentes não lineares das equações do movimento e é imprevisível numa escala temporal maior que alguns dias (MOORE, 1999). Estudos numéricos usualmente analisam a resposta linear de um modelo a um campo de vento particularmente suave por comparação direta com as observações, enquanto a parte não linear é tratada de forma estatística. Nesta última categoria figuram comparações indiretas, como estatísticas de vórtices, inferências sobre a energia cinética turbulenta média numa dada região, análise espectral etc.

Os processos estocásticos predominam nas altas frequências tanto na atmosfera quanto no oceano. Todavia, estas altas frequências são distintas entre os fluidos, uma vez que o espectro de energia do oceano é relativamente mais vermelho 
que o da atmosfera, ou seja, uma parte maior da energia nos oceanos está distribuída em frequências mais baixas que na atmosfera.

Tendo em vista que a variabilidade atmosférica é melhor descrita como um processo ao menos parcialmente estocástico em uma ampla banda de frequências e comprimentos de onda, o movimento induzido no oceano não pode ser considerado como exclusivamente determinístico. Uma descrição mais precisa do movimento forçado pela atmosfera precisa levar em consideração a natureza estocástica dos campos atmosféricos e oceânicos (WILLEBRAND et al., 1980). O forçamento em larga escala da componente estocástica do vento é significativo a ponto de explicar uma parte substancial da variabilidade decadal dos giros oceânicos (FRANKIGNOUL et al., 1997), além de poder fornecer energia para a geração de ondas de Rossby topográficas (CHHAK et al. 2009).

Ferrari e Wunsch (2010), na tentativa de compreenderem as maiores fontes, sorvedouros e reservatórios de energia do oceano, analisaram o espectro de energia cinética de dados de altimetria, de temperatura da superfície do mar (TSM), de bóias e de simulações numéricas. Eles concluíram que uma teoria linear de resposta forçada, sem modos ressonantes, é mais consistente com as observações - apesar de várias evidências de que o movimento no oceano é turbulento. Neste caso, entenda-se turbulência no sentido de que as interações não lineares rapidamente redistribuem a energia para comprimentos de onda menores que os da forçante. Também foi observado que o forçamento pelo vento é importante em todas as escalas. Uma implicação importante fornecida pelos autores é que a variabilidade do oceano nas frequências subinerciais é diretamente forçada pelo vento, enquanto cascatas turbulentas são significativas na porção do espectro dos números de onda grandes nos dados alti- 
métricos e nas simulações numéricas. Devido à resolução dos dados altimétricos utilizados neste estudo, ressalta-se que esta referência a números de onda grandes é relativa aos comprimentos de onda da ordem de $200 \mathrm{~km}$, da mesma forma que alta frequência seria relativa a períodos da ordem de 20 dias a poucos meses. Os resultados de Ferrari e Wunsch (2010) são um indicativo forte que seria um exercício fútil procurar uma relação linear na interação oceano-atmosfera nestas escalas.

A resposta oceânica a perturbações de meso e larga escala, com períodos significativamente maiores que o período inercial e comprimentos significativamente maiores que o raio de deformação de Rossby, realiza-se na forma de ondas de Rossby planetárias. A teoria básica destas ondas já faz parte do arcabouço básico da dinâmica de fluidos geofísicos (GILL, 1982; PEDLOSKY, 1986, CUSHMAN-ROISIN, 1994 KUNDU; COHEN, 2004). A força restauradora destas ondas no oceano aberto é o gradiente meridional de vorticidade planetária. A topografia de fundo, estrutura de massa da coluna d'água e cisalhamento das correntes também contribuem como força restauradora, porém com menor importância (HERRMANN; KRAUSS, 1989). A teoria linear ainda diz que as ondas longas de Rossby são não dispersivas e transportam energia potencial para oeste, colaborando para a manutenção dos giros subtropicais e intensificando as correntes de borda oeste ANDERSON; GILL, 1975).

As ondas de Rossby podem ser observadas através de altímetros (CHELTON; SCHLAX, 1996; POLITO; CORNILLON, 1997; CIPOLLINI et al., 1997). Nestes estudos, notou-se que a velocidade de fase das ondas não eram as mesmas previstas pela teoria clássica. Foi verificado que a presença de um fluxo médio e de gradientes topográficos alteram a velocidade de fase das ondas longas (KILLWORTH; 
BLUNDELL, 2003a; KILLWORTH; BLUNDELL, 2003b) e que a relação de dispersão é variável para cada região (KILLWORTH; BLUNDELL, 2004; KILLWORTH; BLUNDELL, 2005). A partir destas considerações, Killworth e Blundell (2007) apresentaram uma teoria estendida para as ondas planetárias geradas pelo forçamento do vento e/ou por instabilidade baroclínica. Utilizando esta teoria estendida, observou-se uma dominância do primeiro modo baroclínico, com um segundo modo ainda visível e com os mais altos evanescentes (MAHARAJ et al., 2007; MAHARAJ et al. 2009). Wunsch (2009) observou, através da análise da densidade espectral de dados altimétricos, que havia um excesso significativo de energia ao longo da linha 'não dispersiva' do diagrama, abrangendo as ondas de Rossby barotrópicas e as do primeiro modo baroclínico. Dada esta aparente dominância das ondas planetárias de primeiro modo baroclínico, o presente estudo restringir-se-á a elas, não contemplando outros modos.

A transferência de momentum entre a atmosfera e o oceano pode ser descrita em regiões extra-equatoriais através da dinâmica de Ekman. Variações espaciais no campo de ventos podem resultar em processos de convergência ou divergência de massa na camada superior do oceano, através de transporte de Ekman. Há dois cenários específicos em que ocorrem estes processos, o primeiro caso é quando o rotacional da tensão de cisalhamento do vento é diferente de zero. O segundo caso é quando o vento está paralelo à costa. Em ambos os casos, como condição de continuidade, são geradas velocidades verticais na camada superior, ou bombeamento de Ekman.

A resposta oceânica à forçante do vento dá-se em etapas, primeiro as ondas planetárias e então a circulação de larga escala (ANDERSON; GILL, 1975). Em 
ambos os casos, o mais importante é o efeito integrado do rotacional da tensão de cisalhamento do vento na bacia toda e em um período longo, comparado ao inercial. Por esta razão, são de particular interesse as velocidades verticais resultantes dos processos de convergência ou divergência na camada superior. Se a escala espacial e temporal do bombeamento de Ekman for similar à escala das ondas de Rossby, elas serão geradas (KRAUS; WUEBBER, 1982; LIPPERT; KASE, 1985), é o caso de forçamento direto pela atmosfera. Variações do cisalhamento do vento paralelo à borda leste das bacias oceânicas também resultam em velocidades verticais na camada superior, que por sua vez dão origem a ondas de Rossby (ANDERSON; GILL, 1975; KRAUS; WUEBBER, 1982). Todavia, Fu e Qiu (2002) demonstraram que as ondas forçadas pelo rotacional do vento sobrepujam as geradas pelo efeito de borda leste, a partir da análise da correlação entre simulações de um modelo linear de um oceano de duas camadas forçado pelo rotacional da tensão de cisalhamento do vento e entre as observações do TOPEX/Poseidon de 1993 a 2000 para o Pacífico norte. Portanto, justifica-se assim (a) a restrição do escopo das análises no presente estudo aos efeitos do rotacional da tensão de cisalhamento do vento e (b) a ideia de que é viável associar a resposta do oceano às forçantes atmosféricas através da comparação estatística de campos de altura da superfície livre e de ventos.

Mais especificamente, a hipótese do bombeamento de Ekman pode ser confirmada onde há deslocamento da superfície para cima e o rotacional da tensão de cisalhamento do vento resulta em um bombeamento negativo, ou vice-versa. Logo, se assumirmos que o deslocamento é devido apenas à forçante local, espera-se que a correlação entre o deslocamento da superfície e o bombeamento de Ekman esteja defasada de $180^{\circ}$, ou seja, negativa. A hipótese do bombeamento de Ekman junto 
à costa é confirmável se a magnitude da componente paralela à costa da tensão de cisalhamento do vento estiver correlacionada positivamente ao deslocamento da superfície para lag zero, portanto sem defasagem. Nestes casos, trata-se do modelo clássico, onde a atmosfera força o oceano. Assim, espera-se que a altura da superfície livre $(\mathrm{ASM}, \eta)$ esteja correlacionada com o bombeamento de Ekman $\left(w_{E}\right)$ nos locais de geração de ondas planetárias ou de modulação de suas amplitudes.

Variações na altura da superfície marinha também estão associadas a variações térmicas e/ou halinas. Anomalias positivas de altura indicam expansão por aquecimento ou por diminuição de salinidade. De forma contrária, anomalias negativas indicam contração por resfriamento ou por aumento de salinidade. O fluxo de calor do oceano para atmosfera apresenta variabilidade horizontal, causando um aquecimento diferencial da atmosfera. Logo, há uma relação entre a temperatura da superfície do mar e os ventos superficiais.

Há duas hipóteses de como se dá esta relação. A primeira considera que há um acoplamento entre a TSM e a pressão do ar ao nível do mar (LINDZEN; NIGAM, 1987). Gradientes da TSM alteram a temperatura da camada inferior da atmosfera, forçando um fluxo convectivo. Assim, para que a continuidade seja respeitada, sobre as áreas mais quentes do oceano há convergência de ar e sobre as mais frias há divergência. Considerando-se somente este efeito, onde o gradiente de temperatura for máximo, os ventos na superfície também o serão. Portanto, a hipótese de (LINDZEN; NIGAM, 1987) pode ser confirmada onde houver correlação negativa com lag zero entre a TSM e a divergência do campo de vento nos locais onde a superfície do oceano está mais quente. A condição de lag zero assume que esse processo atmosférico advectivo-convectivo tem um tempo característico muito 
inferior ao da variabilidade oceânica de meso e larga escala que é o foco do presente estudo.

A segunda hipótese assume que a estabilidade vertical da coluna de ar é perturbada quando a superfície do oceano está mais quente que a atmosfera adjacente, resultando em ar menos denso nas camadas inferiores. Como consequência, surge um fluxo turbulento nas proximidades da interface oceânica, que é responsável por uma diminuição na taxa de transferência de momentum (i.e., viscosidade) entre o oceano e a atmosfera (WALLACE et al., 1989, HAYES et al., 1989). Portanto, haverá uma diminuição na velocidade dos ventos superficiais sobre águas frias e um aumento sobre águas quentes. Esta hipótese pode ser confirmada em locais onde há uma correlação positiva com lag zero entre TSM e a magnitude do campo de ventos. A hipótese deste mecanismo de acoplamento ar-mar foi proposta por Wallace et al. (1989) originalmente para o Pacífico tropical na escala sazonal e inter-anual, enquanto Hayes et al. (1989) propuseram a mesma hipótese na escala semanal e mensal para a mesma região. Mais recentemente, Caltabiano et al. (2005) sugeriram que esta hipótese também pode ser aplicada à região tropical do Atlântico.

Em ambos os casos, a confirmação definitiva de uma ou outra hipótese dependeria de observações meteorológicas in situ da formação de instabilidade convectiva, para a hipótese de Lindzen e Nigam (1987), ou de uma redução do coeficiente de viscosidade turbulenta para a hipótese de Wallace et al. (1989), associadas às anomalias positivas de TSM. O que se pretende obter neste estudo é uma evidência estatística de que um ou outro processo é dominante.

Combinando as teorias e hipóteses apresentadas até o momento, pode-se propor um mecanismo de retroalimentação em larga escala, cuja ocorrência é passível 
de verificação com a metodologia proposta mais à frente. Este mecanismo iniciase com o rotacional da tensão de cisalhamento do vento gerando divergência (ou convergência) na camada de Ekman. Por continuidade, esta divergência causaria velocidades verticais. Estas velocidades advectariam o gradiente térmico vertical do interior do oceano. O movimento vertical das isopicnais resultariam em ondas de Rossby. A assinatura superficial dessas ondas, também causada pela advecção vertical, geraria anomalias de TSM. Estas anomalias, quer pelo modelo de Lindzen e Nigam (1987), quer pelo modelo de Wallace et al. (1989), causariam anomalias no campo de vento. Dessas anomalias no campo de vento, as que tem rotacional não nulo gerariam divergência na camada de Ekman e o ciclo de retroalimentação se fecha.

Wunsch (2002) relembra que fluxo de massa do oceano é sustentado primeiramente pelo vento e secundariamente pelas marés, em uma revisão da literatura, e ainda afirma que a natureza do campo de ventos é a variável de maior importância no clima. Logo, saber como o oceano responde à forçante do vento é importante para modelos climáticos. Os limites de linearidade delimitam onde a comparação de resultados de modelo com dados reais pode ser determinística (linear) ou apenas estatística (não linear).

O presente estudo pretende testar a hipótese de que as relações estatísticas entre bombeamento de Ekman, TSM e variação na altura da superfície do mar permitem propor áreas de formação e/ou modulação de ondas planetárias. Nestas áreas, um modelo linear simples deve ser capaz de reproduzir as principais características das ondas planetárias. Esta hipótese pressupõe um acoplamento linear entre estas relações. Como esta hipótese será abordada é o assunto do capítulo seguinte. 


\section{Capítulo 2}

\section{Objetivos}

A hipótese de que as relações estatísticas entre o bombeamento de Ekman, a temperatura da superfície do mar e a variação da altura da superfície livre do mar que, em princípio, permitiriam propor áreas de formação/modulação de ondas planetárias pressupõe um acoplamento linear entre estas relações. Dada esta condição, este estudo propõe identificar estas áreas onde o oceano responde linearmente às variabilidades atmosféricas locais em larga escala. Espera-se identificar locais de geração de ondas planetárias por forçamento direto do vento, locais onde a amplitude das ondas é modulada pelo vento.

Por estarem associados a um possível mecanismo de retroalimentação das ondas, os campos de TSM e velocidade do vento serão analisados tendo-se em mente duas hipóteses distintas, a de Lindzen e Nigam (1987) e a de Wallace et al. (1989).

Nos locais onde um modelo numérico linear, forçado apenas pelo rotacional do vento, for capaz de reproduzir ondas de Rossby com razoável verossimilhança, pode-se afirmar que (i) as ondas se comportam de forma linear e (ii) que são forçadas 
pelo vento. Esta hipótese será testada utilizando como entrada do modelo dados observacionais de vento, obtidos por escaterômetro.

Por objetivos específicos, têm-se:

- Elaboração e análise de mapas dos coeficientes de correlação em lag zero entre a variação temporal da anomalia da altura da superfície livre do mar (AASM, $\eta^{\prime}$ ) e o bombeamento de Ekman;

- Elaboração e análise onde ocorre o pico do espectro cruzado entre a variação temporal da AASM e o bombeamento de Ekman;

- Idem, entre a magnitude da velocidade do vento e a TSM e entre o divergente da velocidade do vento e a TSM;

- Realizar os procedimentos acima para os dados não filtrados e filtrados, quando se julgar necessário;

- Elaboração de um modelo numérico simples para simular a AASM forçada pelo vento observado e comparar os resultados com a AASM observada. 


\section{Capítulo 3}

\section{Materiais e métodos}

\section{1 Área de estudo}

O trabalho foi desenvolvido em escala quase global com enfoque no oceano Atlântico, de maneira que a delimitação da área de estudo será dada pela cobertura espacial dos dados: $65^{\circ} \mathrm{S}$ a $65^{\circ} \mathrm{N}, 0^{\circ}$ a $360^{\circ}$ para a comparação entre dados altimétricos e de vento e $40^{\circ} \mathrm{S}$ a $40^{\circ} \mathrm{N}, 0^{\circ}$ a $360^{\circ}$ para a comparação entre dados de vento e de TSM. No entanto, a região equatorial não foi analisada por limitação de tempo face à sua complexidade.

\subsection{Dados}

\subsubsection{Altimétricos}

Dados globais de ASM e de AASM são obtidos pelos altímetros a bordo de satélites, tornando possíveis análises altimétricas de larga escala (ROBINSON, 
2004). O site da Aviso (Archiving, Validation and Interpretation of Satellite Oceanographic data) distribui dados altimétricos dos satélites TOPEX/Poseidon (T/P), Jason-1, ERS-1, ERS-2 e EnviSat.

Os altímetros seguem uma órbita fixa, realizando um ciclo de repetição exata. Neste ciclo, o altímetro amostra diferentes regiões em cada volta, sendo que, após várias voltas orbitais, os altímetros retornam ao posicionamento inicial, re-iniciando o ciclo. No T/P, no Jason-1 e no Jason-2 o ciclo é de 9,9156 dias, enquanto o ERS-1, o ERS-2 e o EnviSat têm um ciclo de 35 dias (POLITO, 2005).

Os dados de ASM disponíveis são o resultado da altitude do altímetro descontado o range do altímetro corrigido. O range do altímetro é a distância entre o instrumento e a superfície do mar, com os erros de calibração e do instrumento corrigidos. Já o range do altímetro corrigido é o próprio range com as correções da troposfera úmida, da troposfera seca, da ionosfera e do viés do estado do mar aplicadas. Por sua vez, a AASM disponível é obtida descontando da ASM a superfície média do mar (modelo CLS01_MSS), a maré da Terra sólida, a maré do oceano geocêntrico, a maré polar (a devida às variações do eixo de rotação da Terra), o efeito do barômetro invertido e as flutuações de alta frequência da topografia da superfície do mar devido à forçantes atmosféricas Dumont et al. (2009). Ressalta-se que, ao se remover a superfície média do mar, as correntes médias ou permanentes também são removidas, não aparecendo nos dados de AASM consequentemente.

Utilizou-se no presente trabalho a série de AASM dos dados de multisatélites interpolada ao longo das passagens (along-track gridded) produzida pelo Ssalto/Duacs (Segment Sol multimissions d'ALTimétrie, d' Orbitographie et de localisation/Data Unification and Altimeter Combination System) e distribuída pela 
Aviso (http://www.aviso.oceanobs.com/duacs/), com suporte do Cnes (Centre National d'Études Spatiales, França). A resolução final espacial dos dados é de $0,25^{\circ} \times 0,25^{\circ}$ e a temporal de 7 dias. Há disponibilidade dos dados de 10/1992 até o presente, com cobertura espacial de $67,5^{\circ} \mathrm{S}$ a $67,5^{\circ} \mathrm{N}$ e precisão nominal de $2 \mathrm{~cm}$.

Os dados deste conjunto em particular são gerados sempre a partir de dados de dois satélites, mesmo que haja mais disponíveis. Este procedimento resulta na uniformidade da densidade de pontos amostrais dos mapas, garantindo uma certa estabilidade nos parâmetros estatísticos.

\subsubsection{Vento}

Dados obtidos por sensoriamento remoto são adequados para lidar com a componente estocástica da velocidade na atmosfera, pois os escaterômetros obtém campos de vento com um espectro mais rico que os modelos operacionais de previsão do tempo (LIU et al., 1998).

O princípio de funcionamento dos escaterômetros é o espalhamento Bragg por ondas capilar-gravidade (ROBINSON, 2004). Por esta razão, limites inferior e superior ao vento que pode ser medido com este aparelho são impostos indiretamente. Caso o estado do mar esteja muito calmo, as ondas não terão amplitude suficiente para serem amostradas, sendo que esse efeito ocorre com velocidades do vento menores que 3 a $4 \mathrm{~ms}^{-1}$. Se o mar estiver muito agitado (ou sob chuva forte), haverá formação de espuma e de outras ondas que impedirão leituras confiáveis acima de 20 a $30 \mathrm{~ms}^{-1}$. 
Sato et al. (2002) demonstraram que os dados do escaterômetro do ERS eram discrepantes quando comparados aos do QuikSCAT e de modelos, sendo que estes foram similares entre si. Esta foi a principal razão da escolha dos dados do QuikSCAT como fonte de dados de vento frente a conjuntos de outros escaterômetros.

As séries temporais globais de campos de vento globais obtidas pelo $S e$ aWinds - o escaterômetro a bordo do satélite QuikSCAT - são fornecidas gratuitamente pelo JPL/PODAAC (Jet Propulsion Laboratory/Phisical Oceanographic Distributed Active Archive Center) da NASA (National Aeronautics and Space Administration, Estados Unidos), com valores das componentes zonal e meridional do vento (http://podaac.jpl.nasa.gov/). Os dados padrões de nível 3 fornecidos tem resolução espacial de $25 \mathrm{~km}\left(0,25^{\circ} \times 0,25^{\circ}\right)$ e o satélite cobre $93 \%$ do oceano global diariamente (LIU, 2002). Na faixa de 3 a $20 \mathrm{~ms}^{-1}$, a precisão do escaterômetro é de $2 \mathrm{~ms}^{-1}$, já entre 20 e $30 \mathrm{~ms}^{-1}$ a precisão é de $10 \%$. Há disponibilidade dos dados desde 08/1999 até 11/2009, quando o mecanismo que posicionava a antena do escaterômetro deixou de funcionar.

\subsubsection{Temperatura da superfície do mar}

Dados de TSM podem ser obtidos remotamente por sensores que operam na região do infra-vermelho (IR) ou que operam com microondas. Neste estudo foram utilizados os dados do imageador de microondas TMI (TRMM Microwave Imager), à bordo do satélite TRMM (Tropical Rainfall Measuring Mission) das agências espaciais americana NASA e japonesa JAXA (Japan Aerospace Exploration Agency). Estes dados estão disponívies no site do GES DISC (Goddard Earth Sciences Data and 
Information Services Center), filiado à NASA (http://daac.gsfc.nasa.gov/). O satélite foi lançado em 1997 e sua cobertura espacial é de $40^{\circ} \mathrm{S}$ a $40^{\circ} \mathrm{N}$ apenas, uma vez que sua missão principal é monitorar e estudar a precipitação tropical. A resolução temporal é de 12 horas, enquanto a espacial é de $0,25^{\circ} \times 0,25^{\circ}$, sendo muito inferior à dos sensores IR, mas suficiente para este estudo. Contudo, os sensores IR não conseguem amostrar regiões com cobertura de nuvens, enquanto as nuvens são transparentes para sensores de microondas, sendo esta a principal razão da escolha dos dados do TRMM/TMI.

\subsection{Metodologia}

\subsubsection{Tratamento dos dados de vento}

Devido à combinação da largura da varredura (swath width) e da separação longitudinal entre passagens vizinhas do satélite QuikSCAT, cada mapa de dados apresenta algumas zonas sem cobertura, as quais são diferentes em cada mapa. Desta forma, foram gerados mapas diários das componentes da velocidade do vento a partir da média entre os mapas obtidos na órbita ascendente e descendente e nas regiões onde apenas um dos mapas possuía dados, foram utilizados estes dados em vez de se tentar calcular uma média, minimizando as zonas sem cobertura.

No entanto, é importante para o cálculo das propriedades derivadas da velocidade do vento que os mapas diários não apresentem lacunas ou descontinuidades, assim as componentes da velocidade do vento foram interpoladas espacialmente em cada um dos mapas. Foi utilizado como interpolador o algoritmo para gradeamento 
de uma superfície de curvatura contínua de tensão ajustável do GMT ( Generic Mapping Tools, http://gmt.soest.hawaii.edu/) (SMITH; WESSEL, 1990), com um fator de tensão de 0,25 .

Além disso, estes dados de nível 3 apresentam em algumas regiões padrões não naturais derivados da interpolação feita nas passagens do satélite. Estes padrões espúrios foram removidos através de filtragem bidimensional espacial em cada mapa diário (figura 3.1), sendo utilizado um filtro bidimensional do tipo Blackman com nove pontos (equação 3.1) (OPPENHEIM; SCHAFER, 1999), que nesta resolução equivale a $2^{\circ}$.

$$
w(n)=0,42-0,5 \cos \left(2 \pi \frac{n}{N-1}\right)+0,08 \cos \left(4 \pi \frac{n}{N}\right)
$$

onde $w$ é a função filtro, $n$ corresponde aos elementos e $N+1$ é a largura do filtro, lembrando que $0<=n<=N$.
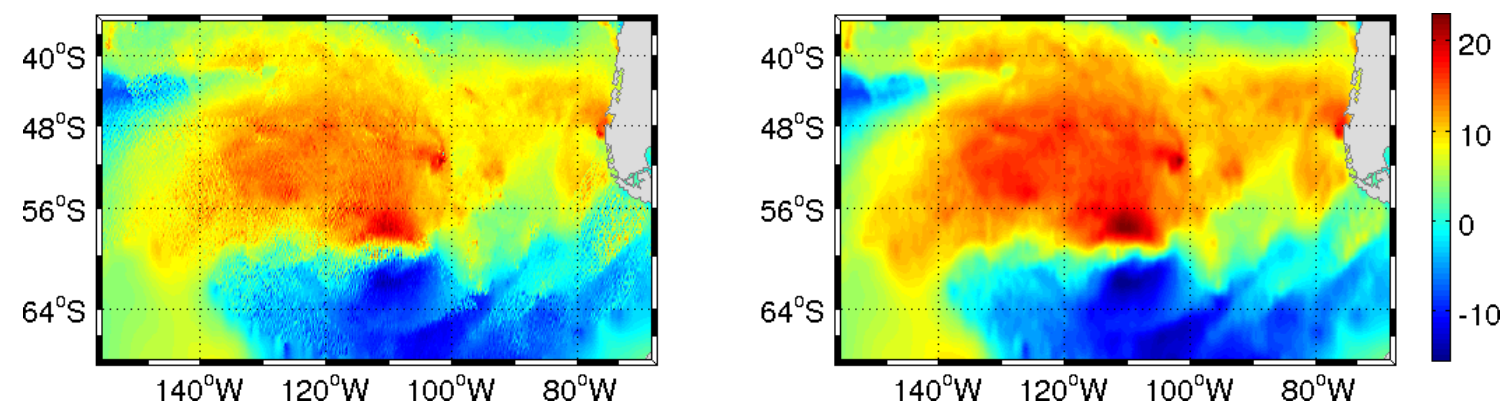

Figura 3.1: Exemplo de um mapa diário para a componente zonal de dados de nível 3 bruto à esquerda e o mesmo mapa filtrado à direita.

Para se obter os resultados a serem comparados com os dados altimétricos, foram gerados mapas das componentes da velocidade do vento para os dias específicos de amostragem do altímetro, de forma que ambos fiquem na mesma grade temporal. Estes mapas foram gerados a partir de uma média ponderada de sete ma- 
pas diários. O mapa diário de cada data de amostragem do altímetro recebe o maior peso, enquanto os três dias anteriores e posteriores recebem pesos sucessivamente menores. No caso, foi novamente utilizada a fórmula (3.1) do filtro Blackman para fornecer os pesos. Espacialmente, ambos os conjuntos de dados estão na mesma grade, não necessitando nenhum tratamento adicional.

Das componentes da velocidade do vento foram obtidas as tensões de cisalhamento zonal e meridional através da metodologia de Large e Yeager (2004), onde:

$$
\begin{gathered}
\vec{\tau}=\rho_{a r} C_{D}\left|\vec{v}_{w}\right| \vec{v}_{w}, \\
10^{3} C_{D}=\frac{2,7}{\left|\vec{v}_{w}\right|}+0,142+\frac{\left|\vec{v}_{w}\right|}{13,09},
\end{gathered}
$$

sendo $\vec{\tau}$ o vetor tensão de cisalhamento, $\rho_{a r}$ a densidade do ar tomada como constante e igual a $1,22 \mathrm{~kg} . \mathrm{m}^{-3}, C_{D}$ o coeficiente de arrasto, $\left|\vec{v}_{w}\right|$ o módulo da velocidade do vento a $10 \mathrm{~m}$ e $\vec{v}_{w}$ o vetor velocidade do vento a $10 \mathrm{~m}$. Esta formulação de $C_{D}$ sugerida por Large e Yeager (2004) é proveniente de uma compilação de observações não publicadas das velocidades do vento entre $1 \mathrm{~ms}^{-1}$ e $25 \mathrm{~ms}^{-1}$.

O rotacional da tensão de cisalhamento do vento foi calculado pelo método das diferenças finitas centradas no espaço. As componentes zonal $\left(\tau^{(x)}\right)$ e meridional $\left(\tau^{(y)}\right)$ da tensão de cisalhamento do vento foram organizadas em uma matriz $M \times N$, onde $M$ é o número de linhas da matriz de dados de ventos de nível três e $N$ é o número de colunas. Desta forma, tem-se:

$$
\vec{k} \cdot\left(\nabla \times \vec{\tau}_{m, n}\right) \simeq \frac{\tau_{m, n+1}^{(y)}-\tau_{m, n-1}^{(y)}}{2 \Delta x}-\frac{\tau_{m+1, n}^{(x)}-\tau_{m-1, n}^{(x)}}{2 \Delta y}
$$


sendo o índice $m$ a posição vertical (linha), o índice $n$ a posição horizontal (coluna), $\tau^{(x)}$ corresponde à componente zonal da tensão de cisalhamento do vento, $\tau^{(y)}$ a componente meridional e $\Delta x$ e $\Delta y$ correspondem à distância de $0,25^{\circ}$ em metros, lembrando que $\Delta x$ é corrigido pelo cosseno da latitude. Devido à esfericidade da Terra, quando $n=1$, tem-se $(n-1)=n_{\max }$ e quando $n=n_{\max }$, tem-se $(n+1)=n_{1}$, de forma que o número de colunas não se altera.

Com o rotacional da tensão de cisalhamento do vento, foi obtida a velocidade vertical na base da camada de Ekman (bombeamento de Ekman) através de:

$$
w_{E}=\frac{\vec{k}}{\rho_{0} f_{0}} \cdot(\nabla \times \vec{\tau}),
$$

sendo $w_{E}$ o bombeamento de Ekman, cuja profundidade é $\mathrm{O}[10-100] \mathrm{m}, \rho_{0}$ é a densidade média da água do mar considerada constante e igual a $1025 \mathrm{~kg} . \mathrm{m}^{-3}$ e $f_{0}$ é o parâmetro de Coriolis.

A magnitude da velocidade do vento (equação 3.6), o bombeamento de Ekman (equações 3.4 e 3.5) e o campo de divergência do vento (equação 3.7) foram calculados para cada mapa diário, sendo que a divergência foi estimada pelo método das diferenças finitas centradas no espaço, de forma análoga à equação 3.4 .

$$
\begin{gathered}
\left|\vec{v}_{w}\right|=\sqrt{u_{w}^{2}+v_{w}^{2}}, \\
\nabla \cdot \vec{v}_{w}^{m, n} \simeq \frac{u_{w}^{m, n+1}+u_{w}^{m, n-1}}{\Delta x}+\frac{v_{w}^{m+1, n}+v_{w}^{m-1, n}}{\Delta y},
\end{gathered}
$$

onde $\vec{v}_{w}$ é a velocidade do vento, $u_{w}$ é a componente zonal de $\vec{v}_{w}$ e $v_{w}$ é a componente meridional. As variáveis $\Delta x$ e $\Delta y$ e os índices $m$ e $n$ são os mesmos da equação 3.4 . 


\subsubsection{Tratamento dos dados altimétricos}

Os dados ao longo das passagens foram interpolados para uma grade regular de $0,25^{\circ}$. Novamente, interpolou-se com o método de Smith e Wessel (1990) com um fator de tensão de 0,25 .

Para cada ponto da grade espacial, foi obtida a derivada temporal da AASM também através do método das diferenças finitas. Mas, para esta derivada foi gerada uma grade temporal correspondente às posições intermediárias da grade original de $\eta^{\prime}$

$$
\left(\frac{\partial \eta^{\prime}}{\partial t}\right)_{p^{\prime}} \simeq \frac{\eta_{p+1}^{\prime}-\eta_{p}^{\prime}}{t_{p+1}-t_{p}}
$$

onde o índice $p$ corresponde à localização na grade temporal de $\eta^{\prime}, t$ é o valor do tempo e $p^{\prime}$ é o índice correspondente às posições intermediárias da grade original, sendo que $p^{\prime}$ está sincronizado com $p$, ou seja, se $p$ for $1, p^{\prime}$ será 1 também.

Esta derivada obtida é uma estimativa linear da velocidade vertical da superfície material $w_{s}$ (equação 3.9 ), a qual foi comparada com o bombeamento de Ekman, uma vez que ambas correspondem à mesma grandeza física, ainda que em posições verticais distintas:

$$
w_{s}=\frac{\partial \eta^{\prime}}{\partial t}
$$

Cabe aqui notar que a comparação é entre $w_{e}$ e a derivada de $\eta^{\prime}$. Esta é a condição de contorno cinemática na superfície para as soluções ondulatórias das equações do movimento. 


\subsubsection{Tratamento dos dados de TSM}

Os dados de nível 3 temperatura da superfície do mar possuem aproximadamente a mesma resolução espacial e temporal que os dados de nível 3 de velocidade do vento e também os mesmos problemas de zonas sem cobertura de dados. Logo, sofreram o mesmo processo de média entre as órbitas e interpolação espacial e temporal para gerar mapas diários de TSM.

Cabe aqui ressaltar que as comparações entre a temperatura da superfície do mar e a divergência da velocidade do vento foram concebidas para testar a hipótese de Lindzen e Nigam (1987), enquanto as comparações entre a temperatura da superfície do mar e a magnitude da velocidade do vento testam a hipótese de Wallace et al. (1989). Em ambos os casos, apenas interessam os resultados obtidos sem atraso de fase, pois conforme explicado na introdução, esta condição assume que o tempo característico desses processos atmosféricos advectivo-convectivo é muito inferior ao da variabilidade oceânica de meso e larga escala.

\subsubsection{Análise estatística}

Os procedimentos acima descritos geraram uma série temporal de valores de anomalia da velocidade vertical da superfície e uma série de bombeamento de Ekman para cada ponto da grade dos dados altimétricos. De forma similar, para cada ponto de grade dos dados de temperatura da superfície do mar há uma série de $\operatorname{TSM}\left(T_{s}\right)$, uma de magnitude da velocidade do vento e uma de divergência da velocidade do vento. 
Calculou-se a correlação cruzada entre $w_{s}$ e o negativo das estimativas de $w_{E}$, pois pela dinâmica de Ekman a velocidade superficial e a velocidade da base da camada são inversamente correlacionadas. Nas regiões onde a correlação for significativa, é possível que o forçamento direto pelo vento ocorra de forma linear.

Para testar a hipótese de Lindzen e Nigam (1987), foi calculada a correlação entre $T_{s}$ e $\nabla \cdot \vec{v}_{w}$. Este cálculo fornecerá indícios estatísticos de que a hipótese se verifica onde forem observadas correlações significativas. Da mesma forma, calculouse a correlação entre $T_{s}$ e $\left|\vec{v}_{w}\right|$ para testar a hipótese de Wallace et al. (1989).

Ainda foi calculada a correlação cruzada entre $\eta^{\prime}$ e $T_{s}$, a fim de verificar se as anomalias da altura - relacionadas com a expansão da coluna d'água - também estão relacionadas com o aquecimento da superfície (CHAMBERS et al. 1997$)$.

Ressalta-se que obter correlações altas em lag zero em qualquer um dos testes garante que relação causa-efeito das hipóteses é possível, mas não assegura que esta relação ocorrerá sempre.

Também foi calculado o espectro cruzado para $w_{s}$ e $-w_{E}, T_{s}$ e $\nabla \cdot \vec{v}_{w}$ e entre $T_{s}$ e $\left|\vec{v}_{w}\right|$. A vantagem de se calcular o espectro cruzado é que ele fornece as potências espectrais em função da frequência, permitindo localizar em quais frequências as duas séries comparadas apresentam algum tipo de similaridade. Todavia, devido à heterogeneidade da potência espectral, locais de maior energia cinética turbulenta no oceano apresentarão picos de potência espectral ordens de grandeza maior que em locais de baixa energia.

Inicialmente, esperava-se utilizar a coerência espectral, mas, no procedimento recomendado por Emery e Thomson (2001), seria necessário tratar as séries 
temporais, inicialmente removendo as médias e as tendências, depois realizando médias em caixas e, por fim, alisando as séries com uma janela móvel. Estes procedimentos tendem a melhorar a confiabilidade estatística de estimativas espectrais, mas apresentam como uma grande desvantagem a diminuição da resolução da frequência. Neste caso, teria-se como consequência a perda de informação dos sinais de longo período (baixa frequência), que em geral são os que mais interessam, inviabilizando a utilização deste método.

Dada a importância das ondas de Rossby planetárias no conteúdo energético de baixa frequência, todas as séries foram submetidas a uma sequência de filtros bidimensionais de resposta impulsiva finita (FIR2D) similares aos utilizados por Polito e Liu (2003). Esses filtros separam o sinal em diversas bandas, sendo funções do período, comprimento de onda e sentido de propagação. As principais bandas filtradas estão associadas ao ciclo sazonal, às ondas planetárias, às ondas de Kelvin e aos sinais de mesoescala que não se propagam como ondas de Rossby. Polito e Liu (2003) demonstraram (a) que a diferença entre a soma das componentes filtradas e o campo original é dominada por ruído de alta frequência e pequeno comprimento de onda e (b) que as componentes são ortogonais e, portanto, as variâncias podem ser somadas. Logo, pode-se concluir que estes filtros não introduzem sinais artificiais nos dados.

Das componentes decompostas, a anual e semianual foram selecionadas para serem comparadas separadamente. A escolha dessas componentes justifica-se, pois apresentam, na maioria dos casos, a maior amplitude e a melhor relação sinal/ruído, além de facilitarem a comparação com a literatura, que foca nestes períodos em geral. 


\subsubsection{Modelo linear}

A linearidade da resposta oceânica a forçante do vento foi testada através da implementação de um modelo linear cuja entrada são os dados de vento. O propósito deste método é obter uma previsão simples da anomalia de altura da superfície livre do mar para se comparar aos dados dos altímetros.

O modelo utilizado é a aproximação de ondas-longas do oceano de uma camada e meia, quase-geostrófico, no plano $\beta$ e com propagação zonal apenas. A dinâmica da camada de Ekman, a qual depende essencialmente da viscosidade, não está presente no modelo. No entanto, seus efeitos, ou seja, a distorção da picnoclina, são parametrizados através da forçante do vento. Este é a forma mais simples de incluir a física essencial de um oceano forçado pelo vento (MEYERS, 1979).

Sob este conjunto de aproximações, a equação da conservação da vorticidade potencial assume a forma de uma equação de onda de primeira ordem:

$$
\frac{\partial \eta}{\partial t}+c_{p} \frac{\partial \eta}{\partial x}=-\frac{g^{\prime}}{g} w_{E}
$$

cuja condição de contorno dinâmica é:

$$
\eta=0 \quad \text { em } \quad x=x_{e}
$$

onde $\eta$ representa as variações da superfície livre do oceano; $c_{p}$ é a velocidade de fase zonal para ondas de Rossby baroclínicas do $1^{\circ}$ modo, longas e, portanto, não dispersivas; $g^{\prime}$ é a gravidade reduzida; $w_{E}$ é o bombeamento de Ekman; e $x_{e}$ é a posição longitudinal da borda leste. Esta equação é a mesma utilizada por Kelly e Thompson (2002) em um estudo semelhante. 
Neste modelo, há três parâmetros a serem definidos: a velocidade de fase $c_{p}$, a gravidade reduzida $g^{\prime}$ e a localização da borda leste $x_{e}$.

A velocidade de fase é simplesmente a obtida das ondas observadas dos dados altimétricos de acordo com Polito e Liu (2003). A introdução de um $c_{p}$ observado pode ser interpretada como a introdução de um $\beta$ efetivo no modelo, uma vez que $c_{p}=-\beta \frac{g^{\prime} H_{1}}{f^{2}}$, sendo $H_{1}$ a espessura da primeira camada. Neste caso, entende-se por $\beta$ efetivo a variação da vorticidade observada e não apenas a variação meridional da vorticidade planetária, que é o beta da teoria clássica.

A gravidade reduzida é fundamental na determinação da amplitude da onda modelada. Como o objetivo do modelo não é determinar com precisão o deslocamento da superfície livre, é utilizado um valor constante de $g^{\prime}=2 \times 10^{-2} \mathrm{~ms}^{-2}$.

Por fim, $x_{e}$ é aproximado para a localização da isóbata de $1000 \mathrm{~m}$ no talude continental leste.

Este modelo pode ser aplicado nas latitudes abordadas neste estudo independentemente, uma vez que não possui nenhuma dependência na coordenada $y$.

\subsubsection{Derivação}

Considere a equação linear da vorticidade para um oceano de uma camada e meia:

$$
\frac{\partial}{\partial t} \nabla^{2} \psi+\beta \frac{\partial}{\partial x} \psi-\frac{f_{0}}{H_{1}}\left[w(0)-w\left(-H_{1}\right)\right]=0,
$$

onde o primeiro termo é a variação local da vorticidade relativa, o segundo é a advecção de vorticidade planetária e o terceiro é termo de estiramento, representado pelo gradiente linear da velocidade vertical no modelo de uma camada e meia. 
A condição de contorno para o equilíbrio da pressão através da interface fornece:

$$
\psi=-\frac{g^{\prime}}{f_{0}} \eta_{i}
$$

sendo $\eta_{i}$ o deslocamento vertical da interface.

E a condição de contorno cinemática na interface é:

$$
w\left(-H_{1}\right)=-\frac{\partial \eta_{i}}{\partial t}
$$

Substituindo equação 3.13 na equação 3.12 , tem-se:

$$
\frac{\partial}{\partial t} \nabla^{2}\left(-\frac{g^{\prime}}{f_{0}} \eta_{i}\right)-\beta \frac{g^{\prime}}{f_{0}} \frac{\partial \eta_{i}}{\partial x}+\frac{f_{0}}{H_{1}} w\left(-H_{1}\right)=\frac{f_{0}}{H_{1}} w(0) .
$$

Usando equação 3.14 para eliminar $w\left(-H_{1}\right)$, obtém-se:

$$
\frac{\partial}{\partial t}\left[\nabla^{2}\left(-\frac{g^{\prime}}{f_{0}} \eta_{i}\right)+\frac{f_{0}}{H_{1}} \eta_{i}\right]-\beta \frac{g^{\prime}}{f_{0}} \frac{\partial \eta_{i}}{\partial x}=\frac{f_{0}}{H_{1}} w(0) .
$$

Multiplicando a equação (3.16) por $H_{1} / f_{0}$,

$$
\frac{\partial}{\partial t}\left[\nabla^{2}\left(-R_{d}^{2} \eta_{i}\right)+\eta_{i}\right]-\beta R_{d}^{2} \frac{\partial \eta_{i}}{\partial x}=w(0),
$$

onde foi utilizada a definição do raio de deformação de Rossby para o modelo de uma camada e meia, ou seja,

$$
R_{d}^{2}=\frac{g^{\prime} H_{1}}{f_{0}^{2}}
$$

Para contabilizar a forçante do vento, deve-se considerar o torque introduzido no oceano pelo rotacional do vento. Um modo de fazer isto no modelo de uma camada e meia é considerar o bombeamento de Ekman como condição de contorno superficial:

$$
w=w_{E}(x, y, t) \text { em } z=0 .
$$


Com esta condição de contorno, a equação (3.17) torna-se:

$$
\frac{\partial}{\partial t}\left[\nabla^{2}\left(-R_{d}^{2} \eta_{i}\right)+\eta_{i}\right]-\beta R_{d}^{2} \frac{\partial \eta_{i}}{\partial x}=w_{E}
$$

Aplicando a aproximação de ondas longas, a qual desconsidera o termo de vorticidade relativa através da comparação com o termo de estiramento, obtém-se:

$$
\frac{\partial \eta_{i}}{\partial t}+c_{p} \frac{\partial \eta_{i}}{\partial x}=w_{E}
$$

onde $c_{p}$ é velocidade de fase zonal das ondas de Rossby não dispersivas já definida anteriormente, que pode ser reescrita como $c_{p}=-\beta R_{d}^{2}$.

A equação (3.21) mostra como a interface em um modelo de uma camada e meia sob a aproximação de ondas longas reage à forçante do vento. Este deslocamento da interface terá uma assinatura na superfície ao se relaxar a aproximação da tampa rígida através de $\eta<<\eta_{i}$, resultando em:

$$
\eta=-\frac{g^{\prime}}{g} \eta_{i}
$$

Ao se substituir a equação (3.22) na equação (3.21), chega-se a:

$$
\frac{\partial \eta}{\partial t}+c_{p} \frac{\partial \eta}{\partial x}=-\frac{g^{\prime}}{g} w_{E}
$$

sendo esta a equação utilizada pelo modelo, ou seja, a equação (3.10).

\subsubsection{Discretização}

Por não se tratar de um modelo já estabelecido, cabe aqui descrever a sua elaboração em detalhes, para que se possa garantir a reprodutibilidade dos resultados. 
Foi utilizado um esquema explícito de diferenças finitas na discretização da equação (3.10). Esquemas explícitos de propagação são incondicionalmente instáveis quando centrados no espaço, de maneira que deve ser sempre avançado ( $c$ negativo) ou retardado ( $c$ positivo) no espaço. Neste caso, a condição de estabilidade será a de Courant-Friedrichs-Lewy (CFL):

$$
0<\left|c_{p} \frac{\Delta t}{\Delta x}\right|<1
$$

sendo $\Delta t$ e $\Delta x$ os passos de tempo e de espaço, respectivamente.

Como para as ondas planetárias $c$ é sempre negativo, a equação 3.10 discretizada fica:

$$
\frac{\eta_{m}^{k+1}-\eta_{m}^{k}}{\Delta t}+c_{p} \frac{\eta_{m+1}^{k}-\eta_{m}^{k}}{\Delta x}=-\frac{g^{\prime}}{g} w_{E}
$$

sendo $k$ e $m$ os índices temporal e espacial, respectivamente.

Isolando $\eta_{m}^{k+1}$, chega-se finalmente à equação utilizada pelo modelo:

$$
\eta_{m}^{k+1}=\eta_{m}^{k}-\Delta t \frac{g^{\prime}}{g} w_{E}-c_{p} \frac{\Delta t}{\Delta x}\left(\eta_{m+1}^{k}-\eta_{m}^{k}\right)
$$

O passo de tempo adotado pelo modelo foi de $3 \mathrm{~h}$, enquanto o passo espacial foi de $0,25^{\circ}$ de longitude, ou seja, $\Delta x=27,78 \cos (\theta) \mathrm{km}$, onde $\theta$ é a latitude. Com estes valores, a condição de estabilidade CFL foi cumprida para as ondas cuja velocidade de propagação era inferior a $200 \mathrm{~km} /$ dia, sendo o caso da maioria das ondas planetárias. 


\section{Capítulo 4}

\section{Resultados e discussões}

\subsection{Coeficientes de correlação}

\subsubsection{Velocidades verticais}

A figura (4.1) apresenta um mapa com os coeficientes de correlação cruzada obtidos entre as séries temporais de $w_{s}$ e as de $-w_{E}$. Estas séries são compostas pelos dados interpolados, mas não filtrados. Consequentemente, misturam-se fenômenos díspares: ciclo sazonal e ondas planetárias, além da presença de outros sinais como ciclos inter-anuais, ondas de Kelvin e ruídos de alta-frequência.

As correlações obtidas na figura (4.1) foram baixas, com valores absolutos máximos de pouco mais de 0,3 . Como este resultado foi obtido sem nenhuma separação de sinais ter sido feita, ele é um indício razoável que tal análise tem potencial para revelar informações importantes sobre processos de interação oceano-atmosfera de larga escala, pois em algumas regiões são observadas correlações improváveis de serem resultado de acaso estatístico. As que mais chamam atenção correspondem 
ao Pacífico subtropical norte e sul e à faixa de correlação positiva entre $0^{\circ} \mathrm{e} 15^{\circ} \mathrm{N}$, especialmente no oceano Pacífico, mas também presente em menor escala no Atlântico. Acredita-se que esta faixa de correlação positiva no Pacífico e Atlântico tropical norte estejam associadas à resposta do oceano ao ciclo anual da convergência dos ventos alísios, uma vez que sua localização coincide aproximadamente com a posição média da Zona de Convergência Intertropical (ZCIT). Neste caso, a convergência atmosférica em baixos níveis resultaria em uma região de alta pressão, que estaria associada a uma tendência de giro anticiclônica, além da ascensão do ar. Consequentemente, o rotacional da tensão de cisalhamento do vento seria negativo, implicando em um bombeamento de Ekman negativo, cuja assinatura na superfície seria de uma anomalia positiva na altura.

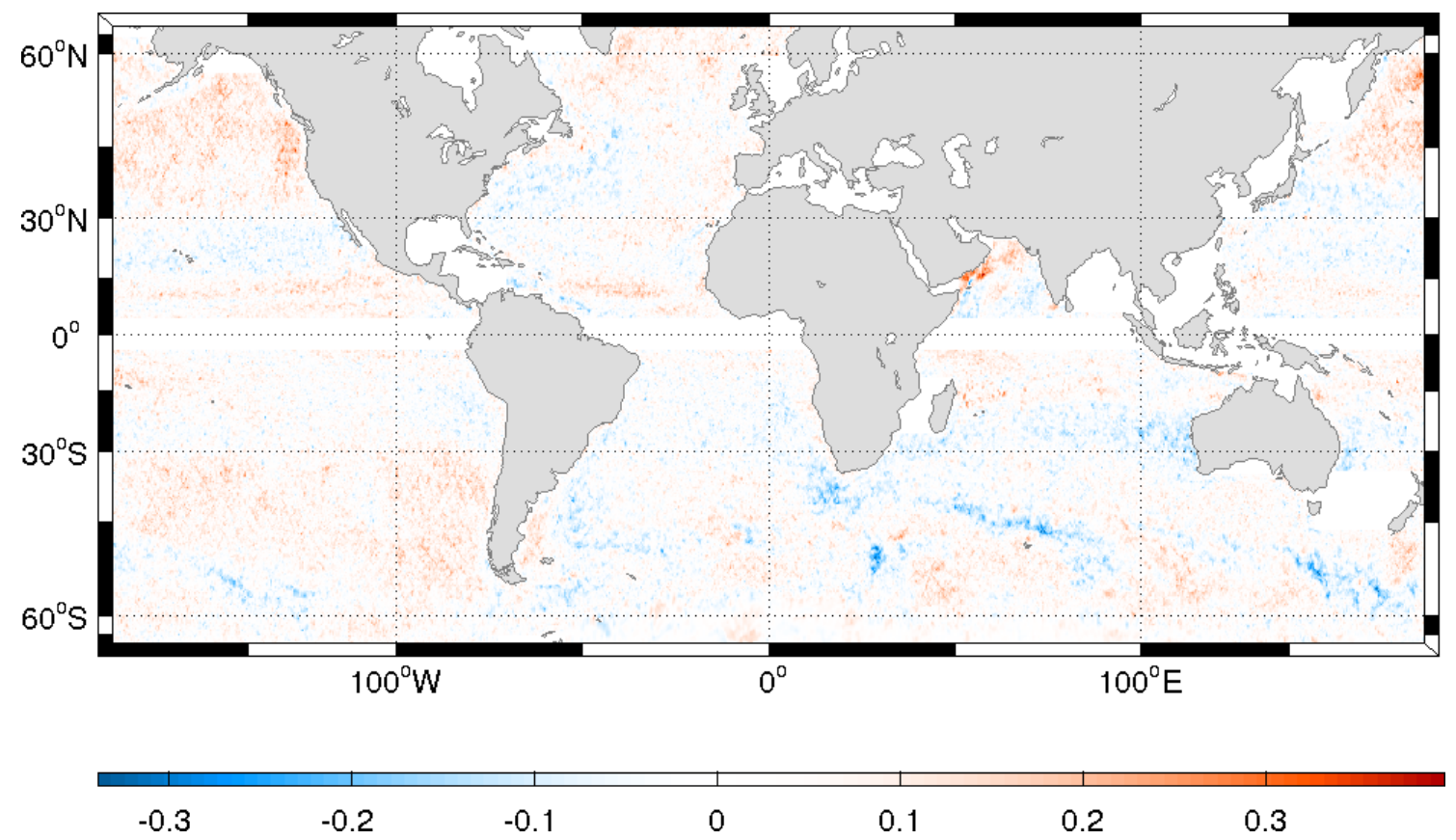

Figura 4.1: Coeficiente de correlação cruzada entre $w_{s} \mathrm{e}-w_{E}$.

No Índico, é observado um foco de correlação positiva no Mar da Arábia. Já no Pacífico de $15^{\circ} \mathrm{N}$ a $30^{\circ} \mathrm{N}$ e no Índico entre aproximadamente $15^{\circ} \mathrm{S}$ a $30^{\circ} \mathrm{S}$ 
e em porções mais ao sul, são observados focos de correlação negativa, os quais não corroboram com a hipótese de resposta da superfície oceânica à dinâmica de Ekman apresentada. O Atlântico sul, por sua vez, mostrou-se como a bacia oceânica com, em média, as correlações mais baixas em valor absoluto. Isto sugere uma investigação mais aprofundada, pois justamente onde a correlação entre $w_{s} \mathrm{e}-w_{E}$ é baixa, observam-se as ondas de Rossby com as menores amplitudes (POLITO; LIU, 2003).

Após filtrar os dados de $w_{s} \mathrm{e}-w_{E}$ apenas com as componentes propagantes para oeste, ou seja, ondas de Rossby com períodos de 6 a 12 meses aproximadamente, observou-se que os coeficientes de correlação obtidos são maiores que os observados com dados brutos, com valores absolutos chegando a 0,78 (figura 4.2).

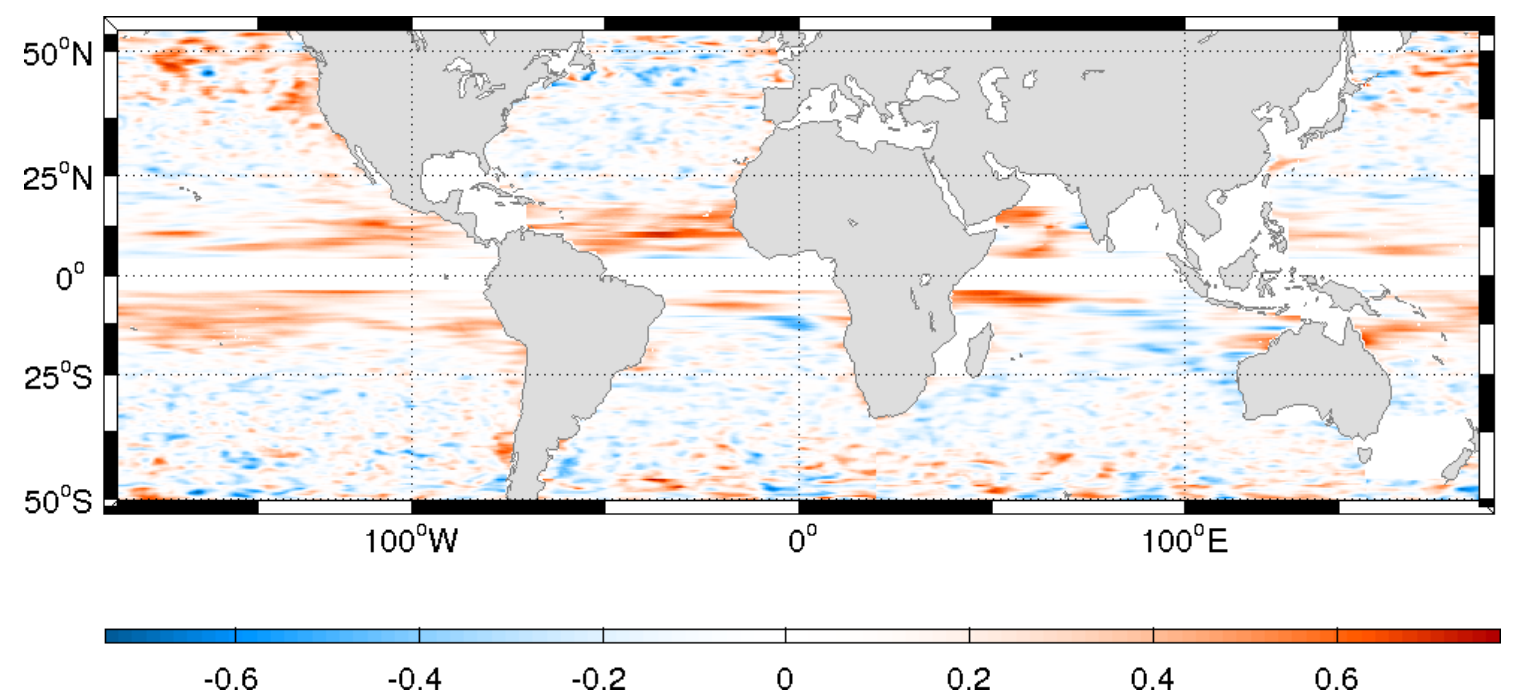

Figura 4.2: Coeficiente de correlação cruzada entre as componentes referentes às ondas propagantes para oeste de $w_{s} \mathrm{e}-w_{E}$.

Neste cenário, pode ser visto que o Atlântico norte tropical, o Pacífico tropical (norte e sul), a borda leste do Pacífico norte subtropical, o Mar da Arábia e uma porção do Índico sul tropical apresentam correlações positivas de 0,3 a 0,6 
entre o bombeamento de Ekman e a velocidade vertical da superfície. Embora haja ocorrência de correlações negativas de magnitude similar aos máximos positivos, não se observam grandes áreas continuas com alto valor de correlação negativa. Além disso, mais uma vez o Atlântico sul é a região com as correlações absolutas mais baixas.

Ao analisar os coeficientes de correlação obtidos somente com a componente anual (figura 4.3), observa-se valores absolutos máximos de até 0,94. Ressalta-se que a componente anual aqui discutida exclui o ciclo sazonal, trata-se apenas da componente anual dos sinais que se propagam para oeste com velocidade compatível com a das ondas de Rossby longas do primeiro modo baroclínico. As feições são similares às do mapa anterior, mas com algumas diferenças. Entre essas diferenças, estão a alta correlação na borda leste tropical do Pacífico sul, as fracas correlações no Mar da Arábia, as grandes correlações negativas no Índico sul e, finalmente, o surgimento de correlações positivas e negativas de magnitude significativa no Atlântico sul tropical.

Já as correlações com a componente semianual (figura 4.4) assemelharam-se muito com as observadas no mapa com todas as componentes de ondas de Rossby, tanto em magnitude quanto em feições.

Estes resultados mostram que, no Índico tropical, $w_{s}$ e $-w_{E}$ estão mais correlacionados em suas componentes semi-anuais do que nas anuais. Este resultado era esperado, uma vez que o Índico apresenta um regime de monções caracterizado pela periodicidade semianual. Todavia, as intensas correlações negativas no Índico sul que ocorrem na comparação das componentes anuais contrariam a hipótese de resposta linear entre a altura da superfície e o bombeamento de Ekman. Nas regiões 
tropicais do Atlântico e do Pacífico, as velocidades verticais estão bem correlacionadas tanto em sua componente semianual quanto na anual, com destaque para a última. Por si só, este resultado é um indicativo de linearidade na interação entre o oceano e a atmosfera nesta região. Contudo, nas altas latitudes e no Atlântico sul como um todo, as correlações foram fracas de maneira geral. Por fim, as altas correlações observadas para a componente anual na borda leste do Pacífico norte e sul sugerem que estas regiões são locais de formação de ondas planetárias de período anual.

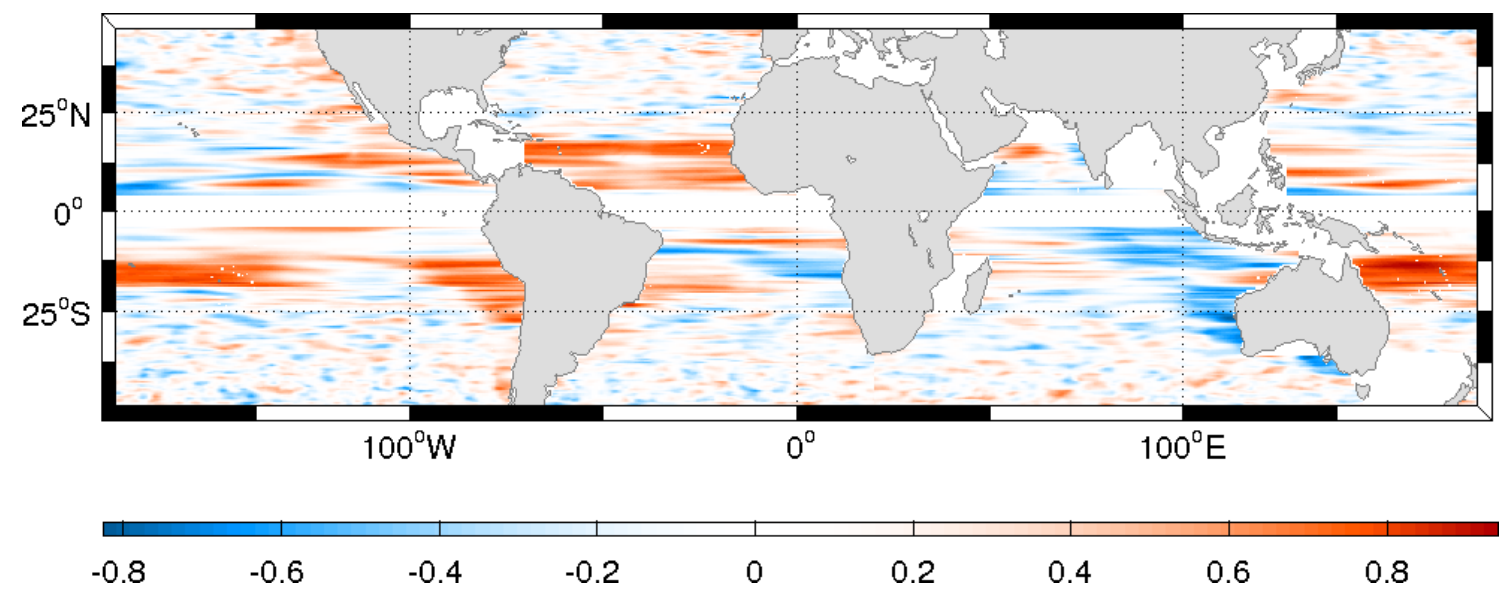

Figura 4.3: Coeficiente de correlação cruzada entre a componente anual de onda de Rossby de $w_{s}$ e $-w_{E}$.

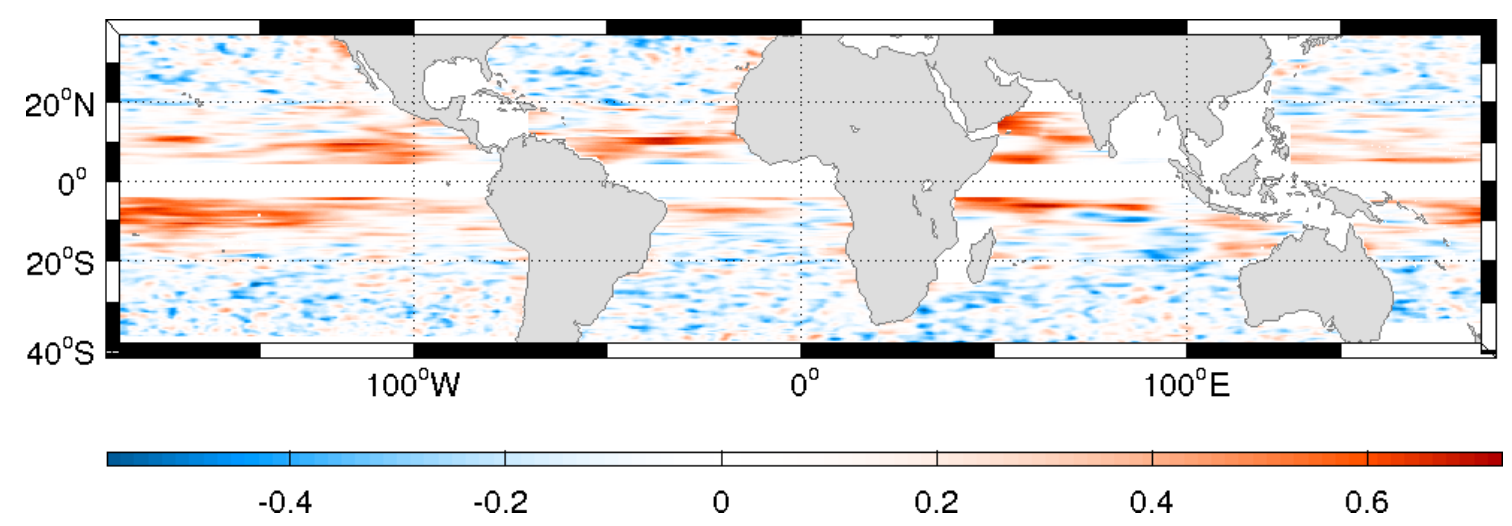

Figura 4.4: Coeficiente de correlação cruzada entre a componente semianual de onda de Rossby de $w_{s}$ e $-w_{E}$. 
Estes coeficiente de correlação cruzada para lag zero funcionam como indicativos de linearidade. Todavia, eles não garantem a relação de causa e efeito, não sendo suficientes para provar se as ondas planetárias observadas são realmente forçadas pelo rotacional da tensão de cisalhamento do vento. Espera-se esclarecer este ponto com as análises subsequentes.

\subsubsection{Vento e TSM}

Considerando a hipótese de que o bombeamento de Ekman influenciaria na TSM através de mistura vertical, espera-se obter correlações positivas no hemisfério sul e negativas no hemisfério norte ao se calcular a correlação cruzada entre as séries de $T_{s}$ e de $\nabla \times \vec{\tau}$. A razão para esta diferença entre os hemisférios reside na relação entre o bombeamento de Ekman e o rotacional da tensão de cisalhamento do vento (equação 3.5), que envolve o parâmetro de Coriolis, o qual tem sinal diferente de acordo com o hemisfério.

Entretanto, as correlações obtidas entre as séries não filtradas de TSM e do rotacional da tensão de cisalhamento do vento mostram um padrão diferente do esperado (figura 4.5). Com exceção das costas leste do Pacífico sul e do Atlântico sul, as correlações são predominantemente negativas no hemisfério sul e, no hemisfério norte, elas são predominantemente positivas. Assim, com exceção de duas regiões onde se tem ressurgência (TOMCZAK; GODFREY, 2003), o bombeamento de Ekman não deve influenciar a TSM, de maneira que as correlações observadas entre a TSM e o rotacional da tensão de cisalhamento do vento devem ser devidas a outro mecanismo. 


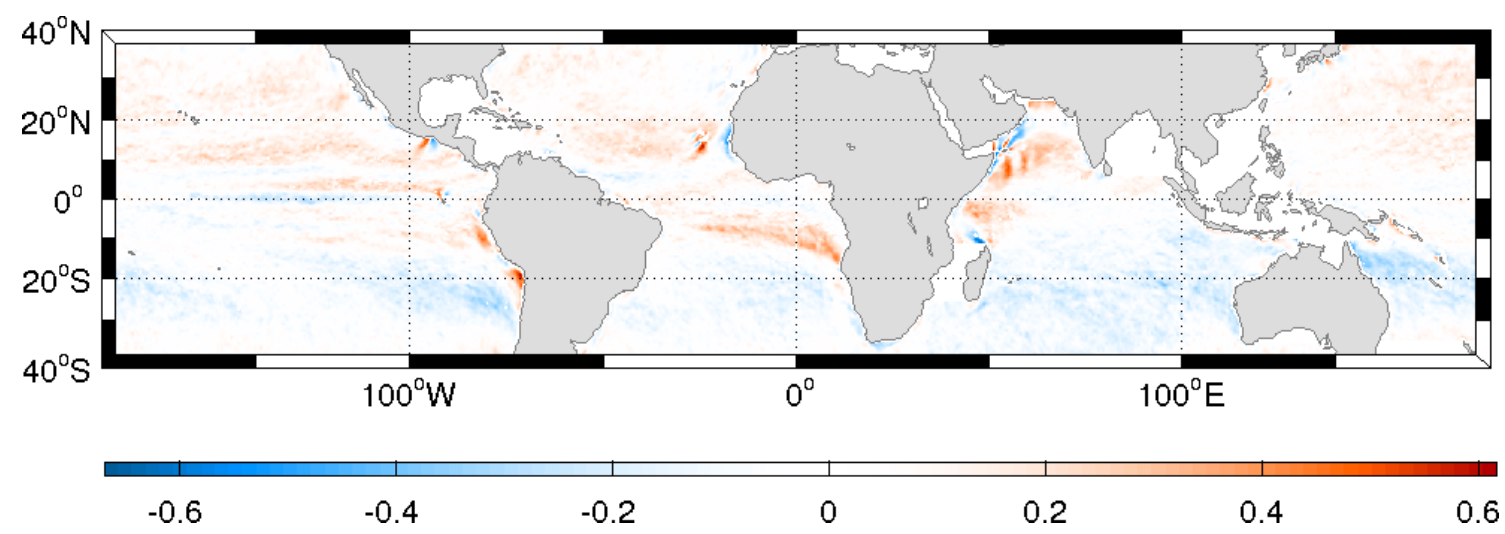

Figura 4.5: Coeficiente de correlação cruzada entre $T_{s}$ e $\nabla \times \vec{\tau}$.

Os coeficientes de correlação obtidos entre a TSM e a magnitude da velocidade do vento (figura 4.6) são negativos na maior parte do domínio chegando a valores de até -0,72. Há algumas regiões com correlações positivas, as quais chegam a 0,33. Curiosamente, estas correlações positivas ocorrem em regiões de ressurgência, com destaque para o Domo de Angola, a área costeira da Corrente Leste Arábica no Mar da Arábia (TOMCZAK; GODFREY, 2003) e na porção norte do Golfo de Bengala no oceano Índico nordeste.

A predominância de correlações negativas está de acordo com o esperado para larga escala (LIU et al., 1994) e pode ser interpretada como um forçamento atmosférico no oceano. Neste cenário, a intensificação dos ventos resfria a superfície do mar através da evaporação, além de possivelmente aumentar a intrusão de águas da termoclina superior na camada de mistura.

Chelton et al. (2001) analisaram dados de TSM provenientes do TMI/TRRM e dados de vento do QuikSCAT no período entre julho e outubro de 1999 para a região do Pacífico tropical leste. Os resultados obtidos pelos autores para a porção equatorial eram consistentes com a hipótese de modificações na estabilidade atmosférica induzidas pela TSM proposta por Wallace et al. (1989). Lembra-se que, por 
esta hipótese, um esquentamento da superfície do mar desestabilizaria a camada atmosférica acima do oceano, desacoplando os ventos superficiais, os quais acelerariam e divergiriam. Analogamente, o inverso também é aplicável, com um esfriamento da superfície oceânica tornando a camada atmosférica logo acima menos turbulenta, melhorando a troca de momentum entre os ventos superficiais e o oceano, desacelerando os ventos e resultando em uma convergência dos ventos superficiais. Todavia, o presente estudo não obteve correlações positivas nesta região. Small et al. (2008) sugerem que correlações positivas ocorrem quando o oceano força a atmosfera, através de fluxo de calor do oceano para a atmosfera, sendo que este mecanismo é mais comum em feições de meso escala, conforme observado por O’Neill et al. (2009).

Lembrando que o sinal sazonal está presente nos dados utilizados na análise da figura (4.6), as correlações negativas eram esperadas, pois é de conhecimento geral que os ventos são mais intensos no período de inverno. A remoção da componente sazonal dos dados através de filtros FIR2D permitirá uma maior sofisticação na análise mais a frente.

Xie (2004) interpreta regiões de correlação zero como sendo locais onde ocorra forçamento do oceano na atmosfera através da hipótese de Lindzen e Nigam (1987). A convergência (divergência) dos ventos sobre uma região oceânica quente (fria) indica uma alteração na intensidade do vento ao redor desta região, porém não sobre ela. Desta forma, a correlação entre a TSM e a velocidade do vento local é próxima de zero.

O padrão observado no mapa de coeficientes de correlação cruzada entre a TSM e a divergência da velocidade do vento (figura 4.7) é muito diferente do observado no anterior (figura 4.6). É observada uma faixa de correlação negativa 
na porção tropical do Atlântico e do Pacífico, a qual assume valores de até -0,48. Ao norte, esta faixa estende-se até cerca de $20^{\circ} \mathrm{N}$, enquanto ao sul ela ocupa até aproximadamente $10^{\circ} \mathrm{N}$. De forma geral, o Índico apresenta correlações negativas, porém de baixa intensidade. Há também uma faixa de correlação positiva $10^{\circ} \mathrm{S}$ e $20^{\circ} \mathrm{S}$ do Atlântico sul e da porção leste do Pacífico sul, porém com correlações máximas de 0,15. Nas regiões subtropicais, as correlações são predominantemente baixas, em geral, menores que 0,1 em valor absoluto.

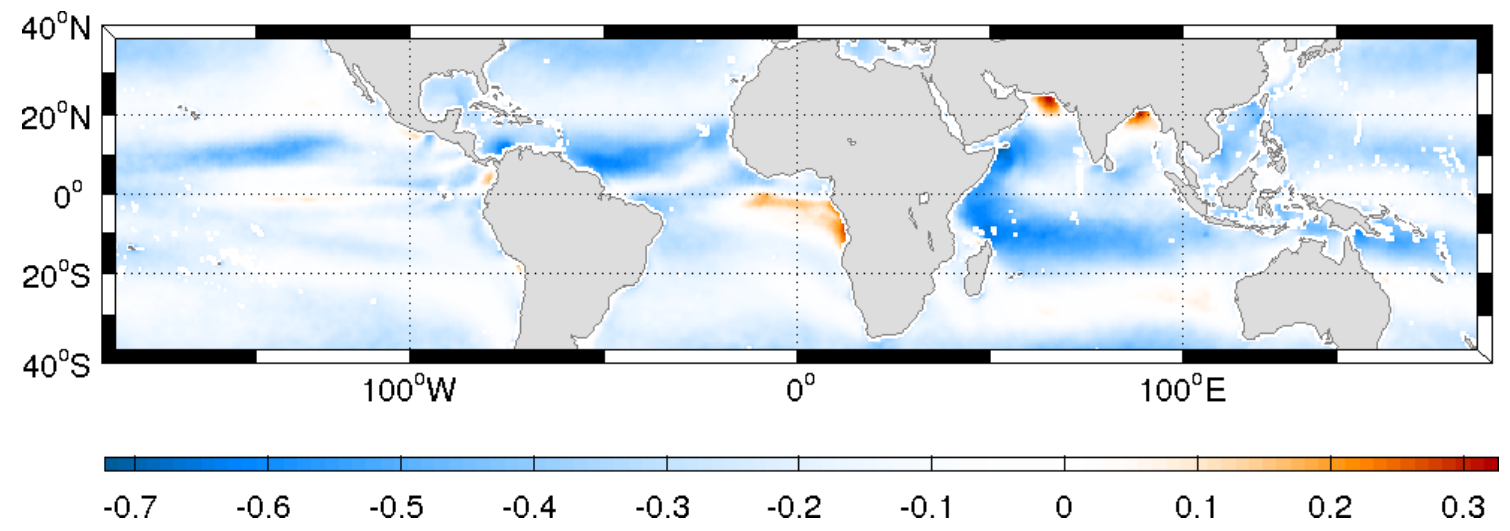

Figura 4.6: Coeficiente de correlação cruzada entre $T_{s}$ e $\left|\vec{v}_{w}\right|$.

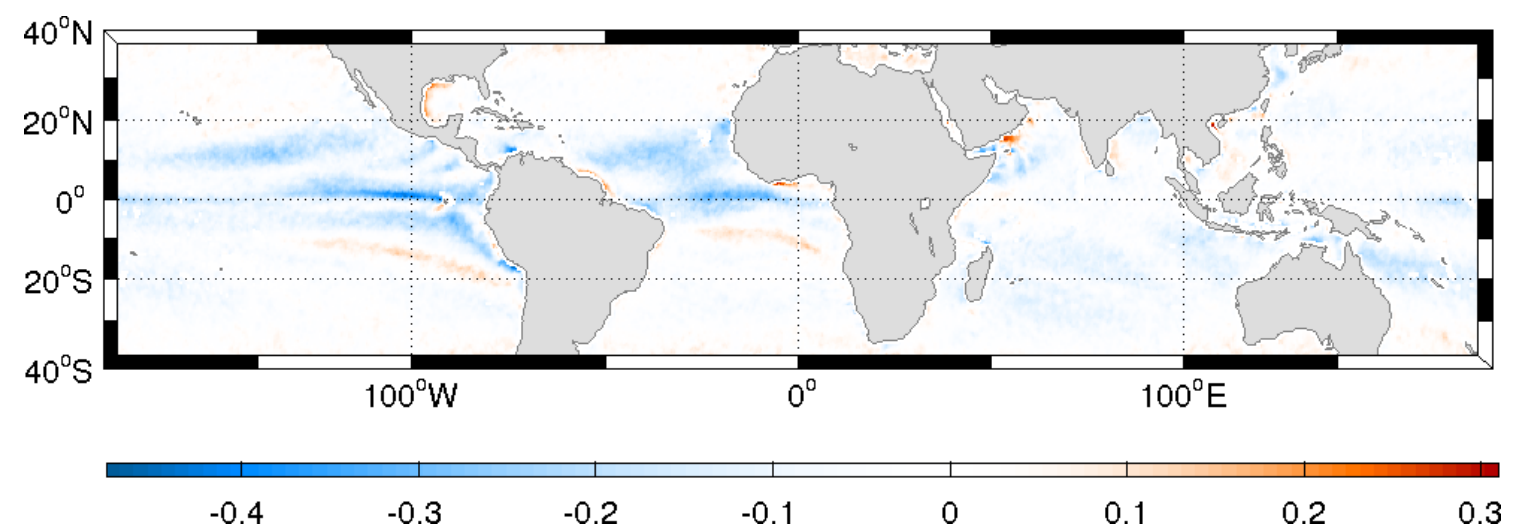

Figura 4.7: Coeficiente de correlação cruzada entre $T_{s}$ e $\nabla \cdot \vec{v}_{w}$.

Acredita-se que diferença observada entre a porção tropical do mapa e as demais regiões esteja relacionada com diferença de temperatura entre a superfície do mar e a atmosfera. Na região tropical, de correlação negativa, a TSM e a temperatura da atmosfera são próximas, de forma que a hipótese de Lindzen e Nigam 
(1987) parece funcionar, é interessante notar que esta região coincide com a posição da ZCIT. No Pacífico equatorial leste, Chelton et al. (2001) afirmaram que a importância da interação oceano-atmosfera pelo forçamento de gradiente de pressão, ou seja, a hipótese de Lindzen e Nigam (1987), era evidentemente secundária. Todavia, os autores ressaltaram que o forçamento pelo gradiente de pressão poderia ser mais importante em larga escala.

Observa-se ainda a coincidência de grande parte das regiões de correlação negativa observadas na figura (4.7) com as regiões de correlação próxima de zero da figura 4.7). Este é mais um indício de interação ar-mar de acordo com o mecanismo de forçamento pelo gradiente de pressão (LINDZEN; NIGAM, 1987), conforme a interpretação de Xie (2004) explicada anteriormente.

Já nas regiões sub-tropicais, de baixa correlação, o oceano está, em geral, mais quente que a atmosfera, de forma que variações na TSM não refletem variações no campo da divergência do vento da forma que a hipótese prevê.

Retomando as relações entre a TSM e o rotacional da tensão de cisalhamento do vento, calculou-se as correlações entre as séries temporais de ambas as variáveis descontadas o sinal sazonal (figura 4.8). Desta vez os coeficientes obtidos estão de acordo com a hipótese de influência do bombeamento de Ekman na TSM em mais regiões. As bordas leste do Atlântico norte e Pacífico norte apresentam correlações negativas, conforme o esperado, e o Atlântico norte de forma geral também segue este padrão, embora com valores absolutos baixos. No entanto, o padrão das correlações no oceano Índico manteve-se o mesmo da figura 4.5, não podendo ser explicado pela hipótese supra mencionada. 


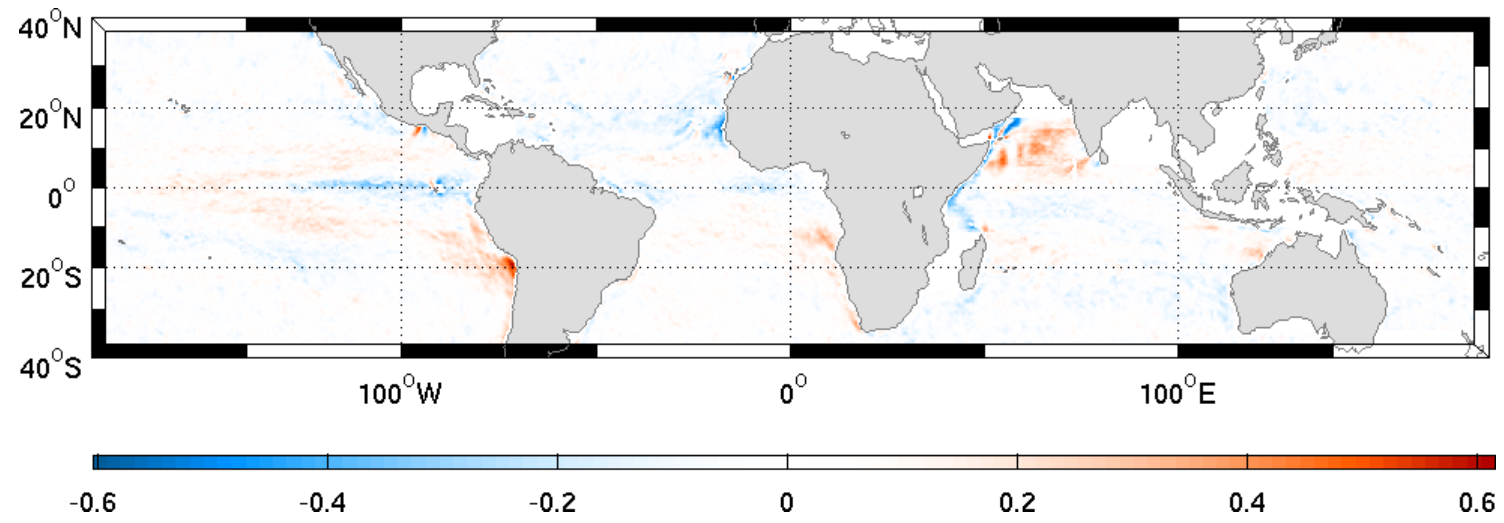

Figura 4.8: Coeficiente de correlação cruzada entre $T_{s}$ e $\nabla \times \vec{\tau}$ sem a componente sazonal.

Ao se extrair a componente sazonal dos dados de TSM e de magnitude da velocidade do vento, obteve-se correlações ainda maiores em valor absoluto (figura 4.9. A média global aumentou de 0,21 para 0,27 e correlação absoluta máxima é de 0,81, representando um ganho de mais de $10 \%$ frente ao resultado com a presença do sinal sazonal. Em termos de feições, as diferenças foram o Mar da Arábia, que não apresenta mais correlações positivas, e o Atlântico sul tropical, onde as correlações positivas que estavam restritas à região do Domo de Angola, agora estão presentes na bacia inteira com maior intensidade, chegando até 0,65 .

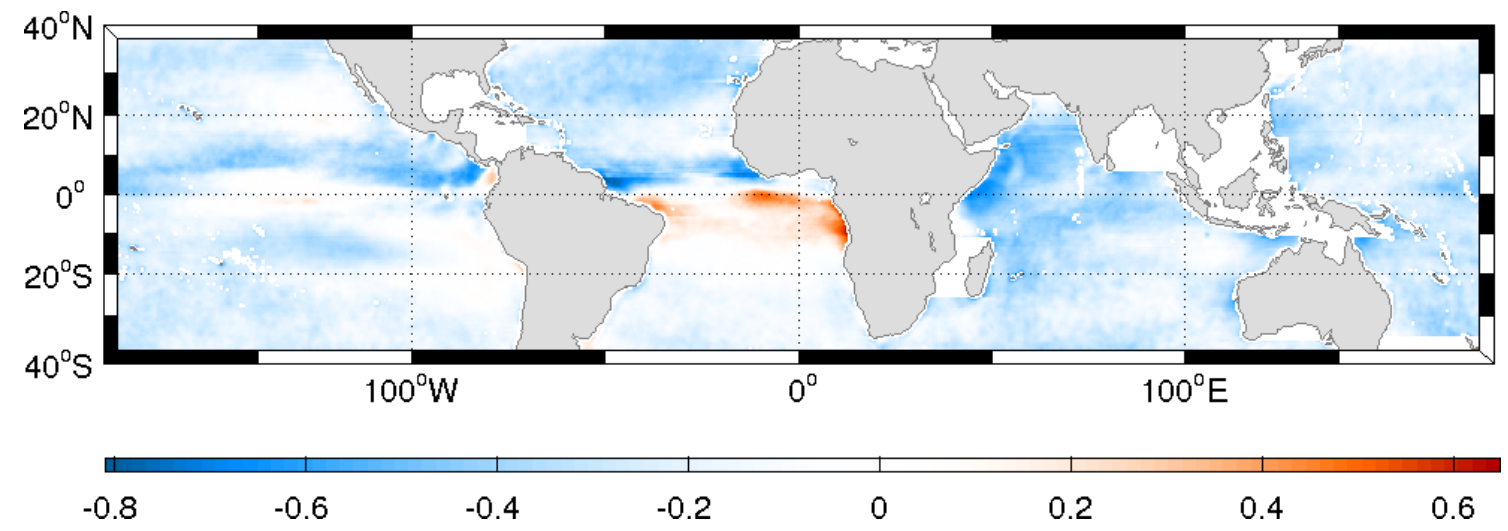

Figura 4.9: Coeficiente de correlação cruzada entre $T_{s}$ e $\left|\vec{v}_{w}\right|$ sem a componente sazonal. 
Assim como no caso com a componente sazonal (figura 4.6), acredita-se que as correlações negativas são devidas ao resfriamento da superfície do mar por evaporação com o aumento do vento, sendo um caso de forçamento do oceano pela atmosfera. Já as correlações positivas corresponderiam à intensificação dos ventos graças à desestabilização da camada atmosférica superficial pelo aumento da TSM, correspondendo a um cenário de forçamento da atmosfera pelo oceano.

Small et al. (2008) também apresentaram coeficientes de correlação entre TSM e velocidade do vento para todo o globo, porém os autores filtraram os dados, removendo os três harmônicos anuais com um filtro de Fourrier e depois preservaram apenas sinais com um período menor ou igual a 40 semanas. Assim, os resultados obtidos pelos autores são notavelmente diferentes dos obtidos no presente estudo, uma vez que eles obtiveram predominância de correlações positivas com um máximo no Pacífico equatorial leste. Contudo, as correlações por eles apresentadas no Atlântico sul tropical são muito similares às observadas na figura (4.9). Essa similaridade pode ser interpretada como um indício de que as correlações positivas do Atlântico sul seriam devido aos processos que ocorrem na faixa de períodos analisadas por Small et al. (2008). Entretanto, este ponto receberá maiores esclarecimentos após a análise das correlações entre as algumas componentes isoladas dos dados.

As correlações também melhoraram ao retirar o sinal sazonal dos dados de TSM e de divergência do vento (figura 4.10), aumentando a média global de 0,056 para 0,072. Neste caso, observa-se que a faixa de correlação negativa no Atlântico tropical se desfez, enquanto as demais feições mantiveram-se similares. Os mínimos de correlação no Pacífico tropical alcançam -0,6, sendo uma melhora substancial em relação ao mínimo de -0,48 da figura 4.7. 


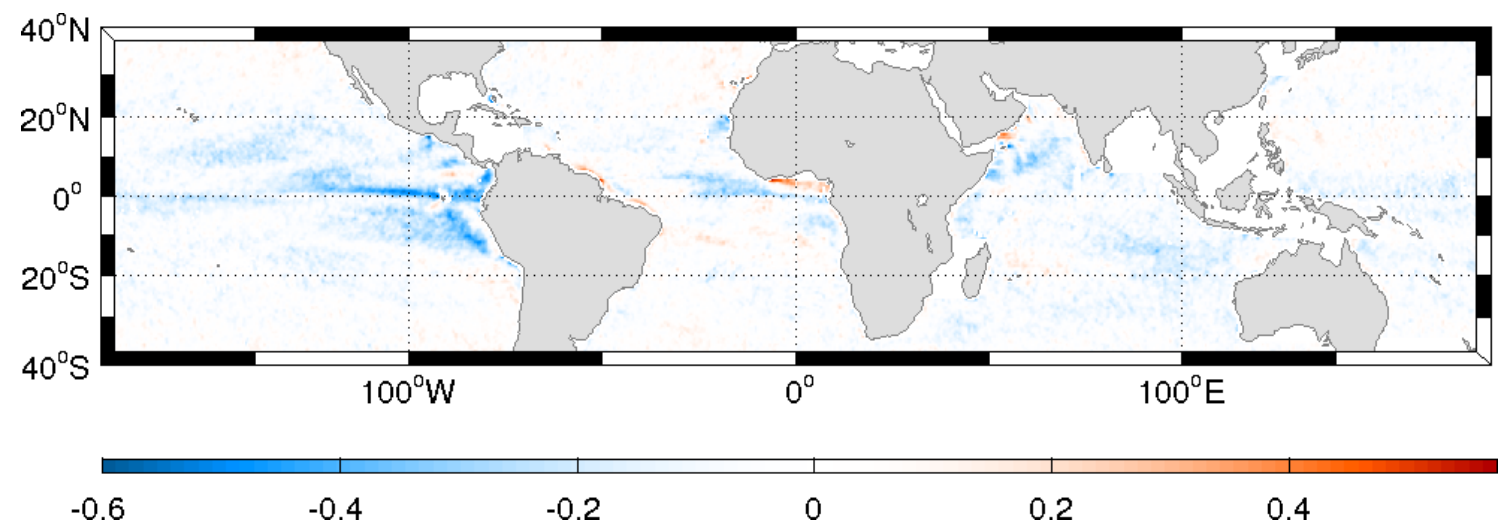

Figura 4.10: Coeficiente de correlação cruzada entre $T_{s}$ e $\nabla \cdot \vec{v}_{w}$ sem a componente sazonal.

Como os coeficientes de correlação obtidos ao se remover a componente sazonal foram melhores nos dois últimos casos de forma geral, é provável que o sinal sazonal presente na TSM esteja fora de fase em relação ao presente nos dados de vento, uma vez que as comparações foram feitas com lag zero.

Considerando a banda espectral relacionada às ondas de Rossby planetárias, calculou-se os coeficientes de correlação entre as componentes das séries temporais de $T_{s}$ e de $\nabla \times \vec{\tau}$ referentes a estas ondas (figura 4.11).

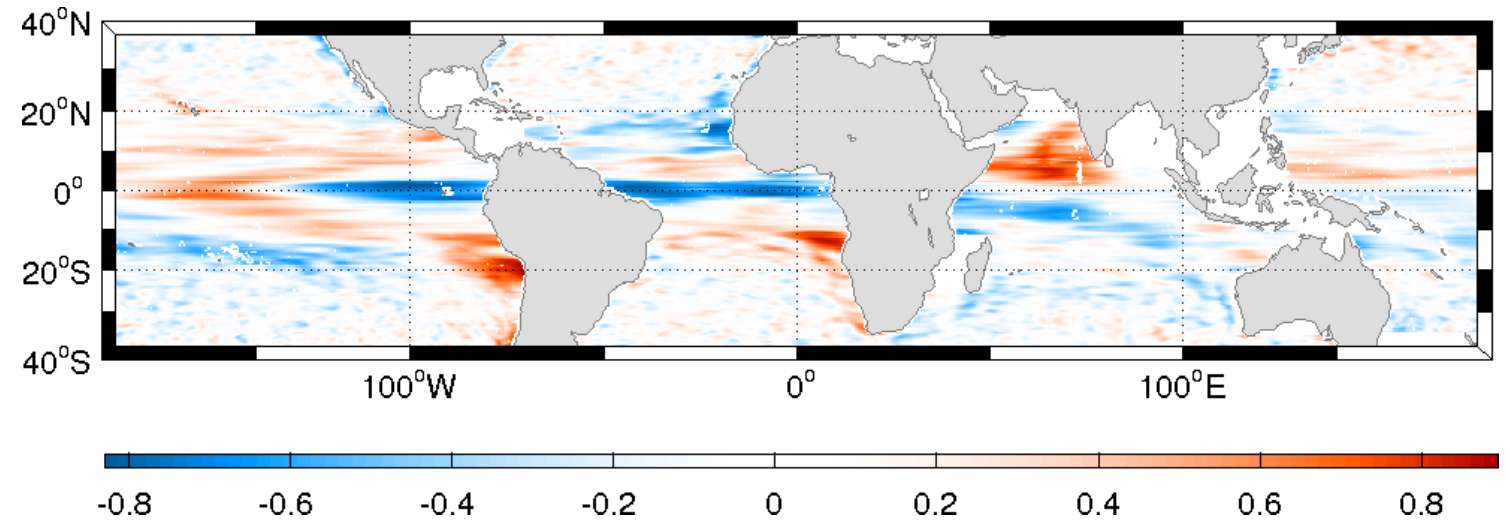

Figura 4.11: Coeficiente de correlação cruzada entre as componentes referentes às ondas propagantes para oeste de $T_{s}$ e de $\nabla \times \vec{\tau}$. 
As correlações positivas (negativas) no hemisfério sul (norte) são ainda mais intensas nas bordas leste do Pacífico e do Atlântico, com destaque para as regiões tropicais. Neste caso, o Pacífico norte é uma exceção, pois as correlações negativas na borda leste ocorrem em latitudes subtropicais, enquanto sua região tropical é predominantemente positiva. Estas são regiões de provável geração de ondas planetárias por forçamento direto pelo bombeamento de Ekman.

O Índico continua sendo uma exceção, mantendo o mesmo padrão de correlações que nas figuras anteriores 4.5 e 4.8). Observa-se ainda na região equatorial, onde a dinâmica de Ekman não é válida, uma intensa correlação negativa no Atlântico e no Pacífico leste. Os mecanismos responsáveis por este resultado não são claros e sua investigação foge do escopo do presente trabalho.

Também foram obtidas as correlações comparando apenas as componentes propagantes para oeste da TSM e da magnitude da velocidade do vento (figura 4.12a). Neste mapa, observa-se que o Atlântico sul tropical, o qual apresentou correlações positivas de até 0,65 na comparação sem a componente sazonal, apresenta correlações positivas em toda a extensão da bacia, com máximo de 0,87 . Uma outra diferença em relação aos resultados obtidos até então é a região subtropical do hemisfério sul, que apresenta correlações predominantemente positivas, mesmo não sendo tão intensas quanto às observadas na região tropical. O Pacífico tropical, o Índico tropical e o Atlântico norte tropical assemelham-se aos resultados anteriores, apresentando intensas correlações negativas, tendo como diferencial o mínimo de correlação, que no caso chega a -0,94. Este máximo positivo no Atlântico sul tropical é mais intenso que o observado na figura (4.9), refutando a explicação dada anteriormente baseada nos resultados de Small et al. (2008) que os valores positivos 
observados na figura sem a componente sazonal seriam devidos a interações de meso escala.

As figuras 4.12b e 4.12c apresentam para pontos distintos as séries temporais não filtradas de $T_{s}$ e de $\left|\vec{v}_{w}\right|$ e as respectivas componentes propagantes para oeste. Pode-se perceber nas séries dos sinais propagantes que a componente anual é a mais importante, a componente semianual também se destaca, alterando a forma das cristas, mas a bianual não está marcante nas séries. Nota-se ainda a semelhança no padrão oscilatório das séries não filtradas das respectivas componentes selecionadas, com pontos extremos e de inflexão ocorrendo muito próximos, de maneira que os filtros não condicionaram o resultado. A comparação entre as componentes de ondas de Rossby de ambas as séries ilustra nitidamente as correlações positiva (figura $4.12 \mathrm{~b}$ ) e negativa (figura 4.12c) obtidas.

Por fim, tem-se os coeficientes de correlação obtidos para as componentes propagantes para oeste da TSM e da divergência da velocidade do vento (figura 4.13a). Embora as diferenças observadas entre a figura 4.12a e (4.9) não sejam dramáticas, as diferenças entre as figuras 4.13a e 4.10 são muito significativas.

Ao contrário dos resultados anteriores para $T_{s}$ e $\nabla \cdot \vec{v}_{w}$ (figuras 4.7 e 4.10, as correlações obtidas são altas, atingindo valores absolutos de até 0,9 tanto para correlações positivas quanto negativas. Estas altas correlações são observadas principalmente no Pacífico tropical e no Índico como um todo, com exceção do Índico equatorial que apresentou núcleos de correlação positiva. O Atlântico tropical, embora possua núcleos positivos de alta correlação, é notavelmente menos correlacionado ao se comparar com a mesma região dos outros oceanos. Estes núcleos positivos no Atlântico sul tropical reforçam a ideia de a hipótese de Wallace et al. $(1989)$ ser 
predominante nesta região. Outra região onde esta hipótese parece adequada para explicar os resultados é o Pacífico equatorial leste em cerca de $5^{\circ} \mathrm{N}$ e $80^{\circ}$ a $100^{\circ} \mathrm{W}$, onde faixa de correlação positiva observada está de acordo com os resultados de Chelton et al. (2001). Nota-se ainda que as regiões subtropicais do Atlântico e do Pacífico apresentam coeficientes de correlação pequenos. Este resultado indica que ao menos nas regiões tropicais, a hipótese de Lindzen e Nigam (1987) está aparentemente ligada à propagação de ondas planetárias.

Observa-se nas 4.13b e 4.13c que a série temporal de $\nabla \cdot \vec{v}_{w}$ não filtrada é bastante ruidosa, mesmo assim a componente de ondas de Rossby extraída desta série acompanha o padrão oscilatório da primeira, mostrando mais uma vez que os filtros não condicionaram o resultado. A componente anual também é a mais importante nas séries dos sinais propagantes, enquanto a bianual não pode ser notada, porém a componente semianual destaca-se muito pouco. Assim, como nos casos da figura 4.12, é clara a correlação entre as séries das componentes de ondas de Rossby de $T_{s}$ e de $\left|\vec{v}_{w}\right|$, sendo positiva na figura 4.12b e negativa na figura 4.12c).

Os resultados obtidos até então sugerem que, na banda espectral de ondas planetárias anuais, a hipótese de Lindzen e Nigam (1987) parece adequada para explicar a interação entre o oceano e a atmosfera em toda a região tropical com exceção do Atlântico sul tropical, onde a hipótese de Wallace et al. (1989) faz mais sentido dada a alta correlação positiva observada entre as componentes anuais de $T_{s}$ e de $\left|\vec{v}_{w}\right|$ nesta região. 

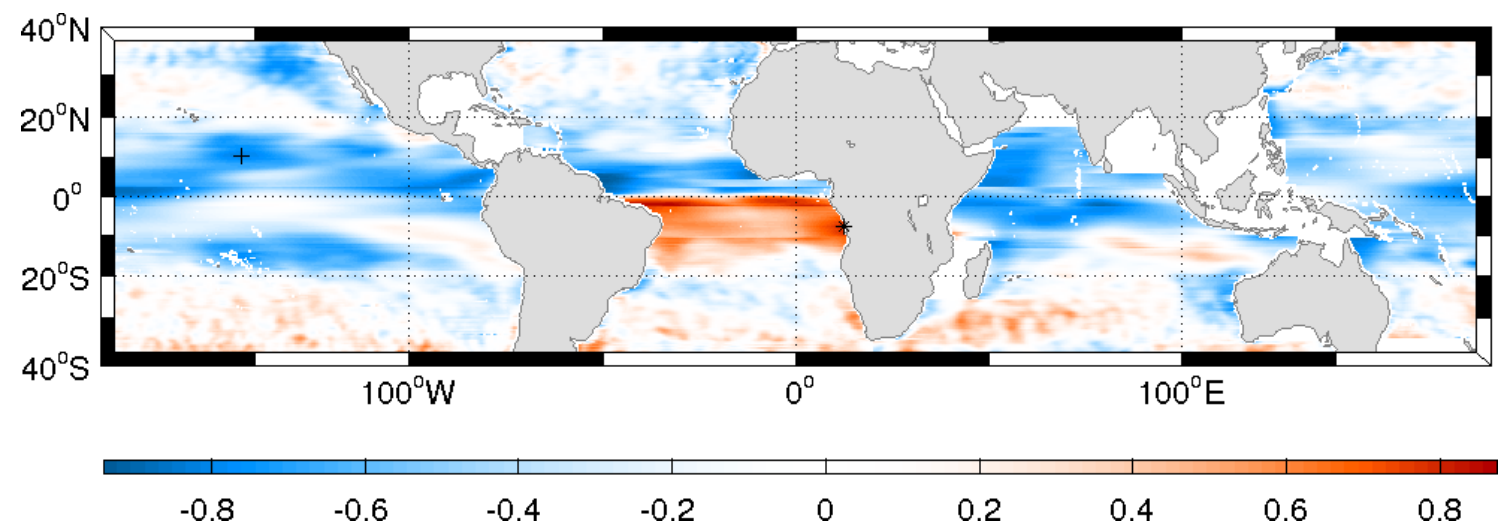

(a)

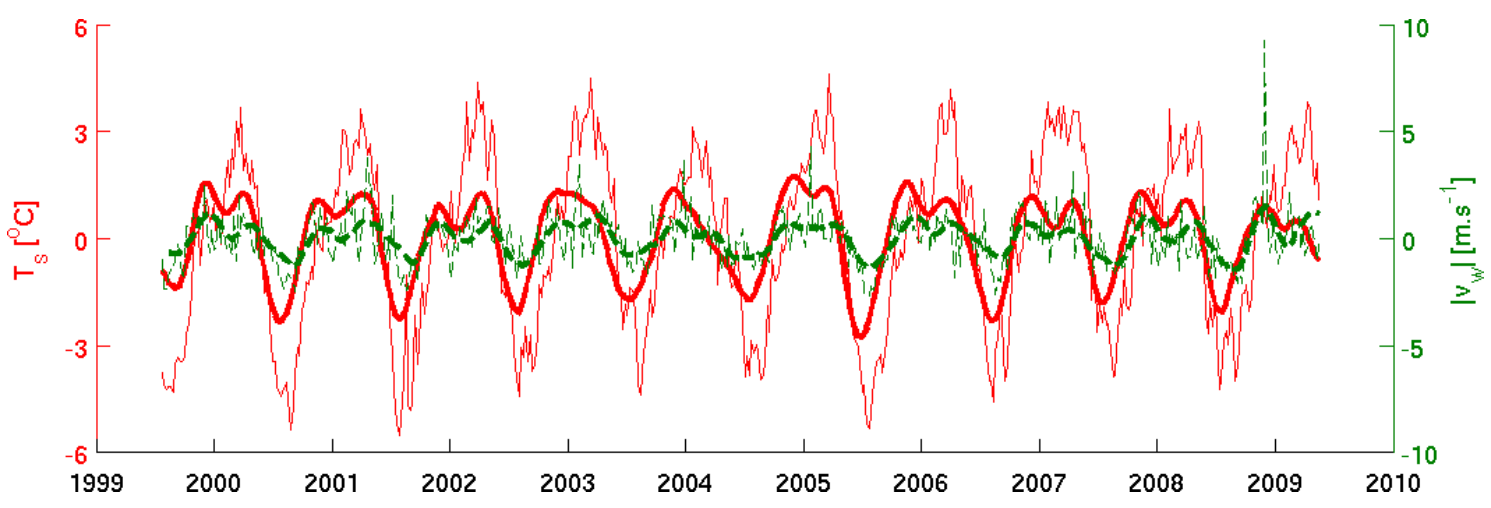

(b)

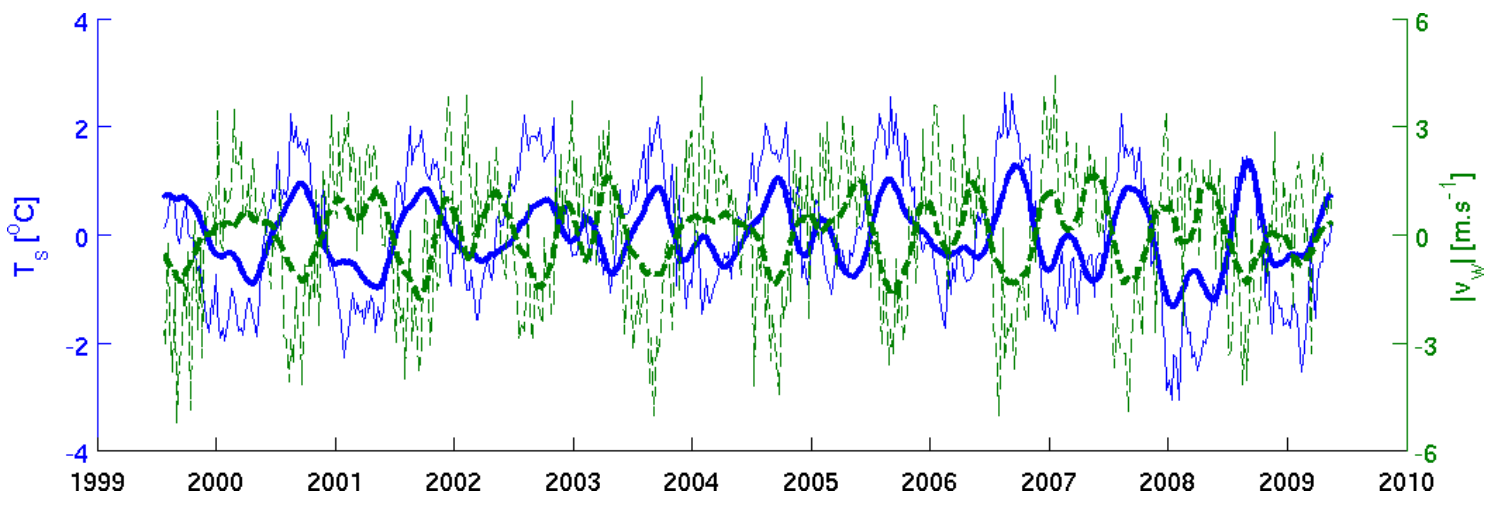

(c)

Figura 4.12: (a) Coeficiente de correlação cruzada entre as componentes referentes às ondas propagantes para oeste de $T_{s}$ e de $\left|\vec{v}_{w}\right|$; (b) Séries temporais de $T_{s}$ (vermelho) e de $\left|\vec{v}_{w}\right|$ (verde) não filtradas descontadas o valor médio (linhas finas) e filtradas nas componentes de ondas de Rossby (linhas espessas) para o ponto representado no mapa por $*\left(12^{\circ} 37,5^{\prime} \mathrm{E}-7^{\circ} 52,5^{\prime} \mathrm{S}\right)$; (c) idem ao item anterior com as curvas para $T_{s}$ em azul e para o ponto representado por $+\left(143^{\circ} 22,5^{`} \mathrm{~W}-7^{\circ} 22,5^{`} \mathrm{~N}\right)$. 

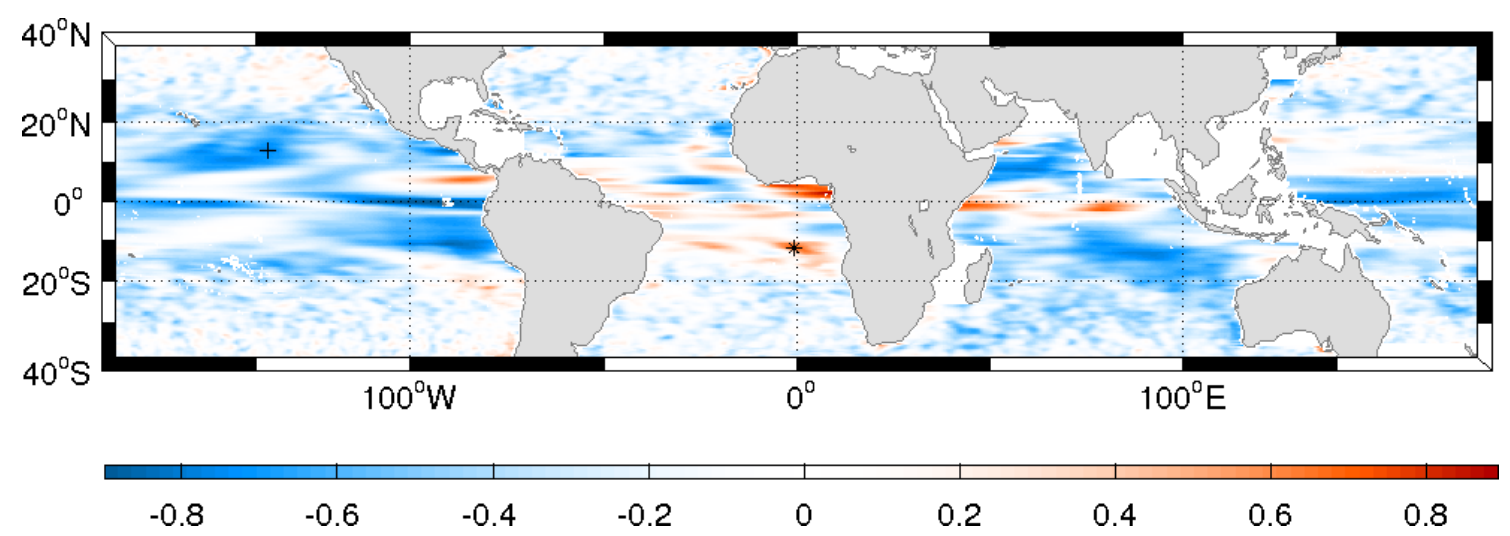

(a)

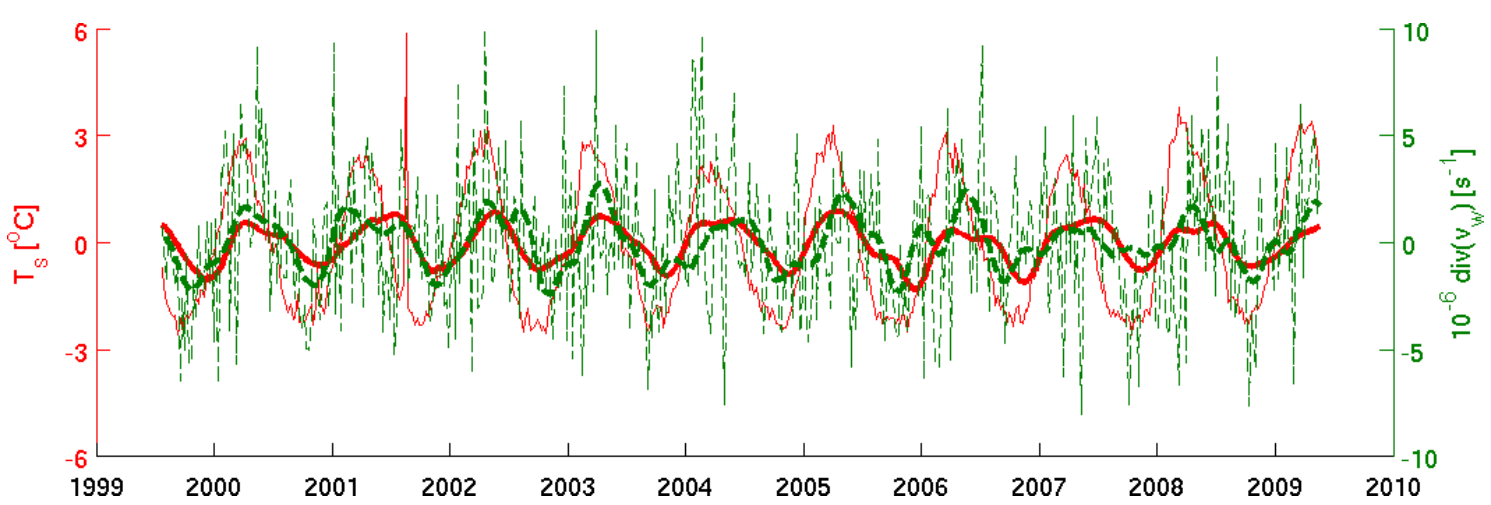

(b)

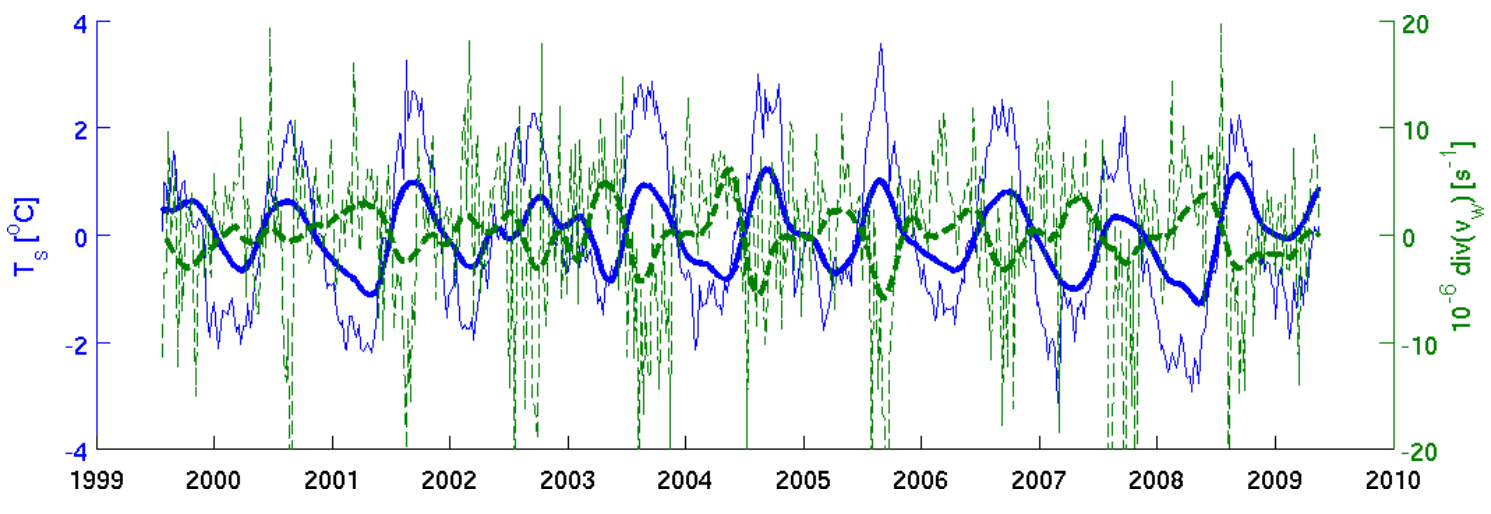

(c)

Figura 4.13: Similar à figura 4.12 para $T_{s}$ e $\nabla \cdot \vec{v}_{w}$, com $*$ localizado em $0^{\circ} 52,5^{\prime} \mathrm{W}-11^{\circ} 52,5^{\prime} \mathrm{S}$ e + em $136^{\circ} 52,5^{\prime} \mathrm{W}-13^{\circ} 07,5^{\prime} \mathrm{N}$. 


\subsubsection{AASM e TSM}

Para a AASM e a TSM, obtiveram-se coeficientes de correlação elevados (figura 4.14), especialmente considerando que os dados desta figura não estão filtrados. Destaca-se o oceano Atlântico, que é a bacia com as maiores correlações, chegando a 0,86. Já o oceano Índico é o que apresenta os menores coeficientes. É interessante notar também os núcleos de correlação negativa de até -0,64 nas regiões tropicais, as quais incluem as ZCIT do Pacífico e do Atlântico. Estes resultados estão de acordo com a literatura, sendo que Leuliette e Wahr (1999) obtiveram correlações de até 0,8 para o Atlântico e 0,7 para o Pacífico entre dados de AASM do T/P e de SST da análise global do NCEP (National Center of Environment Prediction, Estados Unidos).

Como ondas planetárias do primeiro modo baroclínico já foram observadas em dados de TSM (Hill et al. (2000)), calculou-se também os coeficientes de correlação apenas entre a componente relativa às ondas planetárias anuais de $T_{s}$ e de $\eta^{\prime}$ (figura 4.15). Neste caso, também foram observadas altas correlações, com destaque para o Atlântico sul tropical que apresenta coeficientes elevados de cerca de 0,9. Este é um indício de que a propagação das ondas de Rossby do primeiro modo baroclínico causam uma variação na temperatura superficial. No entanto, houve um número maior de regiões relativamente extensas de correlação negativa, em especial na região tropical dos oceanos.

Desta forma, tem-se que a anomalia da altura da superfície do mar, a qual reflete a expansão da coluna d'água, está relacionada com a temperatura superficial tanto de forma geral, como em relação às ondas de Rossby anuais. Em geral, o prová- 
vel aquecimento que expande a coluna d'água também aquece a superfície, gerando os altos coeficientes de correlação positiva. Entretanto, há as regiões de correlação negativa onde a expansão da coluna d'água está relacionada a um esfriamento da superfície, mas ainda assim a AASM e a TSM estão correlacionadas.

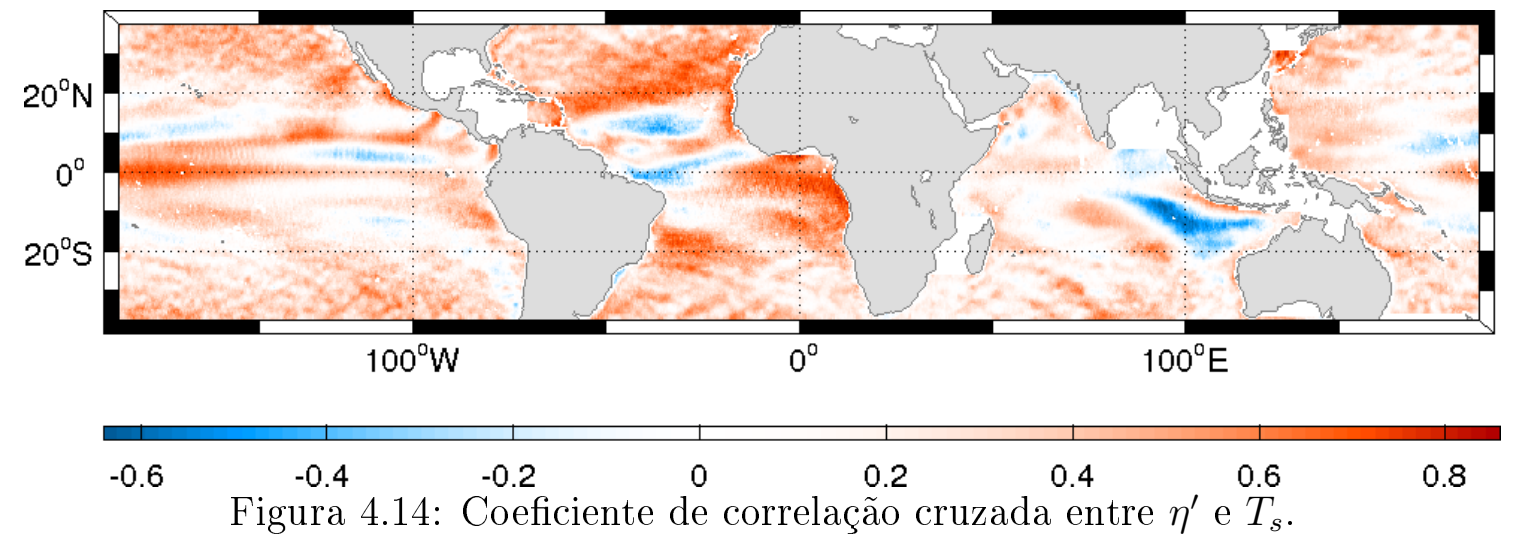

Estes resultados foram obtidos com lag zero, portanto é um processo que ocorre em um tempo muito mais curto que o período das ondas planetárias anuais. Em termos do efeito observado, ou seja, mudança de temperatura da parte superior da coluna d'água, processos radiativos e difusivos são lentos em comparação a processos advectivos e convectivos. Esta conjectura coloca a advecção vertical de temperatura como explicação mais plausível para o mecanismo que gera estas correlações.

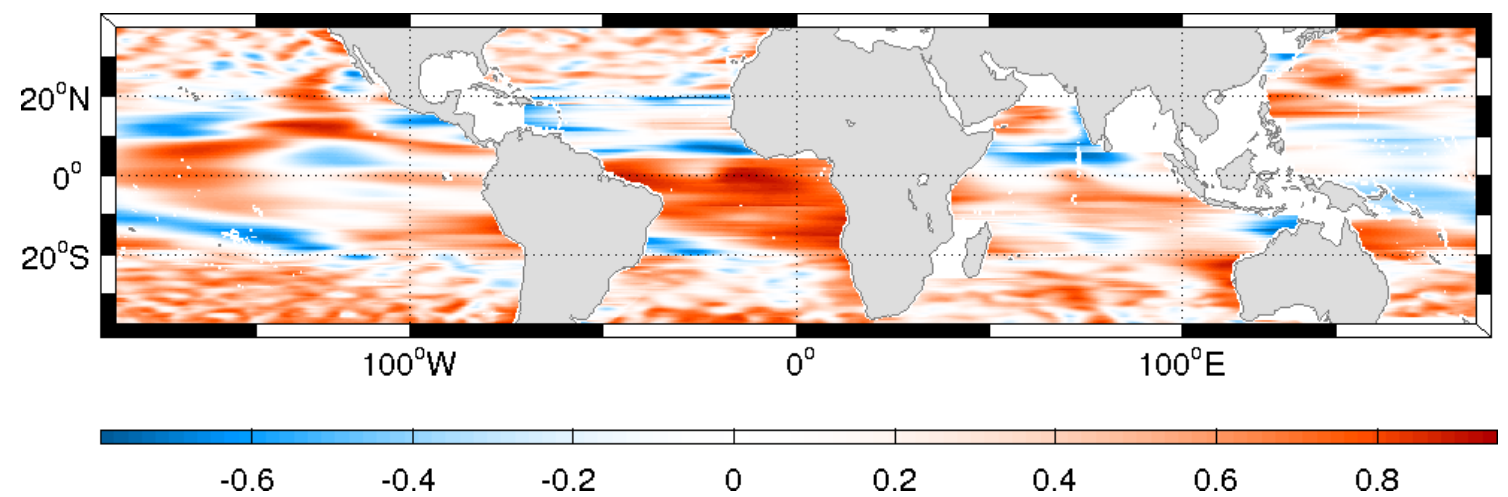

Figura 4.15: Coeficiente de correlação cruzada entre as componentes propagantes para oeste com período anual de $\eta^{\prime}$ e de $T_{s}$. 


\section{$4.2 \quad$ Espectros cruzados}

\subsubsection{Velocidades verticais}

Dos espectros cruzados entre $w_{s}$ e $w_{E}$ foi extraída a potência espectral máxima obtida para cada ponto de grade (figura 4.16). Este valor foi obtido selecionando o máximo absoluto de uma só frequência do espectro cruzado não suavizado. A figura ressalta as feições mais energéticas presentes nas duas séries temporais, independentemente da banda espectral em que ocorrem. Observa-se claramente que há mais potência espectral no hemisfério norte, com média de $1,01 \times 10^{-9} \mathrm{~m}^{2} \mathrm{~s}^{-1}$, que no hemisfério sul, com $0,55 \times 10^{-9} \mathrm{~m}^{2} \mathrm{~s}^{-1}$ de média. Considerando apenas o intervalo entre $40^{\circ} \mathrm{S}$ e $40^{\circ} \mathrm{N}$, esta diferença é ainda maior, com a potência espectral máxima média do hemisfério norte sendo de $1,24 \times 10^{-9} \mathrm{~m}^{2} \mathrm{~s}^{-1}$ contra $0,56 \times 10^{-9} \mathrm{~m}^{2} \mathrm{~s}^{-1}$ do hemisfério sul.

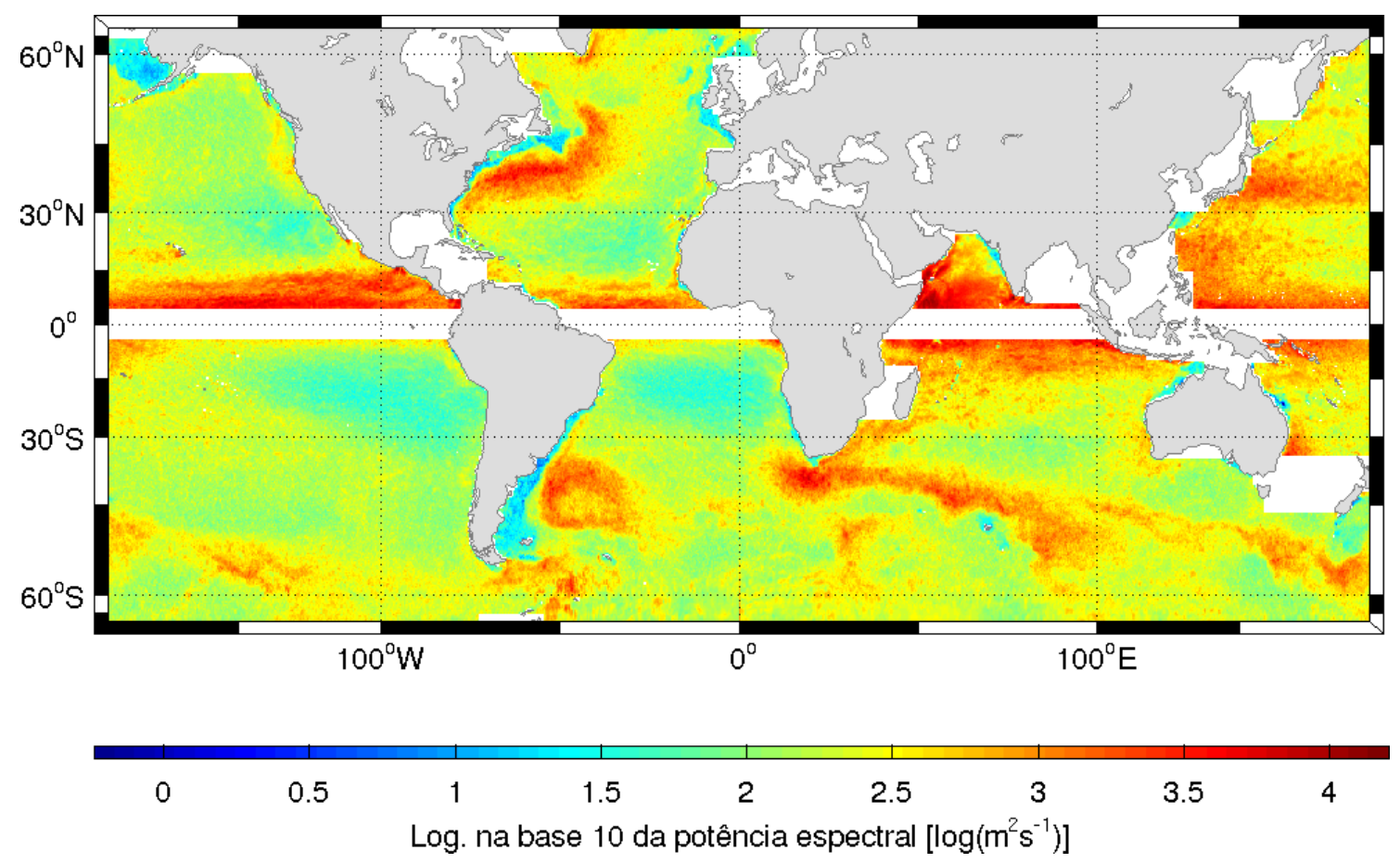

Figura 4.16: Potência espectral máxima do espectro cruzado entre $w_{s}$ e $w_{E}$. 
É interessante notar a região das correntes de borda oeste, da Corrente Circumpolar Antártica e as regiões equatoriais do Atlântico norte, do Pacífico norte e do Índico, onde foram observadas as maiores potências espectrais máximas. Nestas regiões, há bastante energia cinética turbulenta devida a processos inerentemente oceânicos os quais não estão relacionados diretamente com a atmosfera. A distribuição de energia cinética turbulenta observada por Brachet et al. $(2004)$ no Atlântico norte é bastante similar ao padrão de potência espectral máxima obtida no presente estudo. Todavia, por ser proveniente do espectro cruzado, este resultado indica que existem sinais na mesmas bandas espectrais destas variabilidades oceânicas na atmosfera. Uma explicação possível seria que esses máximos de potência são devidos a interações oceano-atmosfera em bandas específicas do espectro por processos predominantemente determinísticos. Outra possibilidade é o espectro da atmosfera possuir muita energia na forma de ruído branco em toda a distribuição espacial e estes máximos indicarem regiões onde também há muita energia na forma de ruído branco no oceano, portanto sendo regiões onde há predomínio de processos estocásticos.

O mapa a seguir (figura 4.17) mostra os períodos onde ocorre a potência máxima dos espectro cruzados entre $w_{s}$ e $w_{E}$. De forma geral, observa-se a dominância de períodos baixos, especialmente nas altas latitudes do hemisfério sul e nas regiões centrais das bacias oceânicas. É importante notar que esta análise foi feita com os dados interpolados sem a aplicação de filtros. No entanto, há várias regiões contínuas, extensas e homogêneas que apresentam períodos maiores, como a região tropical norte, na qual há predominância de períodos de 12 meses, sendo que no Atlântico norte e Índico também há regiões com períodos de 6 meses. O Pacífico 
noroeste não apresenta uma clara dominância de período de máxima potência espectral, um vez que eles variam de 5 a até 14 meses. Todavia, a feição mais notável é o período de 12 meses nas bordas oeste da África, América do Norte e, em menor grau, América do Sul e Austrália.

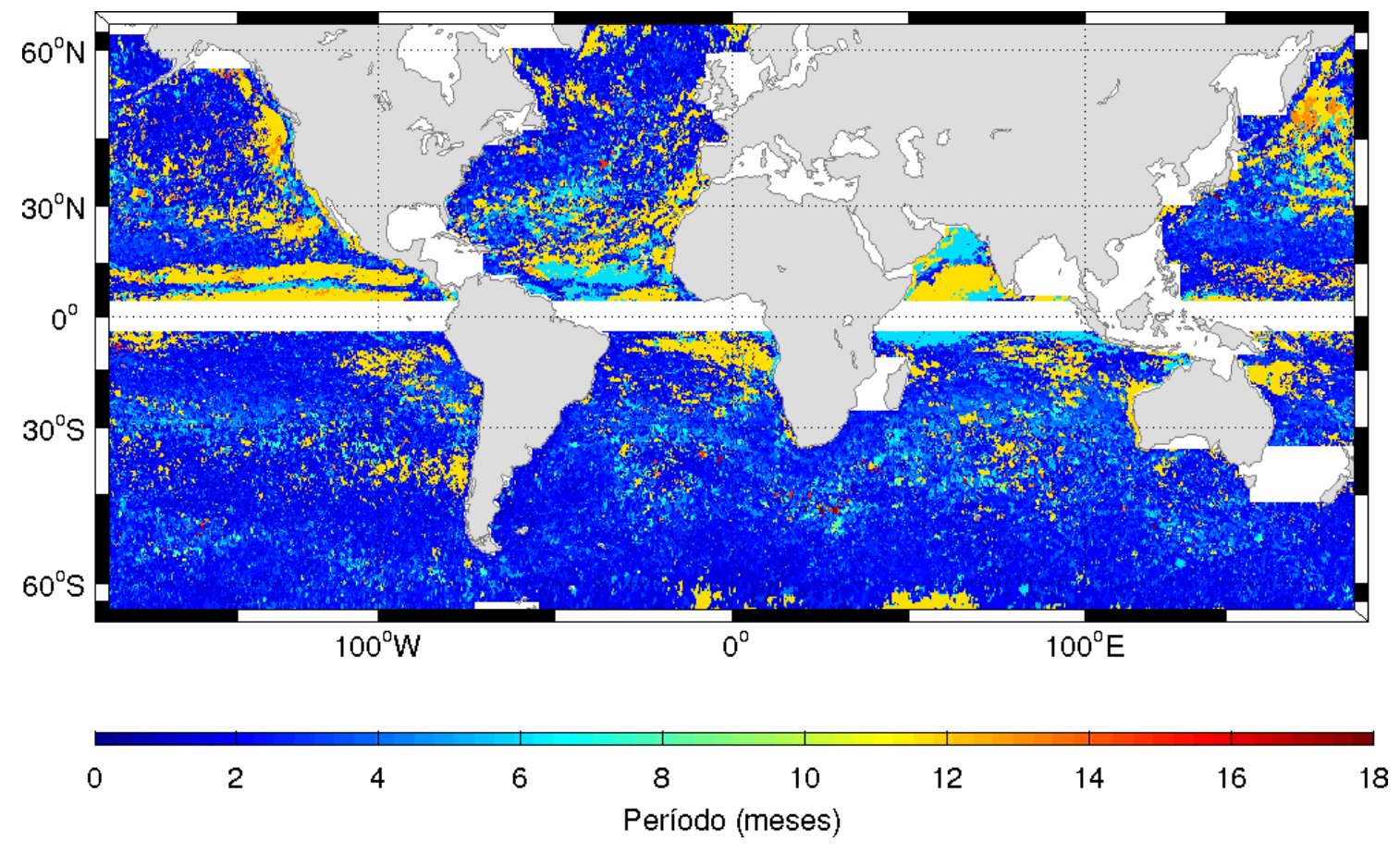

Figura 4.17: Período de potência espectral máxima entre $w_{s}$ e $w_{E}$.

Ao se retirar a componente sazonal dos dados com um filtro FIR2D (figura 4.18), a situação é alterada, não havendo mais a predominância do período de 12 meses na região tropical. Contudo, ainda há a presença do período anual nas bordas leste das bacias oceânicas, sugerindo que estas regiões sejam propícias para a formação de ondas planetárias de período anual.

Baseado neste último resultado, houve o interesse de se observar a potência espectral do espectro cruzado entre as componentes de ondas de Rossby anual e semianual, uma vez que foram os períodos que conseguiram se destacar do ruído de alta frequência. A comparação entre as últimas duas figuras 4.17 e 4.18 é um 
indício de que ciclo sazonal não propagante do rotacional da tensão de cisalhamento do vento é quem força a maioria das ondas de 6 e 12 meses na região tropical e perto da borda leste.

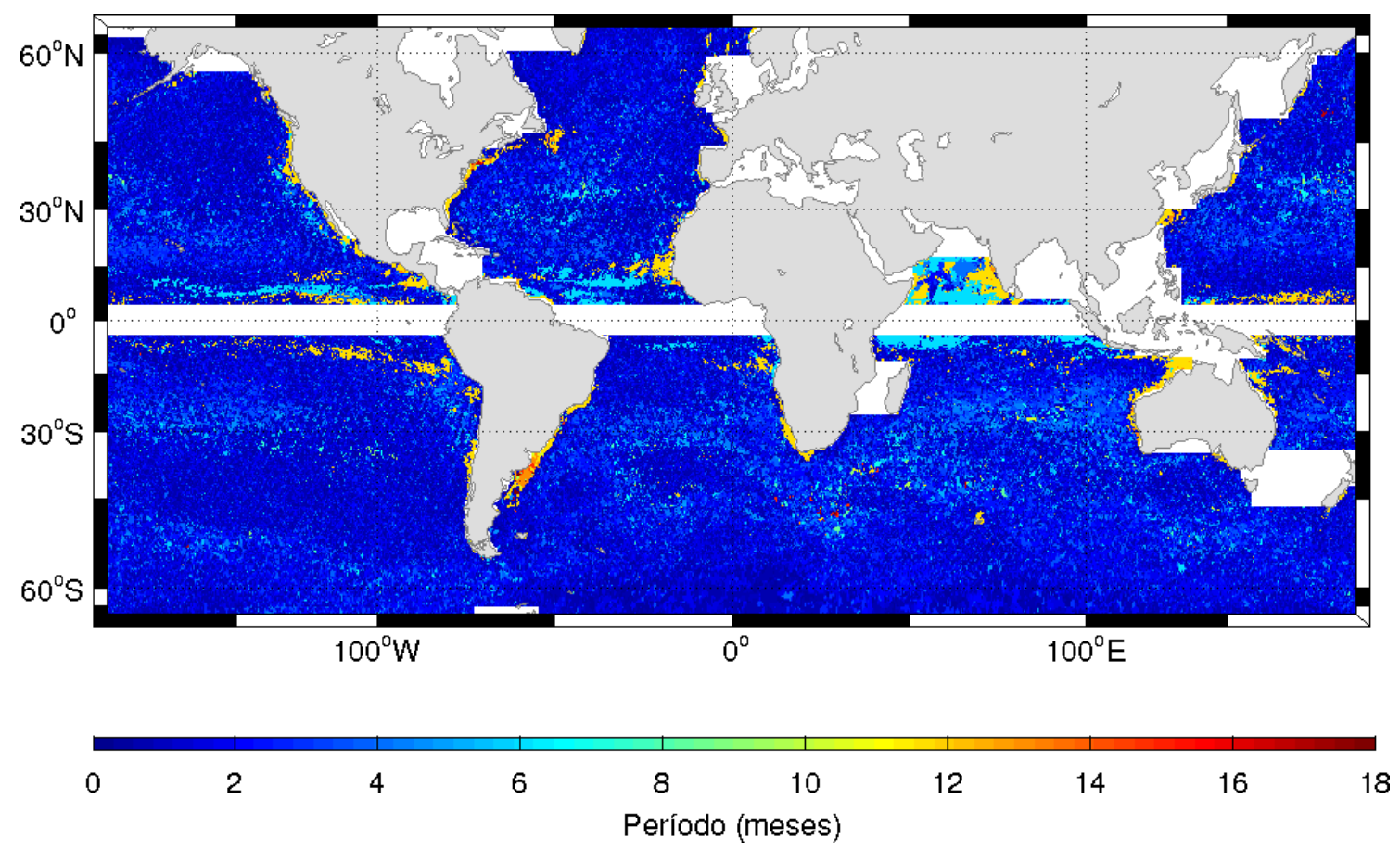

Figura 4.18: Período de potência espectral máxima entre $w_{s}$ e $w_{E}$, retiradas as respectivas componentes sazonais.

No mapa com a componente anual (figura 4.19), ainda são observadas as mesmas feições energéticas presentes no mapa com os dados brutos, com exceção do Atlântico norte tropical que mostrou-se pouco energético. Entretanto, as feições mais interessantes são as feições de energia média presentes nas bordas oeste da Austrália e da região subtropical da América do Norte e América do Sul, reforçando a idéia de que sejam regiões de geração de ondas planetárias anuais. 


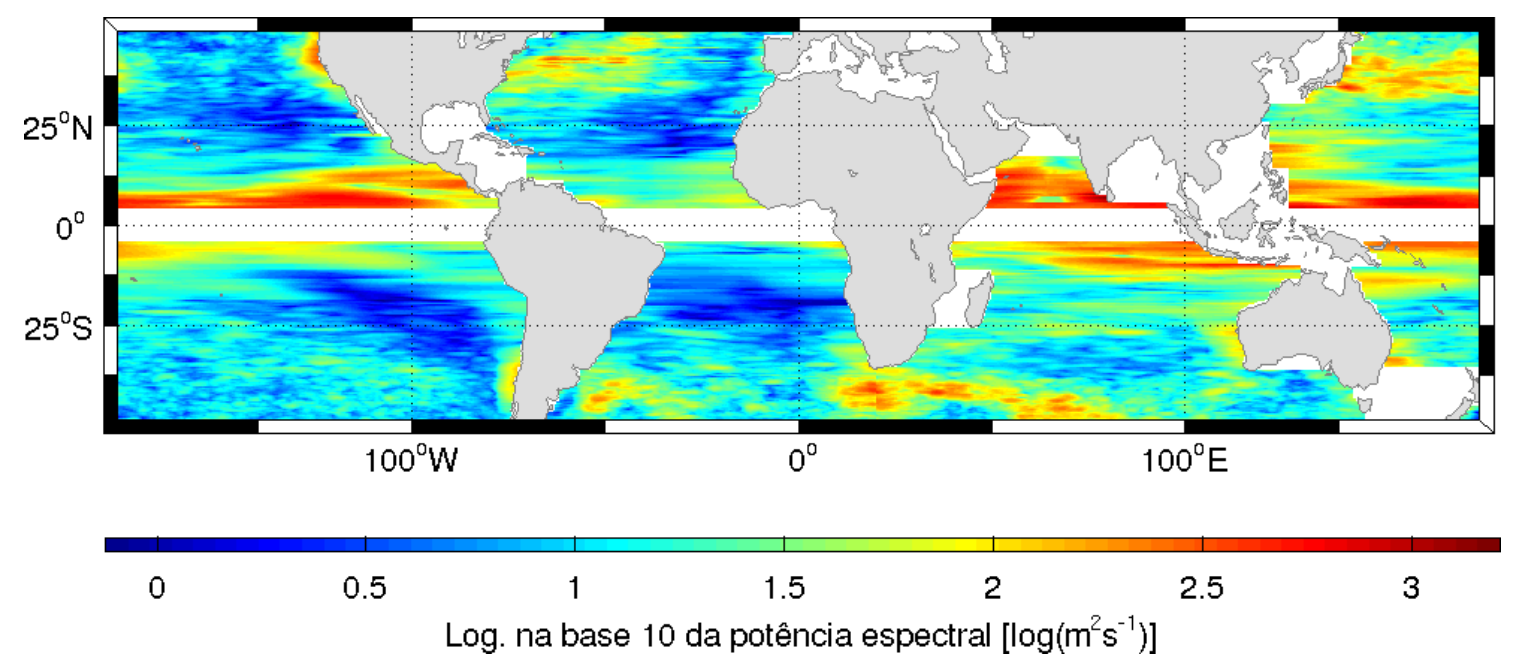

Figura 4.19: Potência espectral máxima do espectro cruzado entre as componentes anuais propagantes para oeste de $w_{s}$ e de $w_{E}$.

As principais feições energéticas continuam presentes no mapa com a potência espectral obtida para o espectro cruzado das componentes semi-anuais (figura 4.20). Destaca-se a presença de um Atlântico norte tropical energético, em contrapartida ao resultado da componente anual, e o Índico tropical, o qual apresenta os máximos de potência, como era esperado. Todavia, houve uma ausência de feições notáveis nas bordas lestes das bacias oceânicas, não sugerindo possíveis regiões de formação de ondas planetárias de período semianual.



Figura 4.20: Potência espectral máxima do espectro cruzado entre as componentes semi-anuais de $w_{s}$ e de $w_{E}$. 
Nas latitudes médias, observam-se no Atlântico e Pacífico noroeste e no Índico sudoeste regiões de alta potência espectral nas figuras 4.19 e 4.20, sendo que na primeira também se observa alta potência espectral no Atlântico sudoeste. Estas regiões são as mesmas onde Polito e Liu (2003) obtiveram os maiores valores de amplitude média quadrática para os sinais de ondas de Rossby anuais e semianuais. Lembrando que a potência espectral obtida no presente estudo é devida a presença de sinais nas séries temporais da AASM e do bombeamento de Ekman, esta semelhança na distribuição geográfica dos resultados é um indicativo da relação entre as ondas oceânicas planetárias e o rotacional da tensão de cisalhamento do vento.

\subsubsection{Vento e TSM}

A potência espectral máxima obtida entre as séries com todos os sinais de $T_{s}$ e de $\left|\vec{v}_{w}\right|$ (figura 4.21) mostra que as regiões subtropicais apresentam uma interação mais intensa em uma mesma banda espectral nas duas séries, com destaque para o Pacífico noroeste. Nas áreas tropicais, há alguns focos de maior energia, como observado no Atlântico norte, no Índico oeste e no Pacífico leste. Contudo, ao contrário da comparação anterior entre as velocidades verticais, não podem ser observadas grandes feições dinâmicas. Isto pode ser explicado pelo fato das ordens de grandeza da TSM e da magnitude do vento não se alterarem no domínio espacial, ao contrário do que ocorre com as velocidades verticais. 


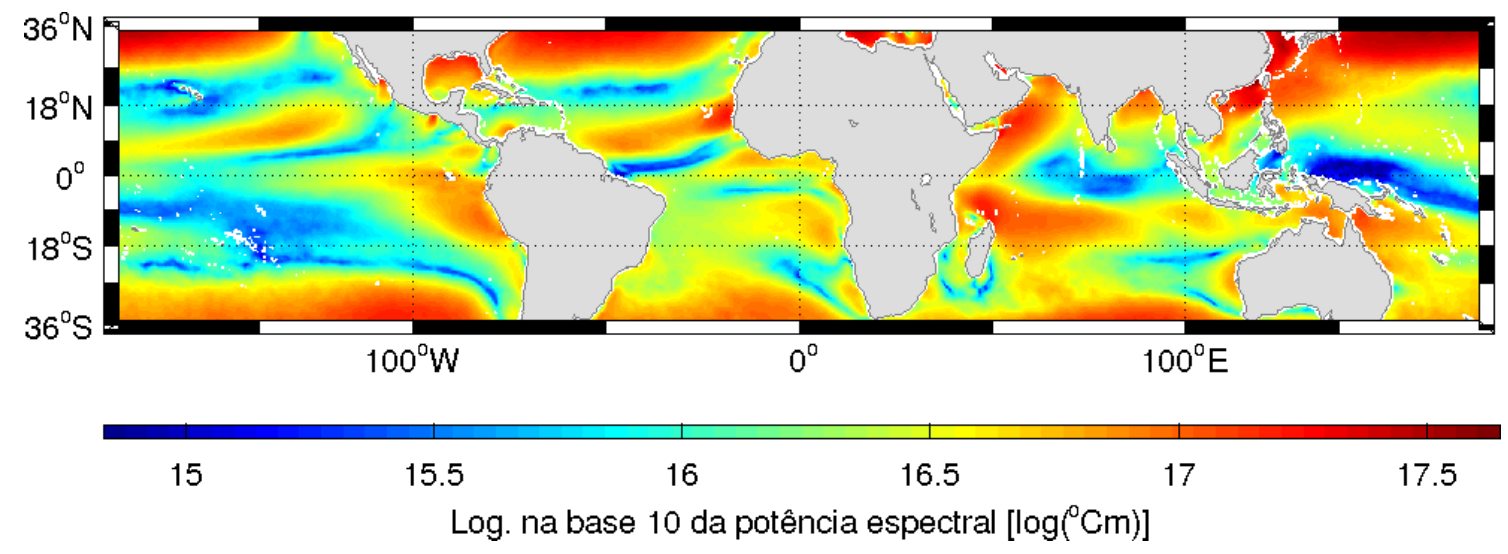

Figura 4.21: Potência espectral máxima do espectro cruzado entre $T_{s}$ e $\left|\vec{v}_{w}\right|$.

Já entre $T_{s}$ e $\nabla \cdot \vec{v}_{w}$ (figura 4.22) há uma maior concentração de energia na porção tropical do Atlântico e do Pacífico leste. Nota-se que é a região da ZCIT, a mesma onde foram observadas as maiores (em valores absolutos) correlações negativas (figura 4.7). Aparentemente, a ZCIT possui uma assinatura marcante nos espectros da TSM e da divergência do vento. O resultado dos coeficientes de correlação (figura 4.7) sugere que o sinal da ZCIT das duas séries está em fase.

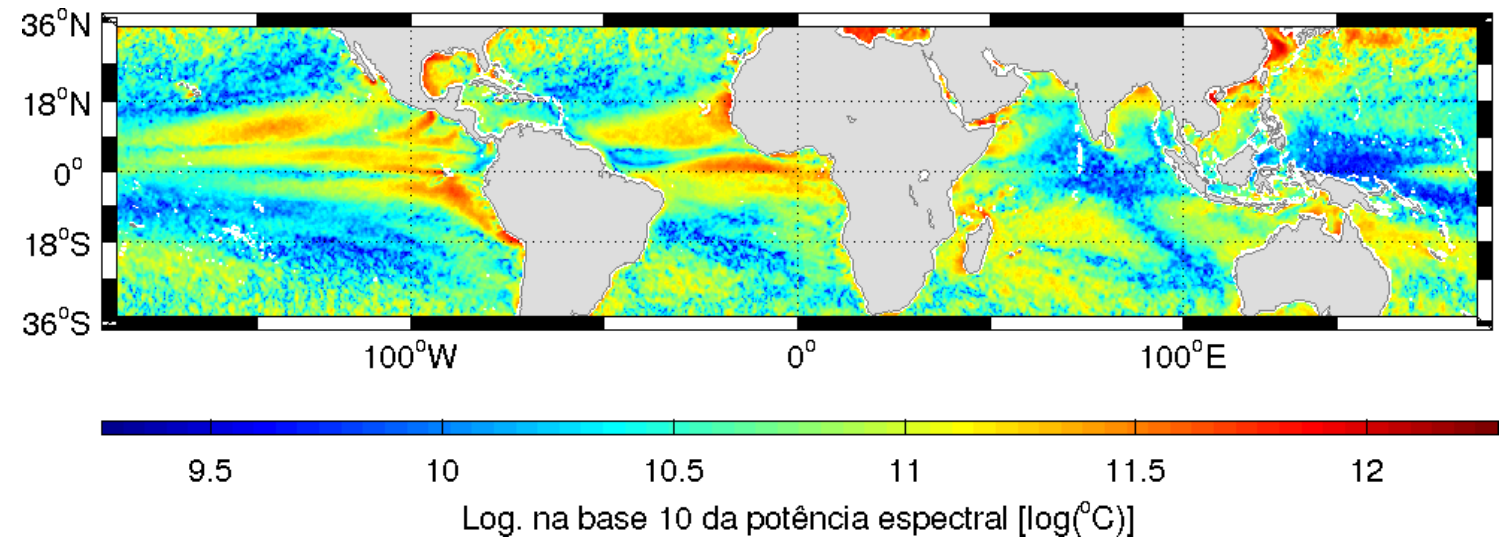

Figura 4.22: Potência espectral máxima do espectro cruzado entre $T_{s}$ e $\nabla \cdot \vec{v}_{w}$.

Tendo em vista que as figuras de potência espectral máxima não informam a banda espectral em que ocorrem, confeccionou-se mapas com os períodos da máxima potência espectral entre $T_{s}$ e $\left|\vec{v}_{w}\right|$ (figura 4.23 ) e entre $T_{s}$ e $\nabla \cdot \vec{v}_{w}$ (figura 4.24). Nestas figuras, observa-se claramente uma dominância do período de um ano (verde claro), 
indicando que o sinal sazonal e/ou o sinal das ondas planetárias de período anual são os mais significativos. Vale notar a dominância do período de 6 meses (azul) no Mar da Arábia, sendo um indicativo do regime de monções típico do oceano Índico. Por fim, ressalta-se a região do Pacífico equatorial oeste, onde ocorre predominância de períodos superiores a 24 meses, os quais não puderam ser obtidos com precisão devido a limitação imposta pela resolução da frequência nos espectros. Wittenberg (2003), utilizando dados de reanálise do NCEP-NCAR (National Center of Atmospheric Research, Estados Unidos) e de análise subjetiva da Florida State University, obteve um aumento na resposta da tensão de cisalhamento do vento às anomalias da TSM relacionadas ao El Niño na região de $5^{\circ} \mathrm{N}-5^{\circ} \mathrm{S}$ e $160^{\circ} \mathrm{E}-150^{\circ} \mathrm{W}$. Assim, especula-se que este sinal de longo período dominante no Pacífico equatorial oeste observado nas figuras (4.23) e (4.24) esteja relacionado ao fenômeno El Niño.

Dada a predominância do período anual nas últimas figuras, decidiu-se examinar a potência espectral do espectro cruzado entre as componentes de ondas de Rossby anuais. Tanto na comparação entre $T_{s}$ e $\left|\vec{v}_{w}\right|$ (figura 4.25) quanto na entre $T_{s}$ e $\nabla \cdot \vec{v}_{w}$ (figura 4.26), pode-se observar as grandes concentrações de energia nas bordas leste dos três oceanos, especialmente na segunda figura. Este é mais um indicativo da formação de ondas de Rossby de período anual nestas regiões.

Levando em consideração a hipótese de formação de ondas de Rossby através de forçamento direto do vento, espera-se encontrar relações entre a altura da superfície livre do oceano e o rotacional da tensão de cisalhamento do vento. As figuras $(4.3)$ e $(4.18)$ são exemplos de relações encontradas neste trabalho. Adicionalmente, os últimos resultados apresentados mostraram que, nas prováveis regiões 
de formação de ondas de Rossby, o seu sinal está fortemente presente nas séries temporais de TSM e de divergência do vento.

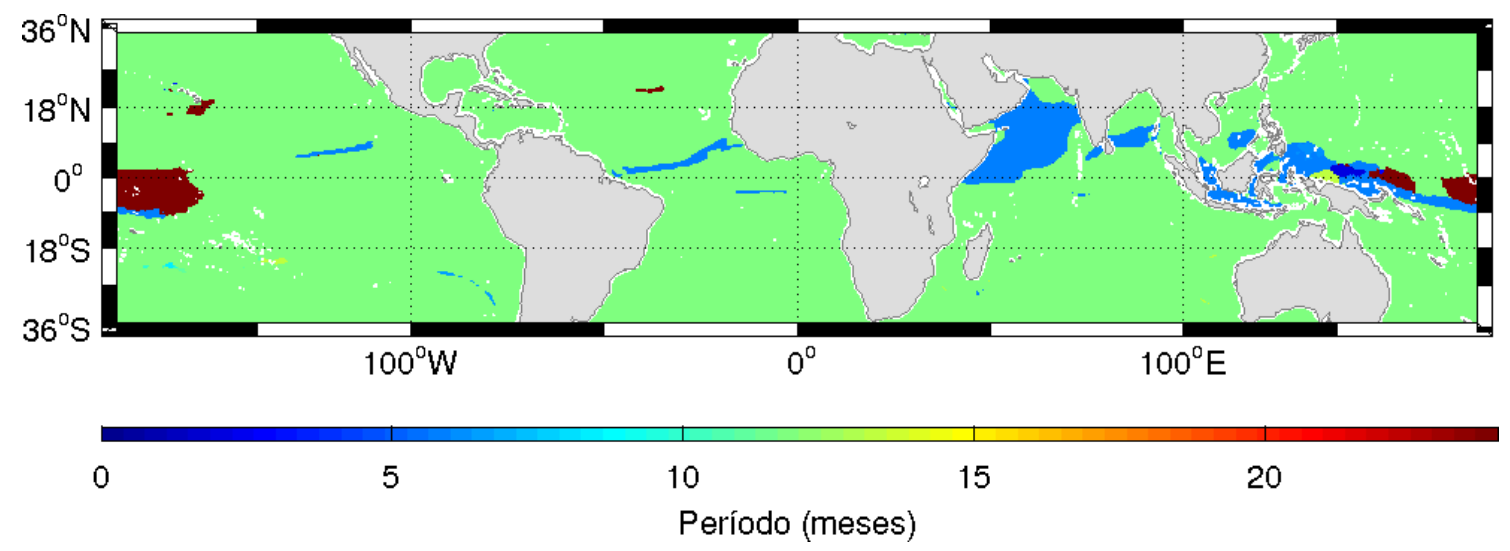

Figura 4.23: Período no qual foi observada a potência espectral máxima entre $T_{s} \mathrm{e}$ $\left|\vec{v}_{w}\right|$.

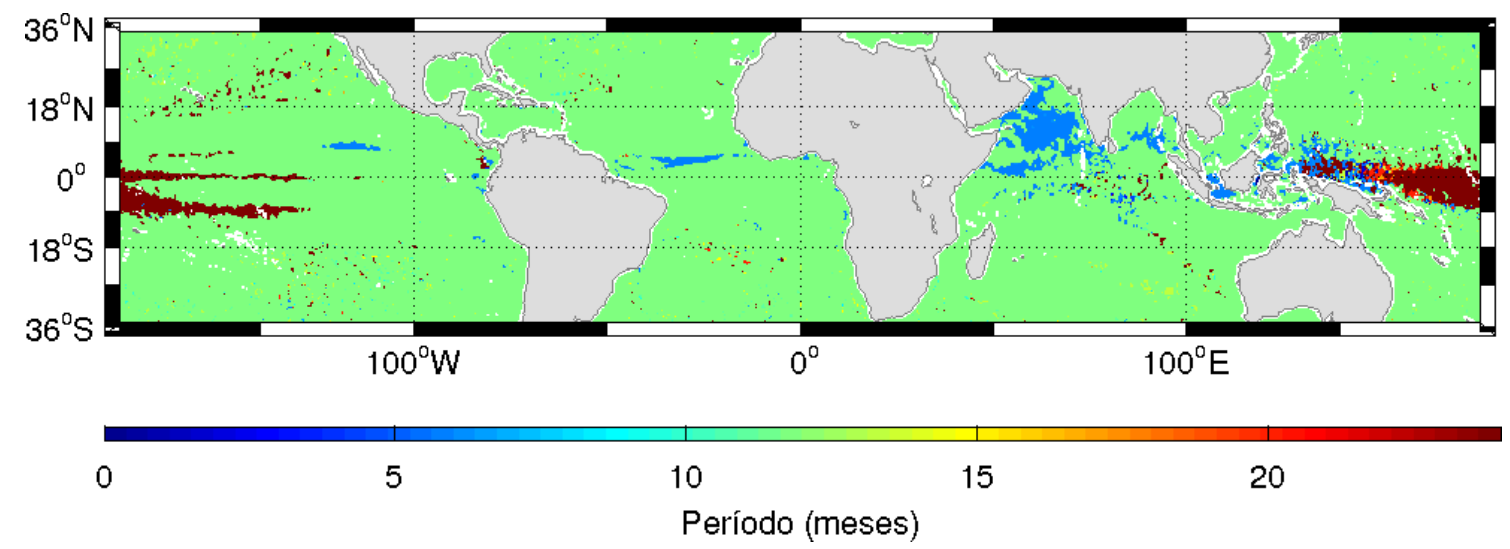

Figura 4.24: Período no qual foi observada a potência espectral máxima entre $T_{s} \mathrm{e}$ $\nabla \cdot \vec{v}_{w}$

Uma forma de interpretar este resultado é supor que o rotacional da tensão de cisalhamento do vento forçou ondas de Rossby nesta região. Estas ondas apresentariam anomalias de altura na superfície. É possível que estas anomalias se refletissem na estrutura térmica, resultando em anomalias térmicas na superfície. Pela hipótese de Lindzen e Nigam (1987), esta variação de temperatura na superfície seria sentida pela atmosfera, que implicaria na formação de regiões de convergência (anomalia de TSM positiva) ou divergência (anomalia de TSM negativa). 
Esta linha de raciocínio leva à suposição de que as bordas leste dos três oceanos sejam possíveis regiões de retroalimentação, além de serem prováveis regiões de geração de ondas planetárias.

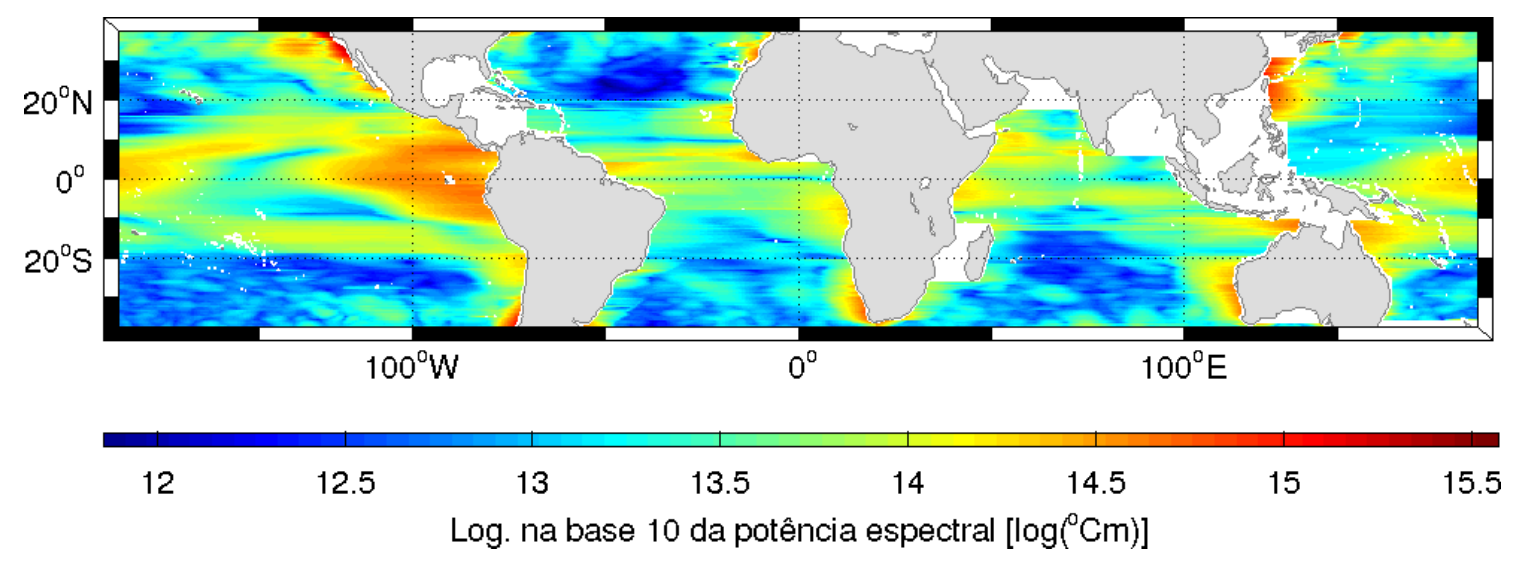

Figura 4.25: Potência espectral máxima do espectro cruzado entre as componentes propagantes para oeste de período anual de $T_{s}$ e de $\left|\vec{v}_{w}\right|$.

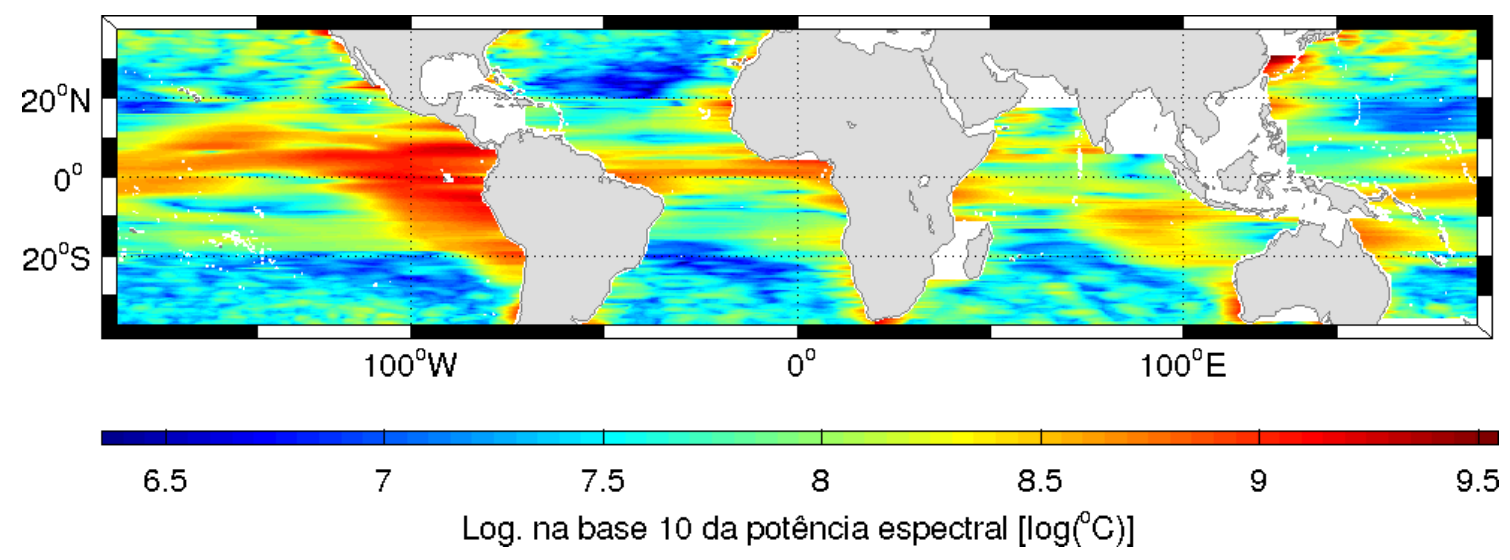

Figura 4.26: Potência espectral máxima do espectro cruzado entre as componentes propagantes para oeste de período anual de $T_{s}$ e $\nabla \cdot \vec{v}_{w}$. 


\subsection{Anomalia da altura da superfície livre modelada}

\subsubsection{Componente anual propagante para oeste}

Partindo dos coeficientes de correlação linear entre as componentes de $w_{s} \mathrm{e}$ $w_{E}$, calculou-se a média das correlações obtidas por latitude por bacia oceânica.

Nas correlações médias para a componente anual (figura 4.27), observase que o Atlântico norte tropical e o Pacífico sul tropical são as regiões com os maiores valores. Estes resultados são interpretados como uma indicação de que nessas latitudes a geração de ondas planetárias é causada por bombeamento de Ekman. Por esta razão, estes são os locais onde se espera que o modelo linear produza os melhores resultados. Contudo, também serão analisados os resultados do modelo em algumas regiões de baixa correlação média, com o intuito de avaliar sua performance em ambas as situações.

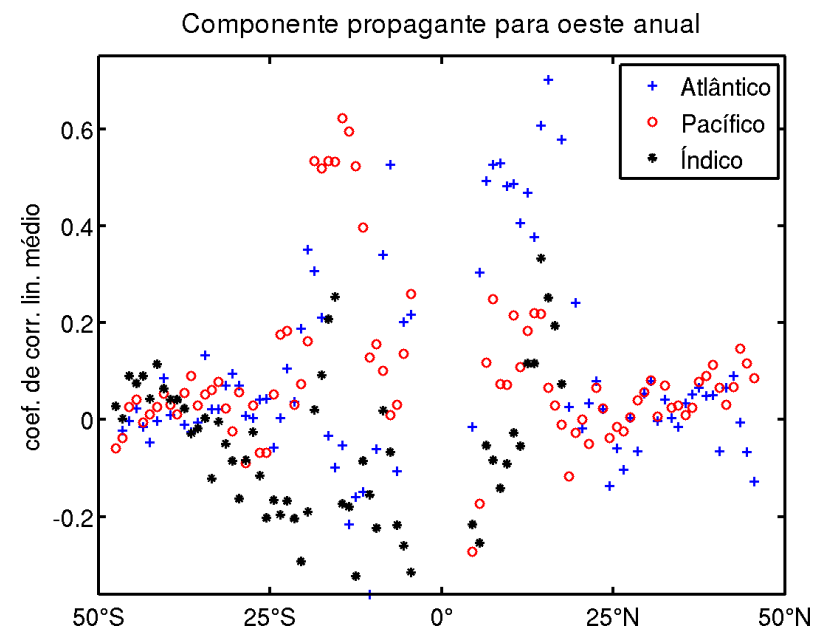

Figura 4.27: Coeficiente de correlação médio entre a componente anual de $w_{s}$ e $w_{E}$ por latitude para cada bacia oceânica. 
Por modelo, entenda-se a aplicação da equação (3.26), a qual é uma discretização da equação (3.23). Para os resultados apresentados nesta seção, o termo forçante utilizado na equação (3.26) foi a componente anual propagante para oeste do bombeamento de Ekman.

Convém estabelecer aqui o que é justo se esperar de um modelo tão simples como o utilizado:

- o modelo apenas reproduzirá o que for gerado pelo rotacional de tensão de cisalhamento do vento (a menos da propagação das condições iniciais no início da série);

- como a velocidade de média fase é imposta, uma coincidência de $c_{p}$ é de baixa relevância;

- a fase em si não é imposta nem controlada de alguma maneira, logo a coincidência de fase é um forte indicativo de que a hipótese de forçamento linear pelo vento é provável na região modelada;

- a ordem de grandeza da amplitude é imposta pelo valor de $g^{\prime}$ que é fixo. Portanto, é de se esperar que o modelo subestime ou superestime a amplitude média numa dada latitude pelo valor fixado ser inadequado, porém as modulações temporais da amplitude são consequências isoladas do bombeamento de Ekman.

Este conjunto de limitações impede que se estabeleça uma comparação quantitativa na forma de uma figura de mérito estatístico. A interpretação dos resultados será feita com base nas figuras, tendo em mente o que foi exposto acima. 
Devido à aplicação dos filtros FIR2D nos dados observacionais de AASM e nos de bombeamento de Ekman, o padrão das ondas observadas e previstas assemelha-se ao senoidal. Por esta razão, foi utilizada a fórmula de cálculo de amplitude média de um conjunto de ondas senoidais (equação 4.1) para se estimar a amplitude média tanto das ondas observadas quanto nas previstas.

$$
\bar{\eta}=\frac{\sqrt{2}}{2} \sigma
$$

onde $\bar{\eta}$ é a amplitude média de um campo de ondas e $\sigma$ é o desvio padrão deste campo.

Os resultados do modelo para o Atlântico tropical entre $12^{\circ} \mathrm{N}$ e $16^{\circ} \mathrm{N}$, região com correlação média de 0,54 , são os que mais se aproximam das observações (figura 4.28). Observa-se que no modelo as amplitudes aumentam para oeste da mesma forma que ocorre nos dados e que a teoria prediz. A amplitude média das previsões corresponde a $67 \%$ da amplitude média dos dados, de forma que a ordem de grandeza das amplitudes do resultado modelado está de acordo com as observações. Além disso, as variações de amplitude no tempo também ocorrem simultaneamente nos dados e no modelo.

Ressalta-se que cada diagrama de Hovmöler corresponde ao resultado médio obtido em um intervalo de $1^{\circ}$ de latitude, entretanto a referência a estes resultados será feita pela sua latitude central por simplicidade. Assim, teve-se em $12,5^{\circ} \mathrm{N}$ uma propagação de ondas planetárias muito similar ao observado pelos altímetros. A principal diferença é a velocidade de fase que no modelo é um pouco maior que nas observações, como pode se observar pela chegada das cristas e cavados à borda oeste da bacia oceânica. A partir de 2004, as cristas e cavados chegam à borda oeste poucos meses antes nos dados modelados em comparação aos observados. 
Os resultados para $13,5^{\circ} \mathrm{N}, 14,5^{\circ} \mathrm{N}$ e $15,5^{\circ} \mathrm{N}$ são similares ao descrito para $12,5^{\circ} \mathrm{N}$. De toda maneira, são resultados que comprovam um bom funcionamento da teoria linear, uma vez que um modelo linear simples foi capaz de reproduzir com boa semelhança as ondas de Rossby observadas no oceano, inclusive com amplitudes comparáveis, as quais corresponderam em média a 74\% das amplitudes observadas. Esperar que as fases entre os dados modelados e os observados fossem idênticas em toda a extensão da bacia oceânica seria um critério de comparação muito restrito, considerando as simplificações impostas pelo modelo. Estas simplificações excluem:

- a influência de mecanismos não lineares que possam alterar $c_{p}$ (PALDOR et al., 2007);

- a influência de outros fatores na variação da vorticidade de fundo, tais como topografia (BARNIER, 1988) e cisalhamento das correntes médias (KILLWORTH et al. 1997);

- a possibilidade de uma pequena propagação meridional observada no Atlântico norte por Polito e Cornillon (1997);

- o efeito counter-Doppler-shift, que consiste na ação em conjunto entre a variação da estratificação e o cisalhamento vertical das correntes médias resultarem na propagação do pacote de ondas na direção contrária à circulação média (YANG, 2000). 


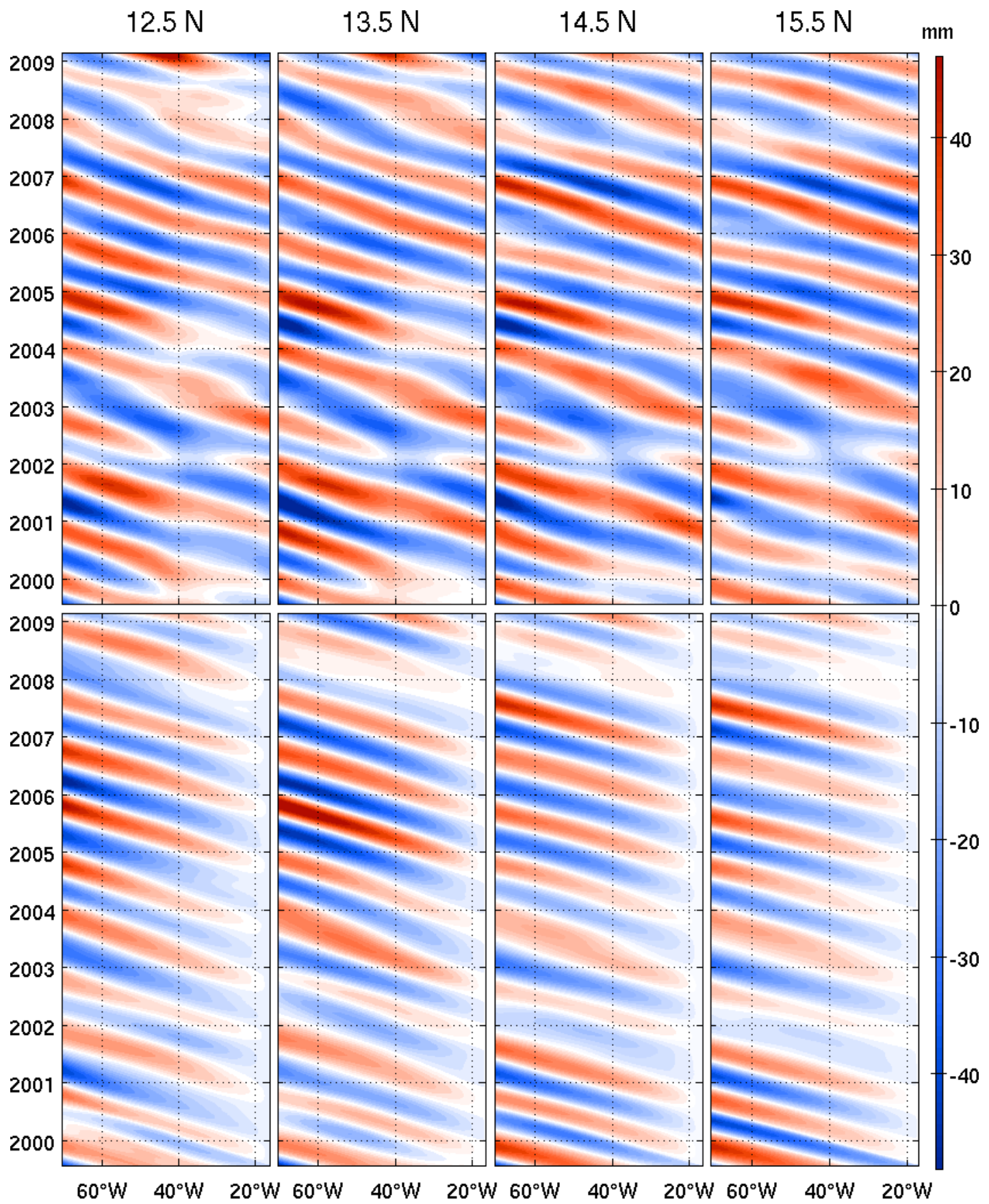

Figura 4.28: Componente anual da anomalia da altura da superfície livre ( $\mathrm{mm})$ observada por altímetros (superior) e a mesma modelada (inferior) no oceano Atlântico entre $12^{\circ} \mathrm{N}$ e $16^{\circ} \mathrm{N}$ (colunas).

Entre $16^{\circ} \mathrm{N}$ e $20^{\circ} \mathrm{N}$ do Atlântico (correlação média de 0,46 ), observa-se que as amplitudes modeladas estão subestimadas (figura 4.28), neste caso a amplitude média modelada corresponde apenas a $57 \%$ da observada. Em $16,5^{\circ} \mathrm{N}$, o padrão 
observado ainda é similar ao descrito para a figura anterior, todavia a partir de 2006 o modelo passa a errar a fase ao chegar na borda oeste em $180^{\circ}$, ou seja, quando foi observado uma crista, o modelo gerou um cavado. Esta diferença ocorreu devido a mudança da velocidade de propagação do cavado observado nos dados entre 2005 e 2006 a partir de $50^{\circ} \mathrm{N}$ aproximadamente. Este fenômeno fez a crista seguinte demorar um pouco mais para cruzar a bacia, gerando a grande diferença de fase observada entre o modelo e a observação a partir desta data.

Já em $17,5^{\circ} \mathrm{N}$ as previsões do modelo voltam a serem similares às observações, porém esta é a latitude com as amplitudes mais subestimadas, com a amplitude média da previsão sendo apenas $43 \%$ da observada. Vale lembrar que a amplitude depende diretamente de $g^{\prime}$, o qual é mantido constante, garantindo que este parâmetro não seja manipulado direta ou indiretamente a fim de melhorar os resultados. Voltando aos resultados para $17,5^{\circ} \mathrm{N}$, nota-se as duas cristas que surgem uma entre 2001 e 2002 e a outra entre 2002 e 2003, sendo que ambas parecem se agrupar em torno de $55^{\circ} \mathrm{W}$, chegando à borda oeste no começo de 2003. Esta feição presente nos dados observados foi muito bem reproduzida pelo modelo, sendo mais um indicativo de forçamento direto pelo vento.

Os resultados em $18,5^{\circ} \mathrm{N}$ discordam significativamente das observações, sendo que só conseguiram reproduzir algumas feições. Isto não chega a ser uma surpresa, pois as ondas observadas possuem um padrão mais complexo com diversas mudanças de velocidade de fase entre $40^{\circ} \mathrm{W}$ e $60^{\circ} \mathrm{W}$. Entretanto, é interessante notar nos resultados do modelo a mudança de velocidade de fase de algumas feições ao longo da bacia, a redução da amplitude e posterior crescimento da crista iniciada em 2004, além da crista começada em 2005 que terminou em $55^{\circ} \mathrm{W}$ em 2006, com o ressur- 
gimento no terceiro trimestre de 2006 no mesmo local. Todas estas feições são de razoável complexidade, sendo muito elucidativo obtê-las com um modelo linear tão simples, cuja grande vantagem é garantir que tais feições só podem ser consequência das variações no rotacional da tensão de cisalhamento do vento.

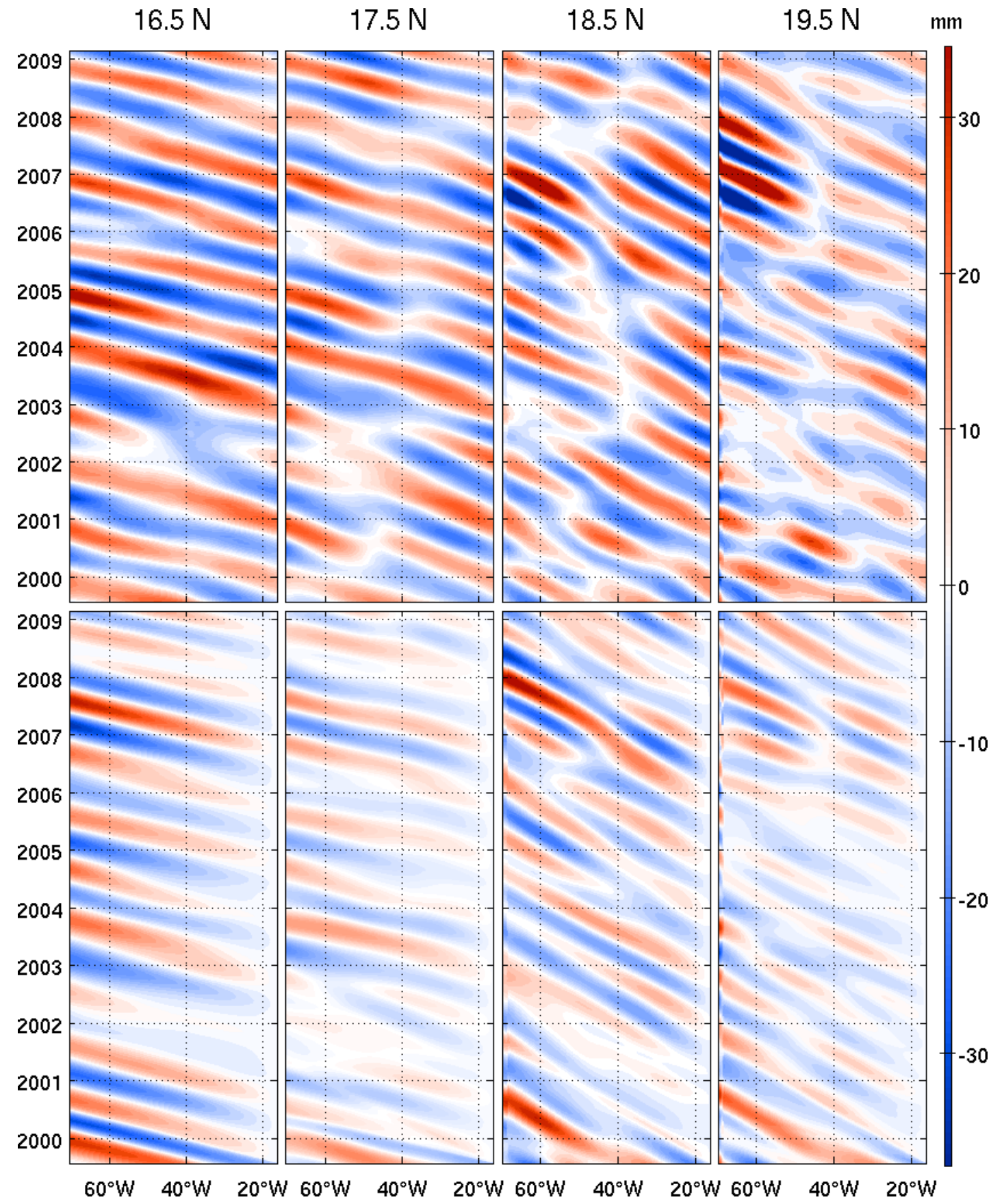

Figura 4.29: Similar à figura 4.28 para o oceano Atlântico entre $16^{\circ} \mathrm{N}$ e $20^{\circ} \mathrm{N}$. 
Porém, o resultado mais interessante está em $19,5^{\circ} \mathrm{N}$. Nos dados altimétricos, é observada uma sucessão de cristas e cavados iniciados em 2005 que se propagam até 2008. Eles são notáveis por sofrerem uma grande alteração em cerca de $45^{\circ} \mathrm{W}$. Aparentemente, eles aceleram significativamente com um curto período de tempo e depois retomam sua velocidade de fase original, dando a impressão de terem mudado de fase. Toda esta feição foi reproduzida com alto grau de semelhança pelo modelo, embora com amplitudes menores, sendo em média $51 \%$ das observadas.

Como o modelo utilizado é de uma e meia camada, ele não apresenta fundo e, portanto, dispensa-se trivialmente qualquer interpretação que envolva a influência da Cordilheira Mesoatlântica como modificadora das ondas planetárias BARNIER, 1988, POLITO, 1997). Assim, este último resultado é um indicativo de como a velocidade de fase das ondas planetárias pode ser alterada apenas através do forçamento pelo vento.

Estes resultados para o Atlântico norte tropical estão de acordo com Cabanes et al. (2006), que observaram que o ajustamento de larga escala ao forçamento pelo vento através da propagação de ondas de Rossby concordava com a anomalia da altura da superfície entre $15^{\circ}$ e $20^{\circ} \mathrm{N}$. Todavia, Chu et al. (2007) concluíram que apenas as ondas de Rossby da porção oeste do Atlântico norte tropical eram provavelmente forçadas por bombeamento de Ekman, enquanto as ondas da porção leste eram provavelmente excitadas por uma forçante na borda leste, por exemplo uma onda de Kelvin. O presente modelo exclui a dinâmica de ondas de Kelvin e reproduz as ondas na porção leste da bacia; ele inclui apenas o bombeamento de Ekman e provê uma explicação mais simples, portanto mais plausível. 
A região entre $11^{\circ} \mathrm{S}$ e $15^{\circ} \mathrm{S}$ no Pacífico apresentou correlação média de 0,53 . Os resultados gerados pelo modelo neste intervalo foram semelhantes em amplitudes, com a amplitude média prevista sendo $82 \%$ da observada. A modulação das amplitudes e a fase das ondas observadas (figura 4.30) também foram semelhantes entre previsões e observações, especialmente de $12^{\circ} \mathrm{S}$ a $15^{\circ} \mathrm{S}$. Nestes casos, as ondas chegaram à borda oeste com a fase muito próxima ao observado nos dados altimétricos. Considerando que o oceano Pacífico possui uma extensão muito maior que o Atlântico, o fato do modelo conseguir reproduzir as ondas planetárias observadas com um baixo desvio de fase é um feito notável, uma vez que qualquer variação na velocidade de fase das ondas reais teria uma bacia maior para se propagar e causar maiores impactos na fase no final da bacia oceânica.

Entre $15^{\circ} \mathrm{S}$ e $19^{\circ} \mathrm{S}$ no Pacífico sul (correlação média de 0,53 ), as ondas observadas (figura 4.31) são mais complexas que as observadas na figura 4.30. Elas apresentam maiores variações da amplitude ao longo da bacia, além de maiores mudanças na velocidade de fase. Todavia, também é possível observar nos dados modelados as mudanças de amplitude e variação de velocidade de fase, levando a um dos resultados mais interessantes do trabalho: as ondas planetárias de período anual modeladas estão muito aproximadamente em fase com as ondas planetárias observadas nesta região. A reprodução da amplitude média pelo modelo também está adequada, sendo $68 \%$ da amplitude média observada.

Os resultados apresentados até agora correspondem às regiões de maior correlação média de acordo com a figura 4.27) - o Atlântico norte tropical e o Pacífico sul tropical. 


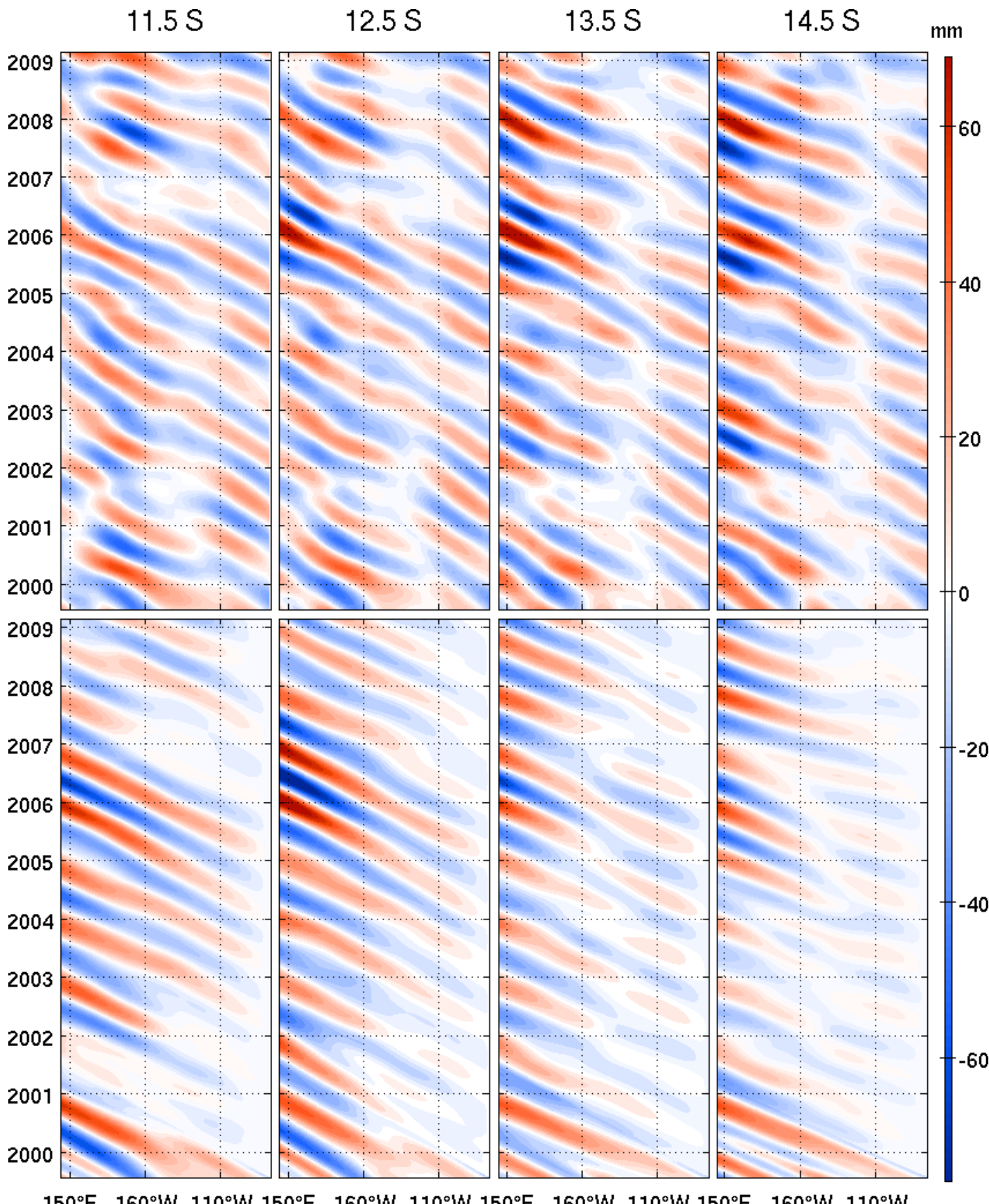

Figura 4.30: Similar à figura 4.28 para o oceano Pacífico entre $11^{\circ} \mathrm{S}$ e $15^{\circ} \mathrm{S}$.

As regiões com correlações menores serão analisadas em seguida, sendo que haverá em uma mesma figura diagramas de Hovmöller de zonas distintas. Uma vez que a amplitude é variável com a latitude, a escala de cor será mantida idêntica apenas entre cada diagrama de observações e o respectivo diagrama de previsões (colunas), não sendo iguais entre as latitudes (linhas). O padrão de cor ainda será 
o mesmo - as cristas são vermelhas; os cavados, azuis e branco como zero. Como o interesse não são as amplitudes específicas de cada onda, apenas os limites das escalas de cores, cujo valor absoluto é igual no extremo positivo e negativo, serão citados na legenda das figuras. Ressalta-se que este limite será o valor absoluto máximo das observações. As barras de cores serão omitidas por simplicidade.

Para o oceano Atlântico, foram amostradas as regiões sul subtropical $\left(30,5^{\circ} \mathrm{S}\right)$, sul tropical $\left(18,5^{\circ} \mathrm{S}\right.$ e $\left.9,5^{\circ} \mathrm{S}\right)$ e norte subtropical $\left(38,5^{\circ} \mathrm{N}\right)$ (figura 4.32 ). A correlação média destas latitudes foram, da latitude mais austral à mais boreal, 0,09, 0,30, $-0,06$ e 0,05 .

Em $30,5^{\circ} \mathrm{S}$, as ondas observadas apresentam mudanças de velocidade de fase ao longo da bacia, as quais não são e nem podem ser reproduzidas pelas ondas modeladas. Porém, há uma faixa que acompanha as ondas que estão na borda leste de 2004 a 2007, cuja amplitude é ligeramente acima da média, e uma outra faixa acompanhando as ondas que estão na borda leste de 2001 a 2004 de amplitude ligeiramente abaixo da média. A amplitude média modelada correspondeu a $65 \%$ da observada. Portanto, os resultados do modelo estão apenas razoavelmente em consonância com os observados e, embora o vento aparentemente não seja tão importante como nas regiões tropicais, ele ainda assim tem uma influência observável.

Já na região tropical, tanto em $18,5^{\circ} \mathrm{S}$ quanto em $9,5^{\circ} \mathrm{S}$ as ondas modeladas estão aproximadamente em fase com as observações. Nota-se a que as amplitudes do diagrama modelado de $18,5^{\circ} \mathrm{S}$ aproximam-se significativamente das observações, correspondendo em média a 97\% do observado. A grande diferença em 9.5S e 18.5S é que na borda leste o modelo prevê amplitude zero (condição de contorno dinâmica), muito diferente das observações. Uma possibilidade é as ondas serem geradas junto à 
costa por vento paralelo à costa (ressurgência costeira) e depois seriam amplificadas pelo bombeamento.

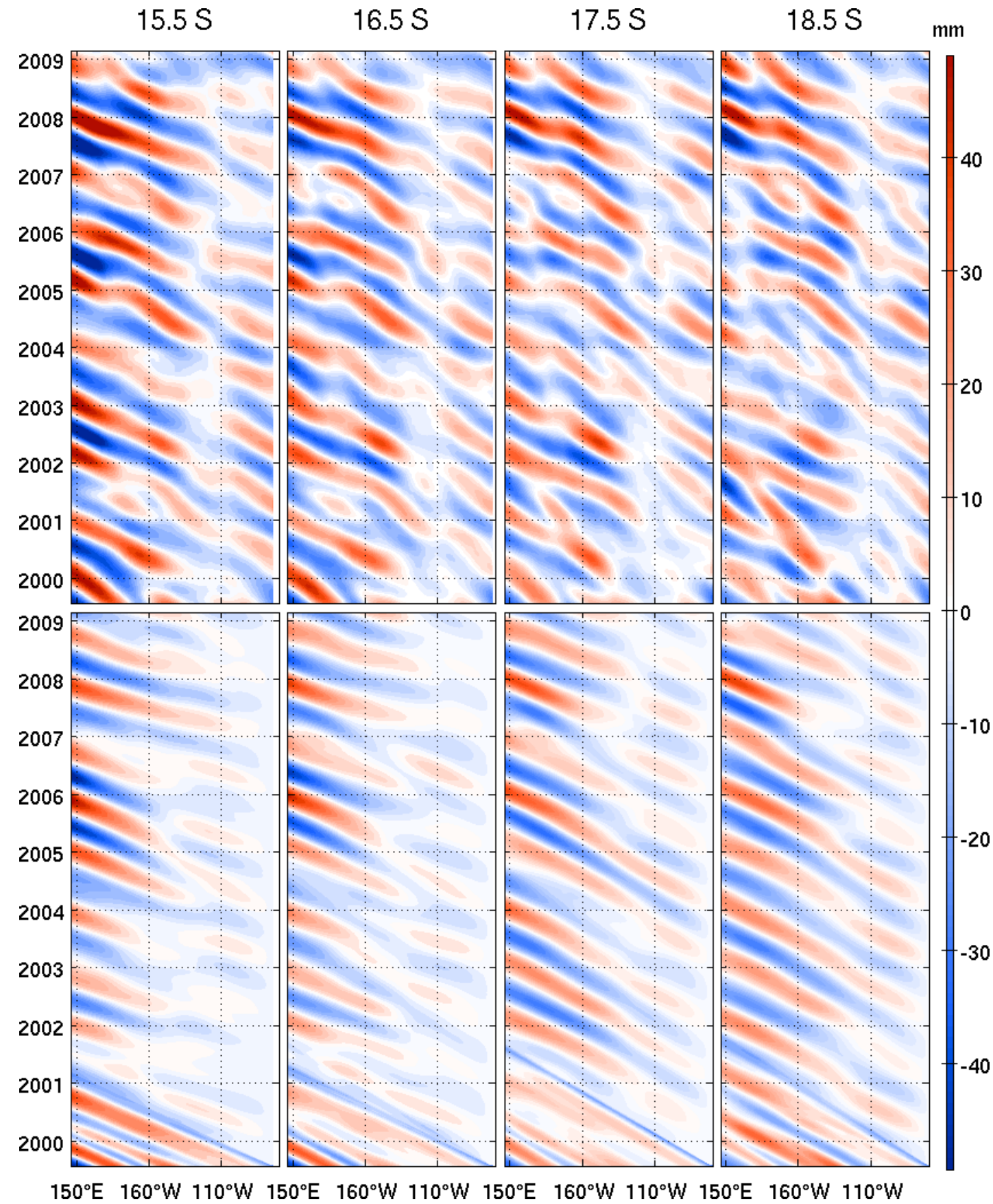

Figura 4.31: Similar à figura 4.28 para o oceano Pacífico entre $15^{\circ} \mathrm{S}$ e $19^{\circ} \mathrm{S}$.

No norte subtropical, observou-se em $38,5^{\circ} \mathrm{N}$ que o modelo reproduz qualitativamente as variações de velocidade de fase observadas nos dados altimétricos. Apesar das baixas amplitudes, que em média foram 54\% das observações, pode- 
se notar que, em média, o modelo corretamente reproduz amplitudes menores do lado leste da bacia. Isto implica que esta assimetria não é consequência direta da presença de correntes instáveis (extensão leste da Corrente do Golfo/do Atlântico Norte), mas se deve, ao menos parcialmente, às diferenças no campo de vento.

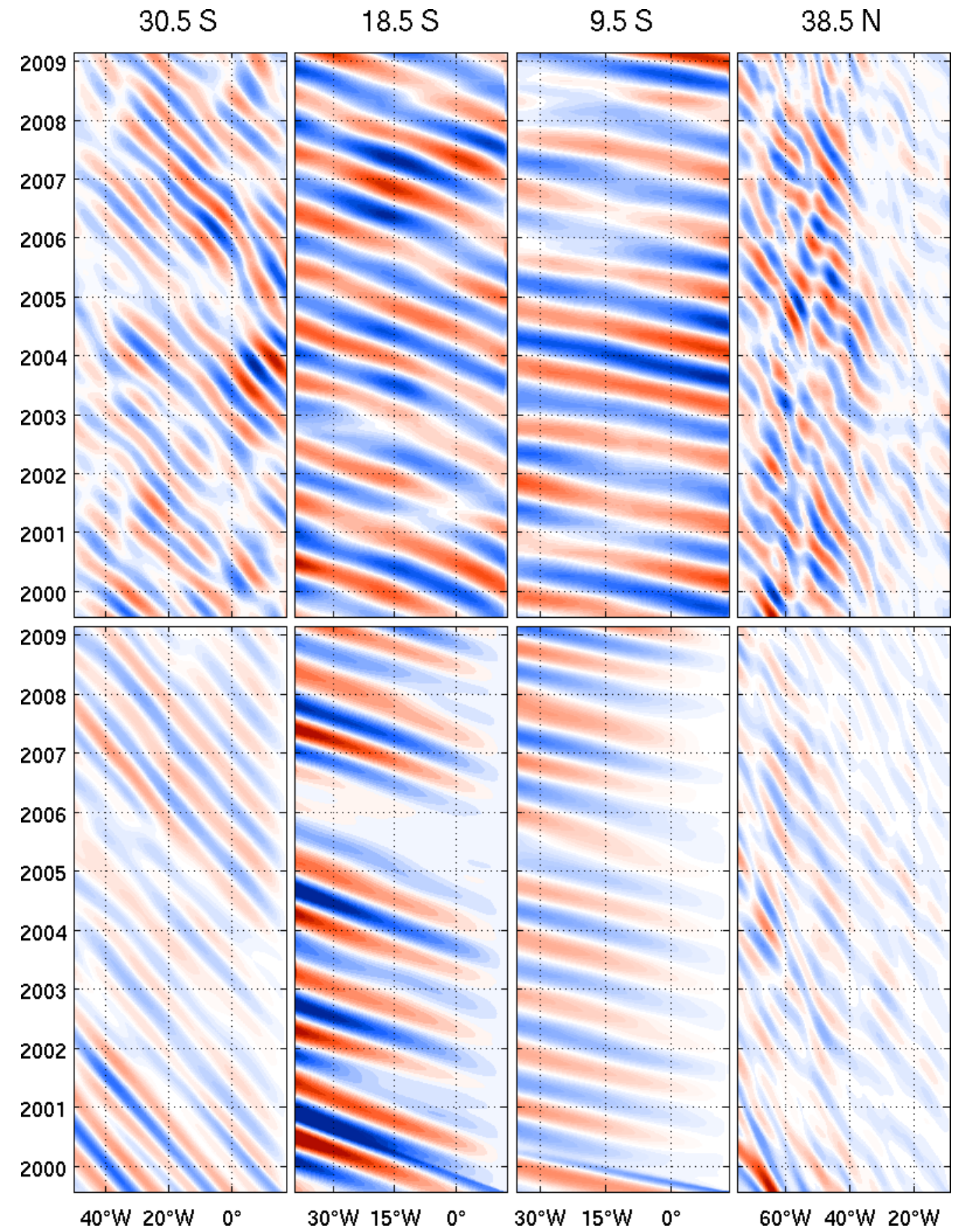

Figura 4.32: Similar à figura 4.28 para o oceano Atlântico em diversas latitudes. Os limites absolutos das escalas de cores são, da esquerda para a direita, $107 \mathrm{~mm}$, $17 \mathrm{~mm}, 27 \mathrm{~mm}$ e $172 \mathrm{~mm}$. 
Em ambas regiões subtropicais do Atlântico, embora em uma visão geral os resultados modelados estejam similares com os altimétricos, a fase das previsões não concordou com as observações de forma precisa. Uma das razões para isto é que as velocidades de fase nestas latitudes são menores que em latitudes tropicais, de forma que pequenas varições nesta velocidade causam um impacto maior na fase das ondas, uma vez que elas demoram um tempo relativamente maior para cruzar a bacia.

No oceano Pacífico, foram analisadas as latitudes de $40,5^{\circ} \mathrm{S}, 14,5^{\circ} \mathrm{N}, 25,5^{\circ} \mathrm{N}$ e $37,5^{\circ} \mathrm{N}$ (figura 4.33 ), sendo que estas latitudes apresentaram correlação média de 0,05, 0,22, - 0,01 e 0,08 respectivamente. Em 40,5ㅇ $\mathrm{S}$ a velocidade de fase é tão baixa, que as ondas originadas a leste de $120^{\circ} \mathrm{W}$ em 1999 ainda não haviam terminado de cruzar a bacia em 2009. Assim, cerca de metade do resultado do modelo é apenas a condição inicial sendo propagada. Não obstante, estas ondas modeladas devido à condição inicial estão razoavelmente em fase com as correspondentes altimétricas. As ondas geradas em 2002 também estão em fase entre o modelo e a observação, como se pode observar na sequência de cristas e cavados no ano de 2009. As amplitudes foram muito parecidas entre os dois diagramas, exceto por algumas cristas e cavados de maior amplitude, os quais foram propagados de $110^{\circ} \mathrm{W}$ no início da série a $170^{\circ} \mathrm{W}$ no final. Estas feições mais intensas resultaram em uma amplitude média prevista superestimada em 55\% em relação à observada. Tendo em vista estes resultados, é interessante notar que embora haja variações nas velocidades de fase das ondas nos dados altimétricos, a velocidade média de cada onda é similar à velocidade média do diagrama inteiro, uma vez que os dados estão aproximadamente em fase com os resultados do modelo. 


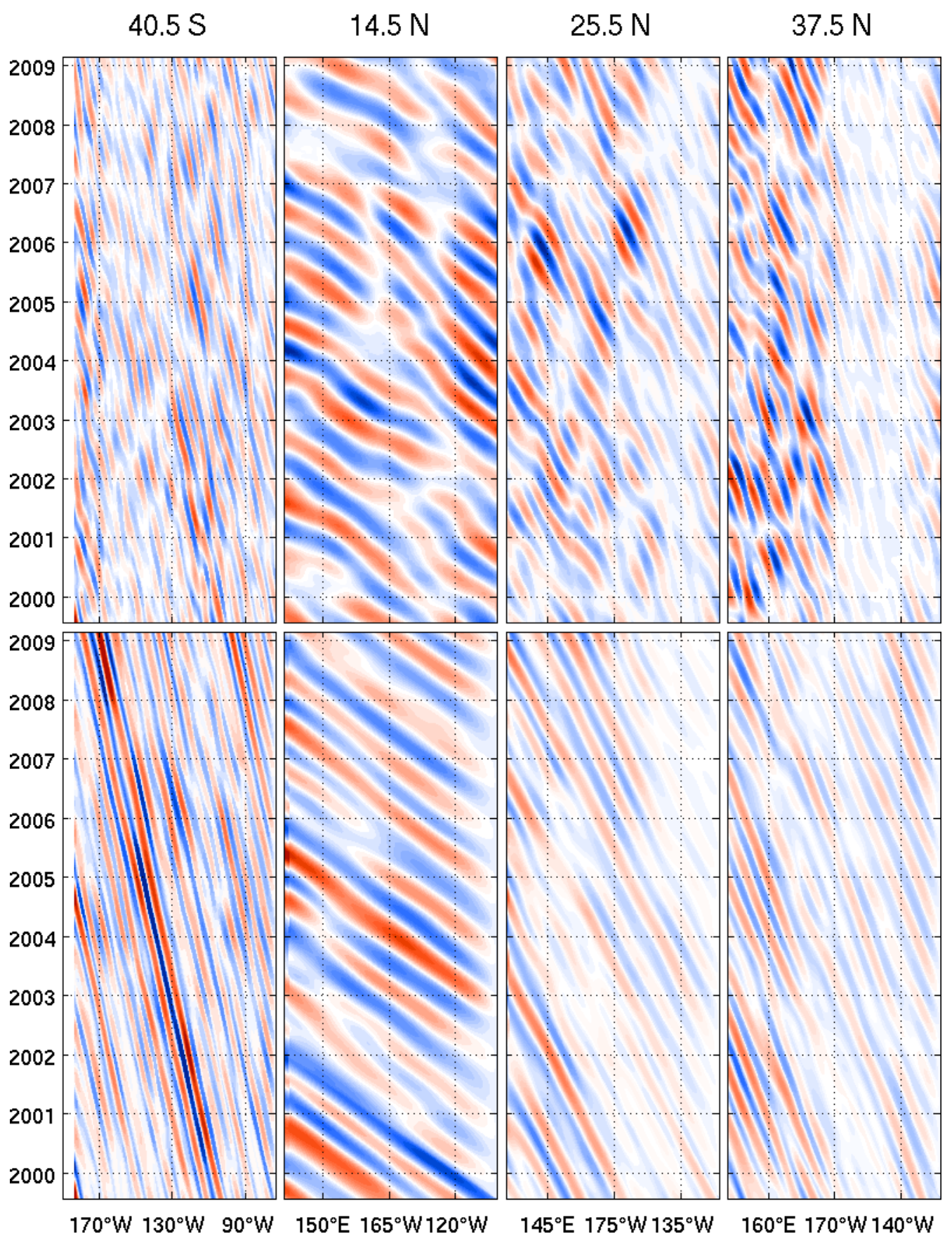

Figura 4.33: Similar à figura 4.28 para o oceano Pacífico em diversas latitudes. Os limites absolutos das escalas de cores são, da esquerda para a direita, $93 \mathrm{~mm}$, $80 \mathrm{~mm}, 125 \mathrm{~mm}$ e $204 \mathrm{~mm}$.

Apesar de boa parte desta última previsão ser a propagação da condição inicial, acredita-se que o forçamento pelo rotacional da tensão de cisalhamento do vento seja o mecanismo gerador das ondas, pois do contrário seria esperada uma 
descontinuidade entre a parte da solução decorrente das condições iniciais e as originadas posteriormente. Estas, originadas na borda leste da bacia oceânica a partir do ano 2000, estão com as amplitudes consistentes com as condições iniciais, sugerindo que elas de fato tenham sido forçadas pelo bombeamento de Ekman.

Em $14,5^{\circ} \mathrm{N}$, foi observada situação similar às demais regiões tropicais já analisadas, onde os dados modelados estão de forma geral em fase e com $92 \%$ da amplitude média dos dados observados. Kelly e Thompson (2002) também obtiveram bons resultados nesta região com o mesmo modelo e com os 2 anos de dados que estavam disponíveis na época.

Em $25,5^{\circ} \mathrm{N}$, as velocidades de fase também são mais lentas em relação às ondas de latitudes tropicais, de forma que os sinais que atingem a borda oeste da bacia até 2006 são originados da condição inicial. Todavia, ao contrário do que se observou em $40,5^{\circ} \mathrm{S}$, as ondas modeladas não conseguem se manter em fase com as observadas, uma vez que estas apresentam padrões complexos, com variações de velocidade de fase e bifurcações.

Finalizando a análise do Pacífico, há os resultados em $37,5^{\circ} \mathrm{N}$. Nesta latitude, a amplitude média das previsões equivale a $75 \%$ da amplitude média das observações e as ondas possuem velocidade de fase ainda menor que a anterior. Contudo os resultados do modelo estão razoavelmente em fase com os observados, sendo uma situação melhor que a observada na latitude anterior. A explicação provavelmente reside na variabilidade das velocidades de fase das ondas, a qual é menor em $37,5^{\circ} \mathrm{N}$ se comparada a $25,5^{\circ} \mathrm{N}$. Fu e Qiu (2002) utilizaram um modelo linear de duas camadas forçado pelo rotacional da tensão de cisalhamento do vento de reanálise do NCEP. Eles concluíram que a correlação entre as simulações e as observações 
eram abaixo do nível de significância entre $20^{\circ} \mathrm{N}$ e $30^{\circ} \mathrm{N}$ e eram significativas ao norte de $30^{\circ} \mathrm{N}$, de maneira que os resultados obtidos no presente estudo estão de acordo.

Para o oceano Índico, foram analisadas três latitudes de sua porção sul $\left(26,5^{\circ} \mathrm{S}, 16,5^{\circ} \mathrm{S}\right.$ e $\left.9,5^{\circ} \mathrm{S}\right)$ e uma ao norte $\left(14,5^{\circ} \mathrm{N}\right)$, representando o Mar da Arábia (figura 4.34). Esta última latitude é a que apresentou a maior correlação média, de valor 0,33, enquanto as latitudes austrais apresentaram correlações de - $0,22,0,21 \mathrm{e}$ $-0,11$ para $9,5^{\circ} \mathrm{S}, 16,5^{\circ} \mathrm{S}$ e $26,5^{\circ} \mathrm{S}$ respectivamente.

Em $26,5^{\circ} \mathrm{S}$, a fase das ondas modeladas não concordam adequadamente com as observações e as amplitudes estão subestimadas, sendo em média $51 \%$ das observações. Para esta latitude, o resultado gerado pelo modelo mostrou-se insatisfatório, uma possível razão é que nesta região as ondas observadas podem ser ondas livres geradas por processos de borda leste (BIROL; MORROW, 2001).

Já para $16,5^{\circ} \mathrm{S}$ os resultados são mistos. As ondas geradas na borda leste até 2005 são reproduzidas razoavelmente pelo modelo, embora com amplitude menor. Todavia, após esta data, não se observa nenhuma relação entre os dados modelados e os altimétricos. A amplitude média das previsões foi $58 \%$ da equivalente observada.

Na latitude de $9,5^{\circ} \mathrm{S}$, as amplitudes das ondas modeladas também estão subestimadas frente às observações, porém em menor grau que na latitude anterior, com a amplitude média correspondente a $70 \%$ da amplitude média das observações. Assim como na latitude anterior, os resultados do modelo estão adequados aos observados ao se considerar as ondas geradas na borda leste da bacia até 2005. Contudo, ao contrário de $16,5^{\circ} \mathrm{S}$, após 2005 , as ondas modeladas continuam em fase com as 
observadas entre o extremo leste e a longitude de $80^{\circ} \mathrm{W}$. A oeste desta longitude, as ondas observadas pelos altímetros aceleram por alguma outra razão que não o forçamento direto do vento, de forma que as ondas modeladas saem de fase.

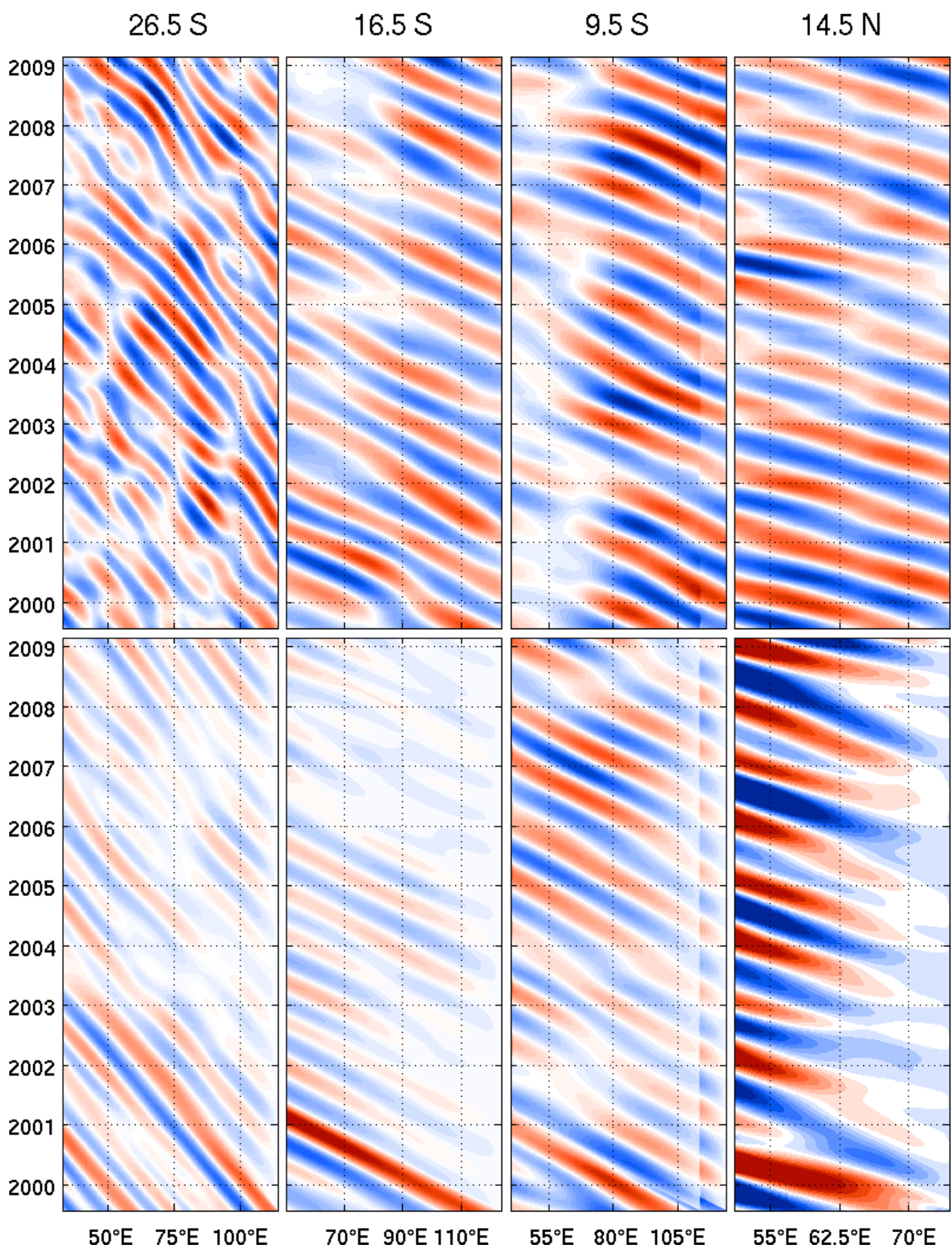

Figura 4.34: Similar à figura 4.28 para o oceano Índico em diversas latitudes. Os limites absolutos das escalas de cores são, da esquerda para a direita, $110 \mathrm{~mm}$, $89 \mathrm{~mm}, 131 \mathrm{~mm}$ e $63 \mathrm{~mm}$. 
Por fim, há a região do Mar da Arábia, onde os resultados do modelo estão aparentemente em fase com as observações, mas com as amplitudes superestimadas em 38\%. Com base na análise de dados de AASM do T/P, temperatura e salinidade de perfis hidrográficos in situ e da componente anual do rotacional da tensão de cisalhamento do vento obtido pelos escaterômetros ERS-1/2, Brandt et al. (2002) propuseram que as ondas de Rossby observadas no Mar da Arábia são uma combinação entre ondas livres geradas na costa oeste da Índia e de ondas continuamente forçadas pela ação do rotacional do cisalhamento do vento. Esta observação dos autores, onde o ciclo anual do rotacional do cisalhamento do vento atua na propagação das ondas planetárias, está de acordo com os resultados obtidos no presente estudo.

\subsubsection{Componente semianual propagante para oeste}

A componente de AASM referente às ondas planetárias de período semianual é menos energética que a respectiva para o período anual, com exceção de poucos locais, como a região ao leste do estreito de Luzon $\left(22^{\circ} \mathrm{N}, 125^{\circ} \mathrm{E}\right)$ no oceano Pacífico (POLITO; LIU, 2003).

Na banda espectral semianual, as correlações entre a anomalia da altura e o rotacional da tensão de cisalhamento do vento médias são menores (figura 4.35) comparadas ao mesmo resultado para a banda anual (figura 4.27), porém há algumas regiões com valores moderados, como o Índico norte (Mar da Arábia). O pico de correlação está em $10,5^{\circ} \mathrm{N}$ no Atlântico, no entanto é um caso isolado do Atlântico norte que, em geral, apresenta correlações médias menores. Dado o resultado das figuras 4.4 e 4.35), as regiões de maior interesse são a região tropical dos três oceanos, com destaque para o Pacífico sul tropical, o Atlântico norte tropical e o Mar 
da Arábia no Índico norte. Ainda serão analisadas algumas latitudes subtropicais para avaliar a performance do modelo para ondas semi-anuais nesta região que, em geral, apresentaram correlações negativas.

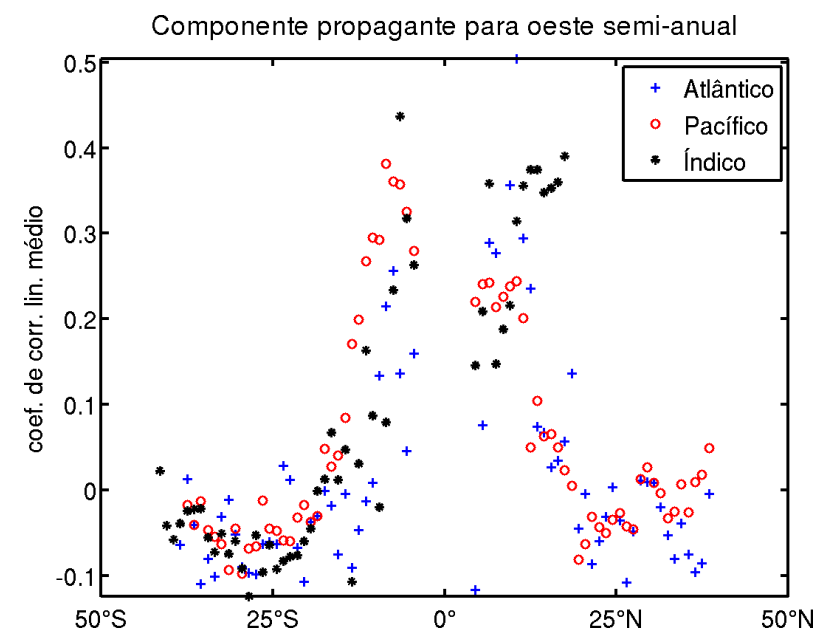

Figura 4.35: Coeficiente de correlação médio entre a componente semianual de $w_{s}$ e $w_{E}$ por latitude para cada bacia oceânica.

Para o oceano Atlântico, foram escolhidas as latitudes de $30,5^{\circ} \mathrm{S}, 8,5^{\circ} \mathrm{S}$, $12,5^{\circ} \mathrm{N}$ e $30,5^{\circ} \mathrm{N}$ (figura 4.36), cujas correlações médias são, respectivamente, 0,05 , $0,21,0,24$ e 0,01 .

Na latitude mais austral $\left(30^{\circ} \mathrm{S}\right)$, embora a amplitude média reproduzida pelo modelo corresponda a apenas $52 \%$ da observada, algumas ondas modeladas estão aproximadamente em fase com as observadas. Porém, este não é um padrão geral, o que explica a baixa correlação média observada nesta latitude. Em $8,5^{\circ} \mathrm{S}$, a amplitude está muito subestimada no modelo, com a média correspondendo apenas à $17 \%$ da observada. Todavia, as poucas ondas observáveis no diagrama modelado estão em fase com as respectivas ondas do diagrama dos dados altimétricos. Para $12,5^{\circ} \mathrm{N}$, a amplitude das ondas modeladas está relativamente mais próxima às obser- 
vações em comparação com os resultados obtidos em $8,5^{\circ} \mathrm{N}$, sendo que a amplitude média das previsões é de $83 \%$. A fase das previsões também está semelhante às observações, justificando os coeficientes de correlação entre as componentes de ondas de Rossby anuais de $w_{s}$ e de $w_{E}$ obtidos nesta latitude, cujo valor médio foi de apenas 0,24, mas máximo foi de 0,53. Por fim, na latitude mais boreal $\left(30^{\circ} \mathrm{N}\right)$, observou-se a mesma situação da respectiva latitude sul: amplitude subestimada, no caso com a média prevista sendo $60 \%$ da observada, e fase semelhante entre modelo e observação. É interessante notar o bom resultado em $12,5^{\circ} \mathrm{N}$, uma vez que Chu et al. (2007) sugeriram um mecanismo de ressonância não linear como fonte geradora de ondas de Rossby semi-anuais nesta região.

No oceano Pacífico, as latitudes escolhidas foram $30,5^{\circ} \mathrm{S}, 11,5^{\circ} \mathrm{S}, 12,5^{\circ} \mathrm{N}$ e $35,5^{\circ} \mathrm{N}$ (figura 4.37). As correlações médias para estas latitudes foram 0,05, 0,27, 0,05 e 0,03 respectivamente.

Tanto em $30,5^{\circ} \mathrm{S}$ quanto em $35,5^{\circ} \mathrm{N}$, as ondas observadas possuem baixa velocidade de fase e pequeno comprimento de onda. Estas características dificultam a capacidade de reprodução destas ondas pelo modelo, pois as implicações de desvios na velocidade de propagação terão um impacto muito grande no posicionamento espaço-temporal da fase das ondas. Assim, não é surpresa as ondas modeladas não estarem em fase com as observadas. Além disso, o modelo também subestimou a amplitude das ondas nestas latitudes, com a amplitude média prevista correspondendo a observada em $54 \%$ e $41 \%$ para a latitude mais ao sul e mais ao norte, respectivamente. É notável ainda, o grande aumento de amplitude observado nas ondas observadas pelo altímetro em $35,5^{\circ} \mathrm{N}$ a oeste de $170^{\circ} \mathrm{W}$, fenômeno que não foi re- 
produzido pelo modelo, o que sugere fortemente outra origem que não o forçamento direto pelo rotacional da tensão de cisalhamento do vento.

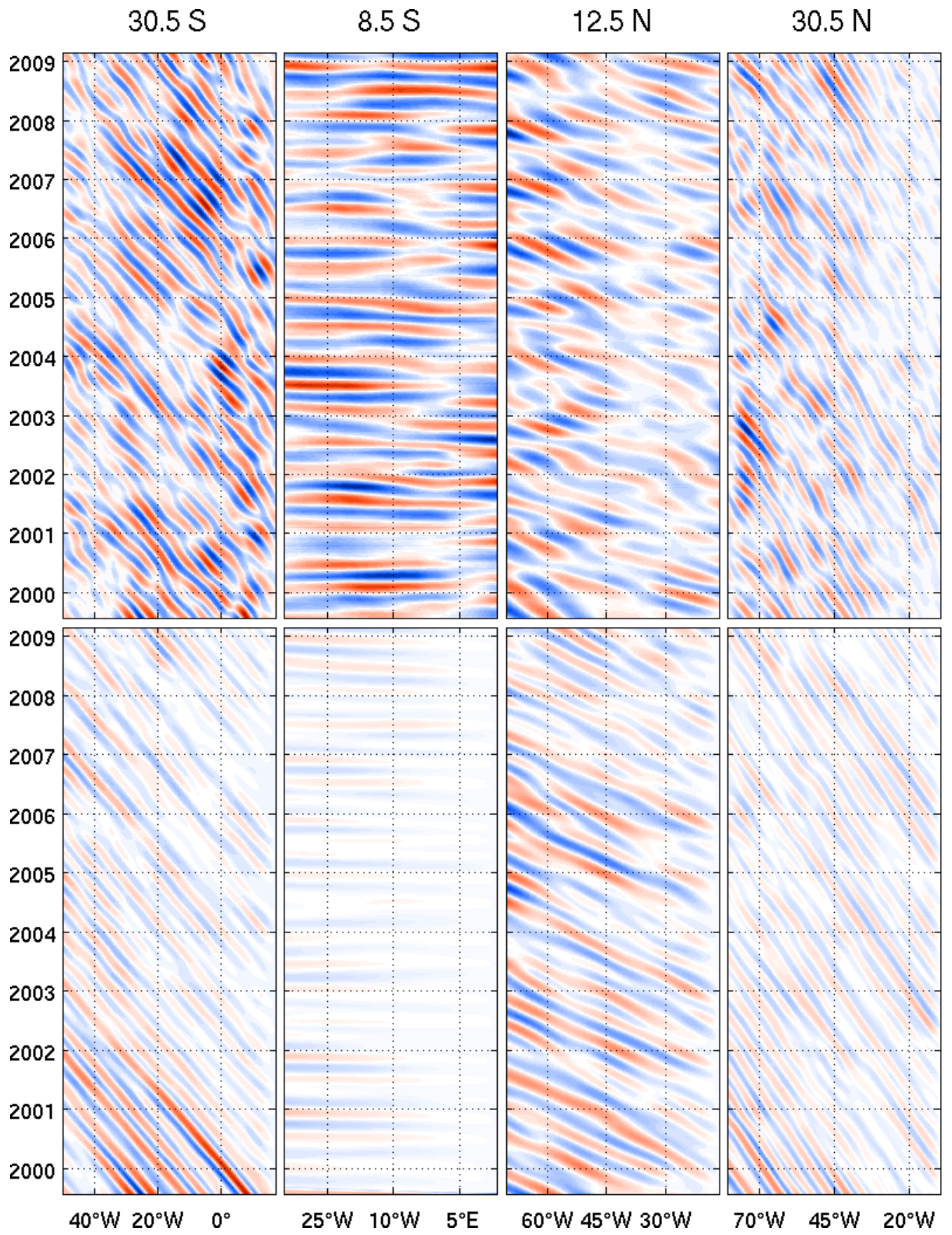

Figura 4.36: Componente semianual da anomalia da altura da superfície livre observada por altímetros (fileira superior) e a mesma modelada (fileira inferior) no oceano Atlântico em diversas latitudes (colunas). Os limites absolutos das escalas de cores são, da esquerda para a direita, $112 \mathrm{~mm}, 29 \mathrm{~mm}, 67 \mathrm{~mm}$ e $177 \mathrm{~mm}$. 


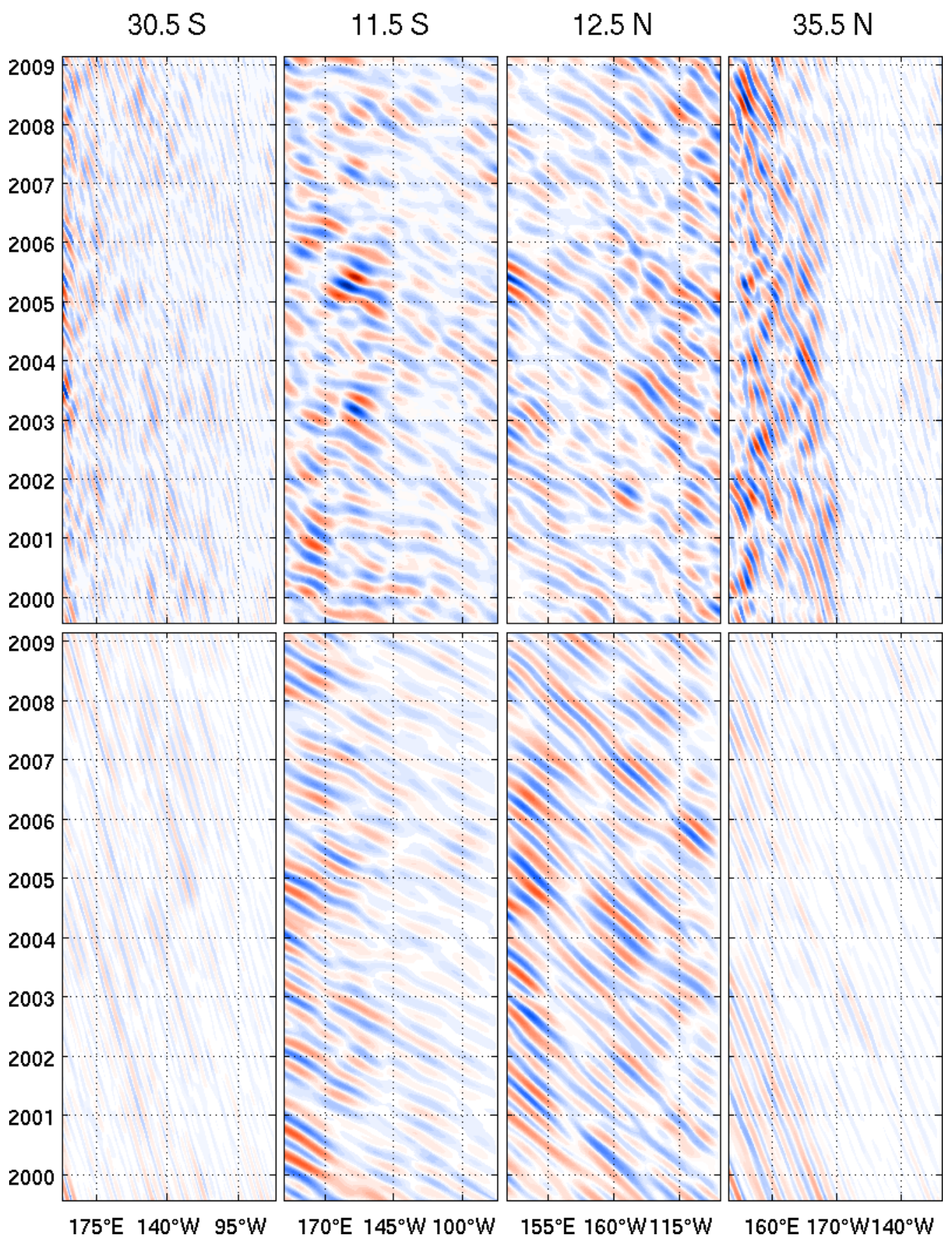

Figura 4.37: Similar à figura 4.36 para o oceano Pacífico em diversas latitudes. Os limites absolutos das escalas de cores são, da esquerda para a direita, $332 \mathrm{~mm}$, $75 \mathrm{~mm}, 122 \mathrm{~mm}$ e $437 \mathrm{~mm}$.

Já na região tropical sul $\left(11,5^{\circ} \mathrm{S}\right)$, a performance do modelo é bem superior, gerando ondas com $87 \%$ da amplitude média das ondas observadas, as amplitudes foram crescentes para oeste, assim como nos dados altimétricos, e as previsões ficaram aproximadamente em fase com as observações. As previsões para a região 
tropical norte $\left(12,5^{\circ} \mathrm{N}\right)$ estão superestimadas em média em $14 \%$. A concordância de fase é observada apenas em algumas ondas, como as geradas entre 2002 e 2003 na borda leste, as quais terminaram de atravessar a bacia oceânica entre 2005 e 2006 . Esta discordância entre as fases pode ser uma das razões para a correlação média ter sido baixa nesta latitude.

As análises no oceano Índico foram feitas em sua porção tropical sul $\left(17,5^{\circ} \mathrm{S}\right.$ e 8,5ㅇ , com correlações médias de 0,01 e 0,08 , e no Mar da Arábia $\left(9,5^{\circ} \mathrm{N}\right.$ e $\left.15,5^{\circ} \mathrm{N}\right)$, cujas correlações médias foram 0,22 e 0,35 (figura 4.38). Em $17,5^{\circ} \mathrm{S}$, a amplitude média modelada equivale a $66 \%$ da observada, enquanto em $8,5^{\circ} \mathrm{S}$ equivale a $99 \%$, praticamente igualando-se às observações. Porém, em ambas as latitudes, o modelo não se manteve em fase com as ondas observadas. Potemra (2001) reproduziu ondas planetárias no Índico sul através de um modelo em larga escala de circulação geral, gravidade reduzida e uma camada e meia. Foi utilizada como forçante a tensão de cisalhamento do vento da climatologia de Hellerman e Rosenstein (1983) com variabilidade mensal, semianual e anual. Em $15^{\circ} \mathrm{S}$, o autor reproduziu ondas de Rossby de período anual com amplitudes entre 80 e $160 \mathrm{~mm}$, similar ao obtido no presente estudo para $17,5^{\circ} \mathrm{S}$ e $8,5^{\circ} \mathrm{S}$.

A discrepância observada entre a previsão e a observação no Índico sul tropical pode ser explicada ao menos de duas formas distintas: (a) a geração de ondas planetárias na costa da Austrália, através do forçamento pelo vento paralelo à costa, e (b) a geração devida à forçamento remoto no Pacífico sejam responsáveis pelas diferenças observadas entre os resultados modelados e os observados. O mecanismo que suportaria o segundo caso consiste na interação das ondas planetárias no Pacífico quase equatorial com as várias ilhas presentes na borda oeste do Pacífico. Essa 
interação causaria propagação de ondas de Kelvin costeiras ao longo da costa da Austrália e da Nova Guiné, chegando ao oceano Índico. As variações do nível do mar resultantes contribuiriam para a formação de ondas de Rossby no Índico sul tropical (POTEMRA, 2001).

$17.5 \mathrm{~S}$

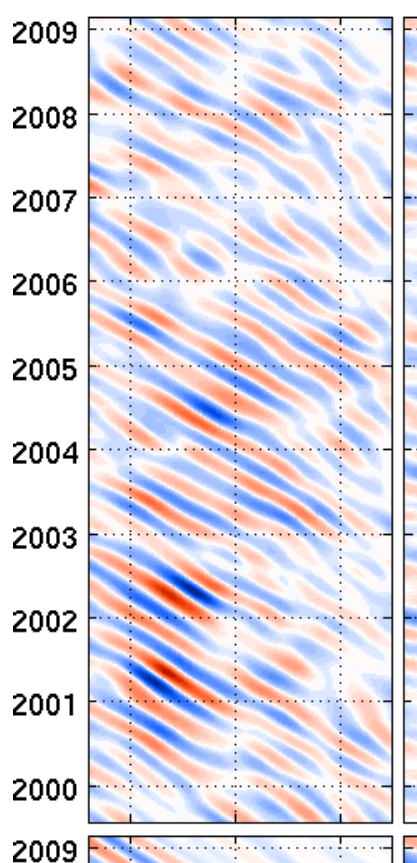

2008

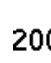

2007

2006

2005

2004

2004

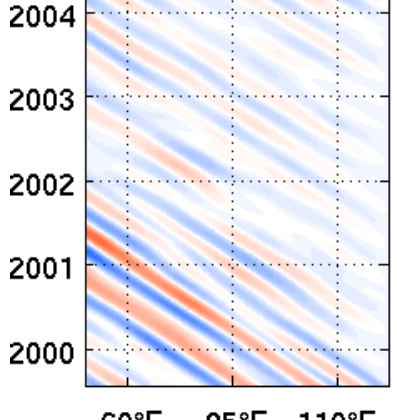

$60^{\circ} \mathrm{E} \quad 85^{\circ} \mathrm{E} \quad 110^{\circ} \mathrm{E}$
$8.5 \mathrm{~S}$
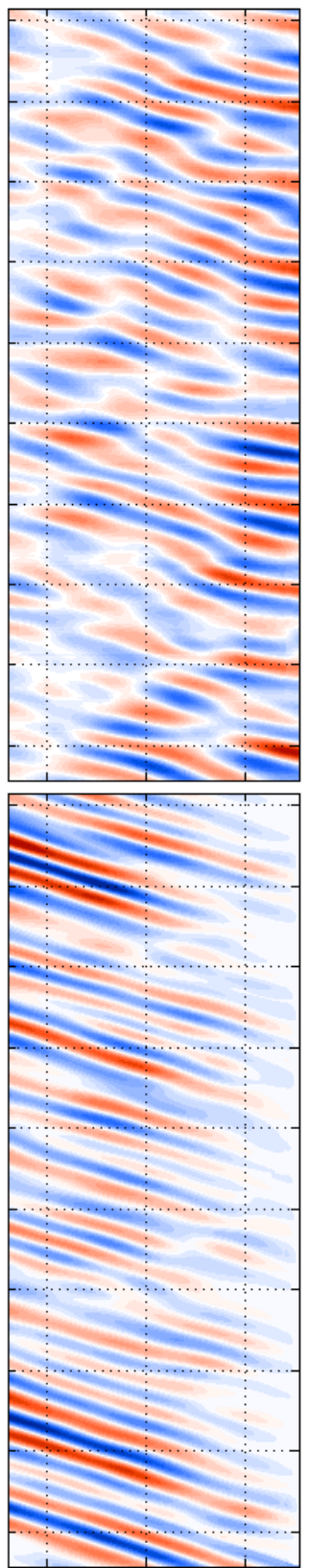

$50^{\circ} \mathrm{E} \quad 75^{\circ} \mathrm{E} \quad 100^{\circ} \mathrm{E}$
$9.5 \mathrm{~N}$
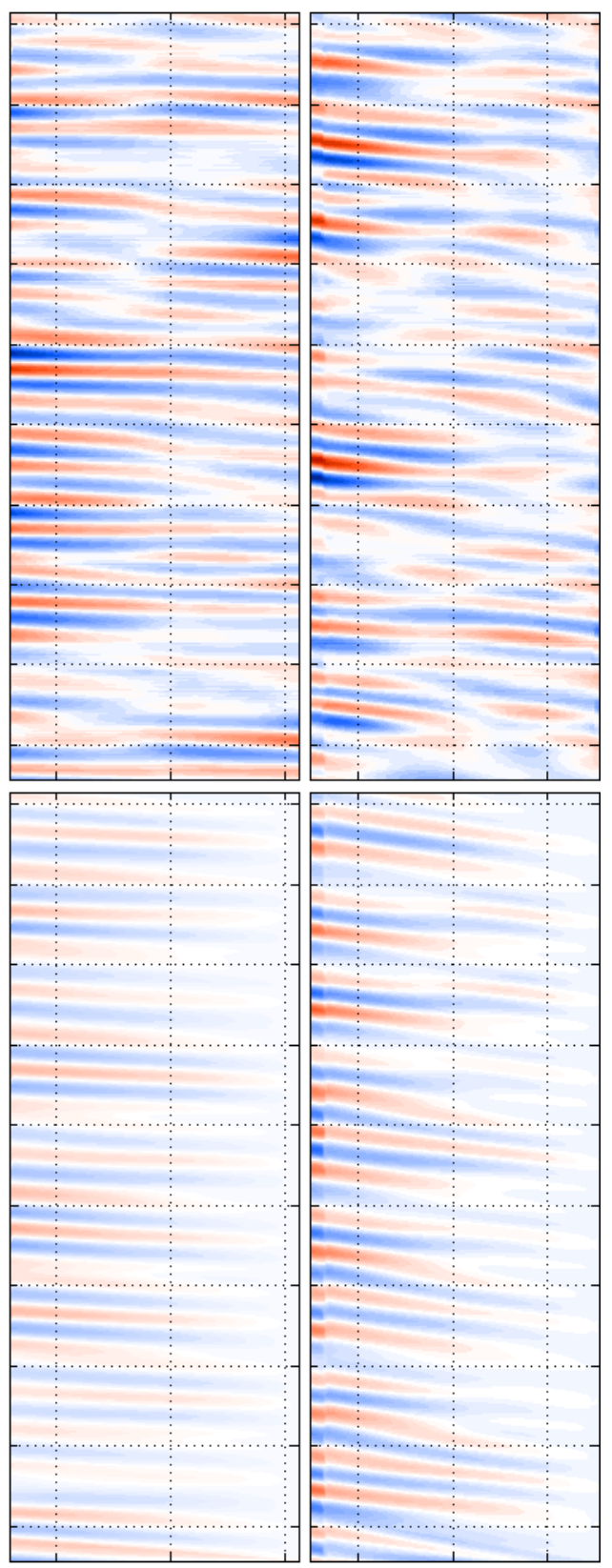

$55^{\circ} \mathrm{E} \quad 65^{\circ} \mathrm{E} \quad 7^{\circ} \mathrm{E} \quad 55^{\circ} \mathrm{E} \quad 62.5^{\circ} \mathrm{E} \quad 70^{\circ} \mathrm{E}$

Figura 4.38: Similar à figura 4.36 para o oceano Índico em diversas latitudes. Os limites absolutos das escalas de cores são, da esquerda para a direita, $135 \mathrm{~mm}$, $121 \mathrm{~mm}, 136 \mathrm{~mm}$ e $78 \mathrm{~mm}$. 
No Mar da Arábia, a concordância de fase entre as previsões e as observações é considerável em ambas as latitudes. Nota-se que as amplitudes estão subestimadas em ambas latitudes, especialmente em $9,5^{\circ} \mathrm{N}$, onde a amplitude média das previsões corresponde a $45 \%$ da observada, enquanto em $15,5^{\circ} \mathrm{N}$ corresponde a 71\%. Devido ao comprimento da bacia nesta região ser aproximadamente $2500 \mathrm{~km}$, um valor relativamente pequeno ao se comparar com as outras bacias oceânicas, as ondas atravessam a bacia em apenas cerca de 3 meses. Subrahmanyam et al. (2001) reproduziram ondas planetárias semianuais para o Mar Arábico entre 1993 e 1995 utilizando um modelo não linear de gravidade reduzida de três camadas e meia, o qual continha termos de viscosidade e advecção não linear, sendo que o modelo foi forçado pela tensão de cisalhamento obtida dos dados de vento do escaterômetro ERS-1. As ondas modeladas pelos autores apresentaram quatro vezes menos energia que as observações provenientes do $\mathrm{T} / \mathrm{P}$. Considerando que a energia é proporcional ao quadrado da amplitude, quatro vezes mais energia traduz-se em o dobro da amplitude, sendo que o resultado obtido no presente estudo apresentou uma relação similar entre as amplitudes previstas e observadas.

Uma hipótese sugerida por Subrahmanyam et al. (2001) é a propagação de ondas de Kelvin geradas na borda leste na baía de Bengala ao longo do perímetro desta baía até a costa leste da Índia. Estas ondas viajariam até a ponta do subcontinente Índico e, na sequência, ao longo da costa oeste da Índia. Conforme estas ondas de Kelvin se propagam pela costa oeste da Índia, elas radiariam ondas de Rossby para o interior do Mar da Arábia, sendo que estas atravessariam a bacia em cerca de 3 a 4 meses, assim como as de período semianual. Esta hipótese considera uma forçante adicional na geração das ondas planetárias, a qual não é contemplada pelo 
modelo dos autores nem pelo modelo do presente estudo, sendo uma possível causa das menores amplitudes previstas pelos modelos frente às observações em ambos os estudos. 


\section{Capítulo 5}

\section{Conclusões}

Uma das questões principais abordadas neste estudo foi o acoplamento linear entre a variação da superfície livre do mar e o rotacional da tensão de cisalhamento do vento de acordo com a dinâmica clássica de Ekman. Este trabalho dá continuidade a uma série de outros estudos como White et al. (1998), Kelly e Thompson (2002), Fu e Qiu (2002), Cabanes et al. (2006), Chu et al. (2007), os quais, em geral, utilizaram séries temporais curtas e/ou restringiram as análises a uma região específica. Os resultados apresentados na seção 4.1.1 permitem concluir que há uma relação linear na banda espectral das ondas planetárias entre o bombeamento de Ekman e a variação da altura da superfície livre do mar, especialmente para a banda anual (figura 4.3), exceto para o quadrante sudeste do oceano Índico, sendo um assunto que será retomado mais adiante. Essa relação é mais intensa nas regiões tropicais, porém este resultado por si só não permite estabelecer relação de causa e efeito, sendo necessária a utilização de resultados do modelo para isto. A linearidade nas relações estatísticas entre o bombeamento de Ekman e a variação 
da ASM implica na possibilidade de se propor áreas de formação e retroalimentação das ondas planetárias, sendo esta umas das hipóteses deste trabalho.

A hipótese de retroalimentação entre o oceano e a atmosfera proposta no presente estudo pode ser simplificada da seguinte forma: o rotacional da tensão de cisalhamento do vento resulta em bombeamento de Ekman que gera ondas baroclínicas onde a correlação entre $w_{s}$ e $-w_{E}$ é positiva (figuras 4.3 e 4.4). Estas ondas apresentam uma assinatura na superfície do mar tanto na altura como na temperatura, evidentes na figura 4.15), dominada por correlações positivas. A variação da temperatura da superfície do mar influencia no campo de rotacional e divergência do vento, como fica aparente na figura (4.11), onde as correlações nas bordas leste das bacias oceânicas são negativas (positivas) no hemisfério norte (sul), e na figura 4.13a, onde a área de correlações negativas é majoritária. Sob essa hipótese, as figuras supra citadas são evidências de que as regiões de borda leste do Atlântico entre $20^{\circ} \mathrm{S}-10^{\circ} \mathrm{S}$ e $10^{\circ} \mathrm{N}-20^{\circ} \mathrm{N}$ e as do Pacífico entre $30^{\circ} \mathrm{S}-10^{\circ} \mathrm{S}$ e $20^{\circ} \mathrm{N}-40^{\circ} \mathrm{N}$ são prováveis locais onde ocorrem geração e retroalimentação das ondas planetárias.

Da análise dos resultados da seção 4.2.1 obteve-se que, em média, há o dobro de potência espectral no espectro cruzado do hemisfério norte que no do hemisfério sul, particularmente em baixas e médias latitudes. Isso explica porque as ondas de Rossby no hemisfério norte tendem a ser mais altas, mais energéticas. Consequentemente, está em consonância com a observação que as correntes de borda oeste no hemisfério norte são mais intensas.

Estudos anteriores já haviam reportado correlações significativas entre a TSM e a AASM (NEREM et al., 1997; WHITE et al., 1998; LEULIETTE; WAHR, 1999). O presente estudo os complementa ao utilizar os dados da última década 
e também obter altas correlações entre essas propriedades (figura 4.14). Assim, este trabalho reforça a conclusão de Leuliette e Wahr (1999), a qual afirma que as variações da TSM representam razoavelmente as variações na altura da superfície devida à expansão térmica da camada superior do oceano, embora a TSM em si seja um proxy imperfeito para o calor armazenado na camada de mistura. A correlação é inversa em áreas associadas à ZCIT no Atlântico e no Pacífico e também, além do Índico sudeste tropical, sendo locais onde a TSM é inapropriada como proxy.

A ubiquidade das ondas planetárias nos dados de TSM (HILL et al., 2000) também resultaram em altas correlações entre os sinais de TSM e de AASM filtrados nas componentes propagantes para oeste na banda anual (figura 4.15). A advecção vertical de temperatura surgiu como o mecanismo mais provável para explicar estas altas corrrelações. Essa advecção deve, portanto, estar associada à pequena divergência horizontal causada pela passagem de ondas de Rossby (GILL, 1982).As bandas de correlação negativa no hemisfério sul parecem estar associadas à defasagem entre as ondas anuais e o ciclo sazonal. Considerando a faixa de latitude próxima a $17^{\circ} \mathrm{S}$ na figura 4.15 , as ondas nessa região tem velocidade de fase de aproximadamente $15 \mathrm{~km} /$ dia segundo Polito e Liu (2003), portanto até a inversão do ciclo sazonal, uma fase da onda viajaria cerca de $3000 \mathrm{~km}$. A distância para oeste a partir da costa leste onde ocorre a inversão de correlação além de ser de mesma ordem, também aumenta em direção ao equador da mesma forma que a velocidade de fase aumenta. Esta é uma indicação que, ao menos no hemisfério sul, (1) as ondas de Rossby anuais são geradas próximas à borda leste, (2) estão associadas à advecção vertical de temperatura e (3) este processo causa uma mudança significativa na TSM. 
Também foram abordadas neste estudo as hipóteses de interação entre a temperatura da superfície do mar e a atmosfera de Lindzen e Nigam (1987), referente ao forçamento pela força do gradiente de pressão da atmosfera pelo oceano, e de Wallace et al. (1989), que assume a geração de uma camada atmosférica turbulenta com o aumento da TSM, a qual reduz a transferência de momentum da atmosfera para o oceano, intensificando os ventos superficiais. Um dos resultados apresentados na seção 4.1.2 é a persistência de correlações negativas entre a magnitude da velocidade do vento e a TSM (figuras 4.6, 4.9 e 4.12a na maior parte do oceano. A explicação mais provável é o forçamento do oceano pela atmosfera através do resfriamento da superfície do mar por evaporação com o aumento da intensidade do vento (LIU et al. 1994).

Porém, o Atlântico sul tropical destacou-se por apresentar correlações positivas nestas figuras e também na figura (4.13a), sendo um indício que nesta região a interação ar-mar de acordo com hipótese de Wallace et al. (1989) seria predominante, especialmente para a banda espectral de ondas de Rossby. Nesta banda espectral, a hipótese de Wallace et al. (1989) também parece adequada para explicar os resultados na região subtropical sul, onde o comprimento de onda das ondas de Rossby aproxima-se da meso escala, a qual é a que apresenta mais feições explicadas por esta hipótese, corroborando Small et al. (2008) e O’Neill et al. (2009). A região do Pacífico equatorial leste no intervalo de $4^{\circ} \mathrm{N}$ a $9^{\circ} \mathrm{N}$ e $80^{\circ}$ a $100^{\circ} \mathrm{W}$ também apresentou evidências (figura 4.13a suportando a hipótese de Wallace et al. (1989), assim como havia sido observado por Chelton et al. (2001).

A hipótese de Lindzen e Nigam (1987) parece apropriada para explicar a interação entre a TSM e os ventos nas regiões tropicais para a banda espectral das 
ondas planetárias (figura 4.13a), exceto no Atlântico sul, conforme já mencionado. Porém, ao se considerar todo o espectro abrangido pelos dados originais, esta hipótese é adequada apenas para a região da ZCIT do Atlântico e do Pacífico, para o Atlântico norte tropical e para o Pacífico leste tropical (figura 4.7). Se a componente sazonal for removida (figura 4.9), apenas o Pacífico leste tropical apresenta fortes indícios de interação ar-mar pela hipótese de Lindzen e Nigam (1987), em concordância com Chelton et al. (2001).

O presente estudo questionou a capacidade de um modelo linear forçado apenas pelo rotacional da tensão de cisalhamento do vento (equação 3.10 em reproduzir as ondas planetárias observadas por altímetros, retomando a questão sobre onde e por qual mecanismo as ondas de Rossby longas do primeiro modo baroclínico são geradas no oceano. Esta questão foi abordada por Kelly e Thompson (2002) para o Pacífico norte entre $10^{\circ} \mathrm{N}$ e $16^{\circ} \mathrm{N}$, utilizando a mesma metodologia do presente trabalho, porém com séries temporais de apenas dois anos. Desta maneira, este assunto foi retomado e extensivamente complementado, uma vez que foram utilizadas séries temporais de dez anos e as análises foram feitas para todas as bacias oceânicas em diversas latitudes para duas bandas espectrais.

Os resultados apresentados na seção 4.3.1 tratam da banda espectral correspondente às ondas planetárias anuais. A performance do modelo em reproduzir as observações foi variável de acordo com as latitudes e bacias oceânicas. No Atlântico norte tropical (figuras 4.28 e 4.29) e Pacífico sul tropical (figuras 4.31 e 4.30) as previsões do modelo mostraram-se muito semelhantes às observações, tanto em fase quanto em amplitude. A primeira é uma forte evidência do forçamento das ondas planetárias de período anual pelo rotacional da tensão de cisalhamento do vento 
e a segunda é um indício da modulação da amplitude das ondas pelo vento, uma vez que é o único parâmetro a influenciar na amplitude, pois a gravidade reduzida $\left(g^{\prime}\right)$ foi mantida constante em todos os experimentos. No caso específico do Pacífico entre $11^{\circ} \mathrm{S}$ e $15^{\circ} \mathrm{S}$ (figura 4.30), há as variações na profundidade da termoclina e na estratificação causadas de tempos em tempos pelo El Niño/La Niña, influenciando em $g^{\prime}$ e $H_{1}$. O modelo não considera essas variações e ainda assim reproduz a AASM de forma muito semelhante às observações. Portanto, apesar da presença de todos esses fatores, flutuações no rotacional da tensão de cisalhamento do vento são o principal fator nas alterações de amplitude e fase das ondas de Rossby nessa região.

As porções tropicais do Atlântico sul (figura 4.32) e Pacífico norte (figura 4.33 também tiveram uma boa reprodução das ondas planetárias pelo modelo, embora as comparações não sejam tão favoráveis como nos casos descritos no parágrafo anterior. Conclui-se que a hipótese de forçamento direto por bombeamento de Ekman na geração e modulação de amplitude das ondas planetárias de período anual é viável na região tropical dos oceanos Atlântico e Pacífico. Contudo, as previsões do modelo para as porções subtropicais de ambas as bacias oceânicas concordaram pouco com as observações. Pôde-se notar no Atlântico em $38.5^{\circ} \mathrm{N}$ que, em média, o modelo reproduz corretamente amplitudes menores do lado leste da bacia, apesar das baixas amplitudes. Este último fato implica que esta assimetria não é consequência direta da presença de correntes instáveis (extensão leste da Corrente do Golfo/do Atlântico Norte), mas se deve, ao menos parcialmente, às diferenças no campo de vento.

As previsões geradas pelo modelo para o Índico sul (figura 4.34) foram em geral pouco similares às observações, com baixa concordância de fase e amplitudes 
subestimadas $40 \%$ em média. Isto não é surpreendente, haja visto a vasta região azul na figura (4.3). Uma explicação plausível para a baixa performance do modelo neste caso é uma terceira forçante, além do bombeamento de Ekman e do vento paralelo à costa da Austrália, que são as ondas de Kelvin costeiras remotamente forçadas no Pacífico (POTEMRA, 2001), aumentando a complexidade das ondas planetárias observadas. Já no Mar da Arábia, a reprodução das ondas de Rossby pelo modelo foi superior, com a concordância de fase e amplitude superestimada em $38 \%$ indicando uma forte atuação do rotacional da tensão de cisalhamento do vento na geração e modulação da amplitude das ondas, resultado que está de acordo com as considerações de Brandt et al. (2002).

A habilidade do modelo quanto à reprodução das ondas planetárias de período semianual discutidas na seção 4.3 .2 também foi diferente para as várias regiões analisadas. No Atlântico norte tropical (figura 4.36), no Pacífico sul tropical (figura 4.37) e no Mar da Arábia (figura 4.38), tanto a fase quanto a amplitude das previsões estão de acordo com as observações, sendo que as amplitudes estão subestimadas no Mar da Arábia. As previsões para o Atlântico sul tropical (figura 4.36) estão com a fase concordando com a observação, porém a amplitude está demasiadamente subestimada. A situação inversa é observada para o Pacífico norte tropical (figura 4.37), onde as amplitudes previstas e observadas estão similares, mas as fases não concordam em geral. Já as previsões para as porções subtropicais do Atlântico e do Pacífico (figuras 4.36 e 4.37) e para o Índico tropical sul (figura 4.38) apresentaram amplitudes subestimadas, salvo $8,5^{\circ} \mathrm{S}$ no Índico, e discordância de fase em geral. Mesmo com o fraco desempenho quanto à reprodução do sinal das ondas planetárias pelo modelo nestas áreas, houve evidências de que o forçamento pelo rotacional da 
tensão de cisalhamento do vento é relevante na geração destas ondas, pois as variações zonais e temporais na amplitude das mesmas apresenta semelhanças marcantes.

Em suma, as contribuições principais deste trabalho são:

(i) Apresentar evidências de que a causa das ondas de Rossby planetárias serem mais energéticas no hemisfério norte do que no sul é a covariabilidade entre a AASM e o bombeamento de Ekman nas escalas aqui analisadas. Identificar em que faixas do espectro e em que regiões essa covariabilidade ocorre.

(ii) Identificar as hipóteses mais plausíveis para explicar as variações entre a TSM e o vento. Demonstrar que o Atlântico sul tropical é uma região ímpar nesse sentido e sugerir que essa característica está ligada a processos associados às ondas de Rossby do primeiro modo baroclínico.

(iii) Demonstrar que, principalmente na região tropical, as ondas são lineares e forçadas pelo bombeamento de Ekman. Mesmo em locais onde a variação inter-anual da estratificação é grande, o principal controlador da amplitude das ondas é o rotacional do vento. 


\section{Referências Bibliográficas}

ANDERSON, D. L. T.; GILL, A. E. Spin-up of a stratified ocean with application to upwelling. Deep-Sea Res., v. 22, p. 583-596, 1975.

BARNIER, B. A numerical study on the influence of the Mid-Atlantic Ridge on nonlinear first-mode baroclinic Rossby waves generated by seasonal winds. $J$. Phys. Oceanogr., v. 18, p. 417-433, 1988.

BIROL, F.; MORROW, R. Source of the baroclinic waves in the southeast Indian Ocean. J. Geophys. Res., v. 106, n. C5, p. 9145-9160, 2001.

BRACHET, S.; LE TRAON, P. Y.; LE PROVOST, C. Mesoscale variability from a high-resolution model and from altimeter data in the North Atlantic Ocean. J. Geophys. Res., v. 109, p. C12025, 2004. Disponível em: <http://dx.doi.org/10.1029/2004JC002360>

BRANDT, P. et al. Annual Rossby waves in the Arabian Sea from TOPEX/POSEIDON altimeter and in situ data. Deep-Sea Res. Part II: Topical Studies in Oceanography, v. 49, n. 7-8, p. 1197-1210, 2002.

CABANES, C.; HUCK, T.; VERDIÈRE, A. Contributions of wind forcing and surface heating to interannual sea level vatiations in the Atlantic Ocean. $J$. Phys. Oceanogr., v. 36, p. 1739-1750, 2006. 
CAltabiano, A. C. V.; ROBInSOn, I. S.; PEZZI, L. P. Multi-year satellite observations of instability waves in the Tropical Atlantic Ocean. Ocean Sci. Discuss., v. 2, p. 1-35, 2005.

CHAMBERS, D. P.; TAPLEY, B. D.; STEWART, R. H. Long-period ocean heat storage rates and basin-scale heat fluxes from TOPEX. J. Geophys. Res., v. 102, n. C5, p. 10525-10533, 1997.

CHELTON, D.; SCHLAX, M. Global observations of oceanic Rossby waves. Science, v. 272, p. 234-238, 1996.

CHELTON, D. B. et al. Observations of coupling between surface wind stress and sea surface temperature in the Eastern Tropical Pacific. J. Climate, v. 14, p. 1479-1498, 2001.

CHHAK, K.; MOORE, A.; MILLIFF, R. Stochastic forcing of ocean variability by the North Atlantic Oscillation. J. Phys. Oceanogr., v. 39, p. 162-184, 2009.

CHU, P. et al. On long baroclinic Rossby waves in the tropical North Atlantic observed from profiling floats. J. Geophys. Res., v. 112, p. C05032, 2007. Disponível em: <http://dx.doi.org/10.1029/2006JC003698>.

CIPOLLINI, P. et al. Concurrent altimeter and infrared observations of Rossby wave propagation near $34 \mathrm{~N}$ in the northeast Atlantic. Geophys. Res. Let., v. 24, p. 889-892, 1997.

CUSHMAN-ROISIN, B. Introduction to Geophysical Fluid Dynamics. 1st. ed. Upper Saddle River: Prentice Hall, 1994. 320 p. 
DUMONT, J. P. et al. OSTM/Jason-2 Products Handbook. Centre National d'Études Spatiales, 2009.

EMERY, W. J.; THOMSOn, R. E. Data Analysis Methods in Physical Oceanography. 2nd. ed. Amsterdan: Elsevier, 2001. 400 p.

FERRARI, R.; WUNSCH, C. The distribution of eddy kinetic and potential energies in the global ocean. Tellus A, v. 62, n. 2, p. 92-108, 2010.

FRANKIGNOUL, C.; MÜLLER, P.; ZORITA, E. A simple model of the deacadal response of the ocean to stochastic wind forcing. J. Phys. Oceanogr., v. 27, p. 1533-1546, 1997.

FU, L.-L.; QIU, B. Global observations of oceanic Rossby waves. $J$. Geophys. Res., v. 107, n. C12, p. 3220, 2002. Disponível em: <http://dx.doi.org/10.1029/2001JC001131>.

GILL, A. Atmosphere-Ocean Dynamics. London: Academic Press, 1982. 662 p.

HAYES, S. P.; MCPHADEN, M. J.; WALLACE, J. M. The influence of sea-surface temperature on surface wind in the eastern equatorial pacific: Weekly to monthly variability. J. Climate, v. 2, p. 1500-1506, 1989.

HELLERMAN, S.; ROSENSTEIN, M. Normal monthly wind stress over the world ocean with error estimates. J. Phys. Oceanogr., v. 13, p. 1093-1104, 1983.

HERRMANN, P.; KRAUSS, W. Generation and propagation of annual Rossby waves in the North Atlantic. J. Phys. Oceanogr., v. 19, p. 727-744, 1989. 
HILL, K. L.; ROBINSON, I. S.; CIPOLLINI, P. Propagation characteristics of extratropical planetary waves observed in the ATSR global sea surface temperature record. J. Geophys. Res., v. 105, n. C9, p. 21927-21945, 2000.

KELLY, K.; THOMPSON, L. Scatterometer winds explain damped Rossby waves. Geophys. Res. Let., v. 29, n. 20, p. 1991, 2002. Disponível em: <http://dx.doi.org/10.1029/2002GL015595>.

KILLWORTH, P.; BLUNDELL, J. Long extra-tropical planetary wave propagation in the presence of slowly varying mean flow and bottom topography. i: the local problem. J. Phys. Oceanogr., v. 33, p. 784-801, 2003.

KILLWORTH, P.; BLUNDELL, J. Long extra-tropical planetary wave propagation in the presence of slowly varying mean flow and bottom topography. ii: ray propagation and comparison with observations. J. Phys. Oceanogr., v. 33, p. 802-821, 2003.

KILLWORTH, P.; BLUNDELL, J. The dispersion relation for planetary waves in the presence of mean flow and topography: I. analytical theory and onedimensional examples. J. Phys. Oceanogr., v. 34, p. 2692-2711, 2004.

KILLWORTH, P.; BLUNDELL, J. The dispersion relation for planetary waves in the presence of mean flow and topography: II. two-dimensional examples and global results. J. Phys. Oceanogr., v. 35, p. 2110-2133, 2005.

KILLWORTH, P.; BLUNDELL, J. Planetary Wave Response to Surface Forcing and Instability in the Presence of Mean Flow and Topography. J. Phys. Oceanogr., v. 37, p. 1297-1320, 2007. 
KILlWORTH, P. D.; de Szoeke, R. S.; CHELTON, D. B. The speed of observed and theoretical long extratropical planetary waves. J. Phys. Oceanogr., v. 27, p. 1946-1966, 1997.

KRAUS, W.; WUEBBER, C. Response of the North Atlantic to annual wind variations along the eastern coast. Deep-Sea Res., v. 29, p. 851-864, 1982.

KUNDU, P. K.; COHEN, I. M. Fluid Mechanics. 3rd. ed. London: Academic Press, 2004. 638 p.

LARGE, W. G.; YEAGER, S. G. Diurnal to decadal global forcing for ocean and sea-ice models: The data sets and flux climatologies. NCAR Tech. Note, TN460+STR, 2004. 105 p.

LEULIETTE, E. W.; WAHR, J. M. Characteristics of mid-latitude Rossby wave propagation from multiple satellite datasets. J. Phys. Oceanogr., v. 29, p. 5991251, 1999.

LINDZEN, R. S.; NIGAM, S. On the role of sea surface temperature gradients in forcing low-level winds and convergence in the tropics. J. Atmos. Sci., v. 44, p. 2440-2458, 1987.

LIPPERT, A.; KASE, R. Stochastic wind forcing of baroclinic Rossby waves in the presence of a meridional boundary. J. Phys. Oceanogr., v. 15, p. 184-194, 1985.

LIU, W. T. Progress in scatterometer application. J. Oceanogr., v. 58, p. 121-136, 2002. 
LIU, W. T.; TANG, W.; POLITO, P. S. NASA scatterometer provides global oceansurface wind fields with more structures than numerical weather prediction. Geophys. Res. Let., v. 25, n. 6, p. 761-764, 1998.

LIU, W. T.; ZHANG, A.; BISHOP, J. K. B. Evaporation and solar irradiance as regulators of sea surface temperature in annual and interannual changes. $J$. Geophys. Res., v. 99, p. 12623-12637, 1994.

MAHARAJ, A. et al. An evaluation of the classical and extended Rossby wave theories in explaining spectral estimates of the first few baroclinic modes in the South Pacific Ocean. Ocean Dynam., v. 57, n. 3, p. 173-187, 2007.

MAHARAJ, A.; HOLBROOK, N.; CIPOLLINI, P. Multiple westward propagating signals in South Pacific sea level anomalies. J. Geophys. Res., American Geophysical Union, v. 114, n. C12, p. C12016, 2009. Disponível em: <http://dx.doi.org/10.1029/2008JC004799>

MEYERS, G. On the annual Rossby wave in the Tropical North Pacific Ocean. $J$. Phys. Oceanogr., v. 9, p. 663-674, 1979.

MOORE, A. M. Wind-induced variability of ocean gyres. Dyn. Atmos. Oceans, v. 29, p. $335-364,1999$.

NEREM, R. S. et al. Improved determination of global mean sea level variations using TOPEX/POSEIDON altimeter data. Geophys. Res. Let., v. 24, n. 11, p. 1331-1334, 1997.

O’NEILL, L. W.; CHELTON, D. B.; ESBENSEN, S. K. The effects of SST-induced surface wind speed and direction gradients on midlatitude surface vorticity and divergence. J. Climate, v. 23, p. 255-281, 2009. 
OPPENHEIM, A. V.; SCHAFER, R. W. Discrete-Time Signal Processing. Upper Saddle River: Prentice Hall, 1999. 468-471 p.

PALDOR, N.; RUBIN, S.; MARIANO, A. J. A consistent theory for linear waves of the shallow-water equations on a rotating plane in midlatitudes. J. Phys. Oceanogr., v. 37, p. 115-128, 2007.

PEDLOSKY, J. Geophysical Fluid Dynamics. 2nd. ed. New York: Springer-Verlag, 1986. $728 \mathrm{p}$.

POLITO, P. S. Observation of long first-mode baroclinic Rossby waves in the North Atlantic and their connection with wind forcing. Tese de Doutorado. University of Rhode Island, p. 101, 1997.

POLITO, P. S. Utilização de Dados de Altímetros em Oceanografia. In: de Souza, R. B. (Ed.). Oceanografia por Satélites. São Paulo: Oficina de Textos, 2005. cap. 2.

POLITO, P. S.; CORNILLON, P. Long baroclinic Rossby waves detected by TOPEX/POSEIDON. J. Geophys. Res., v. 102, p. 3215-3235, 1997.

POLITO, P. S.; LIU, W. T. Global characterization of Rossby waves at several spectral bands. J. Geophys. Res., v. 108, n. C1, p. 3018, 2003. Disponível em: <http://dx.doi.org/10.1029/2000JC000607>

POTEMRA, J. Contribution of equatorial Pacific winds to southern tropical Indian Ocean Rossby waves. J. Geophys. Res., v. 106, n. C2, p. 2407-2422, 2001.

ROBINSON, I. S. Measuring the Oceans from Space. Chichester: Springer-Praxis books in geophysical sciences, 2004. ISBN 3-540-42647-7. 
SATO, O. T.; POLITO, P. S.; LIU, W. T. Intra-decadal varibility in the Ekman heat flux from scatterometer winds. Geophys. Res. Let., v. 29, n. 17, p. 1831, 2002. Disponível em: <http://dx.doi.org/10.1029/2002GL014775>.

SMALL, R. J. et al. Air-sea interaction over ocean fronts and eddies. Dyn. Atmos. Oceans, v. 45, p. 274-319, 2008.

SMITH, W. H. F.; WESSEL, P. Gridding with continuous curvature splines in tension. Geophysics, v. 55, p. 293-305, 1990.

SUBRAHMANYAM, B. et al. Indian Ocean Rossby waves observed in TOPEX/POSEIDON altimeter data and in model simulations. Int. J. Remote Sensing, v. 22, n. 1, p. 141-167, 2001.

TOMCZAK, M.; GODFREY, J. S. Regional Oceanography: an Introduction. 2nd. ed. Delhi: Daya Books, 2003. 390 p.

WALlACE, J. M.; MITCHELL, T. P.; DESER, C. The influence of sea-surface temperature on surface wind in the eastern equatorial pacific: Seasonal and interanual variability. J. Climate, v. 2, p. 1492-1499, 1989.

WHITE, W. B.; CHAO, Y.; TAI, C.-K. Coupling of biennial oceanic Rossby waves with the overlying atmosphere in the Pacific basin. J. Phys. Oceanogr., v. 28, p. 1236-1251, 1998.

WILlEBRAND, J.; PHILANDER, S. G. H.; PAKANOWSKI, R. C. The Oceanic Response to Large-Scale Atmospheric Disturbances. J. Phys. Oceanogr., v. 10, p. 411-429, 1980. 
WITTENBERG, A. T. Extended wind stress analyses for enso. J. Climate, v. 17, p. 2526-2540, 2003.

WUNSCH, C. What is the thermohaline circulation? Science, v. 298, n. 5596, p. 1179-1181, 2002.

WUNSCH, C. The oceanic variability spectrum and transport trends. Atmosphereocean, v. 47, n. 4, p. 281-291, 2009.

XIE, S.-P. Satellite observations of cool ocean-atmosphere interaction. Bull. Am. Meteor. Soc., v. 85, n. 2, p. 195-208, 2004.

YANG, H. Evolution of long planetary wave packets in a continuously stratified ocean. J. Phys. Oceanogr., v. 30, p. 2111-2123, 2000. 